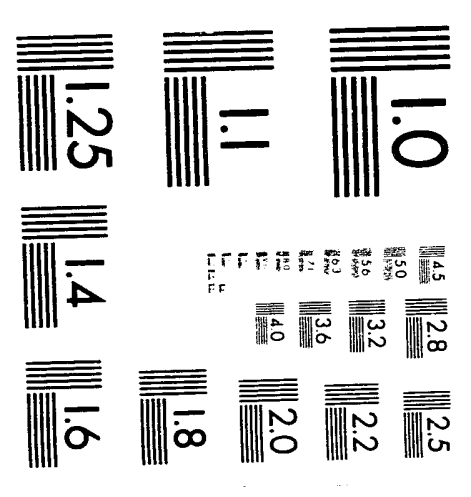






\section{Stepwise Integral Scaling Method and Its Application to Severe Accident Phenomena}

Manuscript Completed: August 1993

Date Published: October 1993

Prepared by

M. Ishii, H. C. No, * G. Zhang

F. Eltawila, NRC Project Manager

School of Nuclear Engineering

Purdue University

West Lafayette, IN 47907-1290

Prepared for

Division of Systems Research

Office of Nuclear Regulatory Research

U.S. Nuclear Regulatory Commission

Washington, DC 20555-0001

NRC FIN G1171

Under Grant No. NRC-04-89-361

*Korea Advanced Institute of Science and Technology

Seoul, Korea 


\begin{abstract}
Severe accidents in light water reactors are characterized by an occurrence of multiphase flow with complicated phase changes, chemical reaction and various bifurcation phenomena. Because of the inherent difficulties associated with full-scale testing, scaled down and simulation experiments are essential part of the severe accident analyses. However, one of the most significant shortcomings in the area is the lack of well-established and reliable scaling method and scaling criteria. In view of this, the stepwise integral scaling method is developed for severe accident analyses. This new scaling method is quite different from the conventional approach. However, its focus on dominant transport mechanisms and use of the integral response of the system make this method relatively simple to apply to very complicated muti-phase flow problems. In order to demonstrate its applicability and usefulness, three case studies have been made. The phenomena considered are

1) corium dispersion in $\mathrm{DCH}$,

2) corium spreading in BWR MARK-I containment, and

3) incore boil-off and heating process. The results of these studies clearly indicate the effectiveness of their stepwise integral scaling method. Such a simple and systematic scaling method has not been previously available to severe accident analyses.
\end{abstract}


TABLE OF CONTENTS

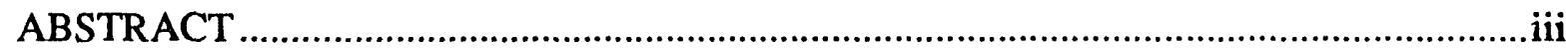

LIST OF FIGURES ............................................................................................... vi

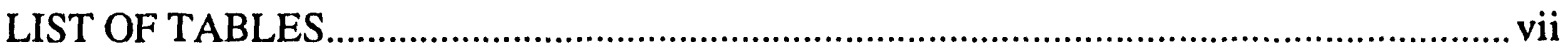

ACKNOWLEDGEMENT .............................................................................................. viii

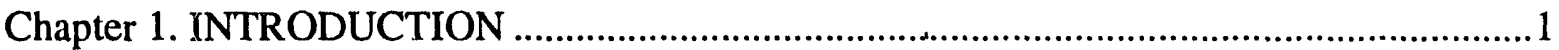

Chapter 2. DESCRIPTION OF STEPWISE INTEGRAL

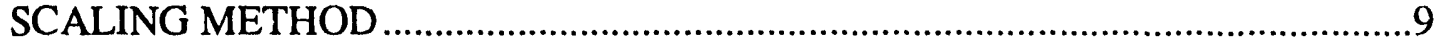

Chapter 3. SCALING STUDY OF CORIUM DISPERSION IN DCH ..............................12

Chapter 4. SCALING STUDY OF SPREADING OF MOLTEN CORIUM

IN MARK-I BOILING WATER REACTORS ...................................................... 32

Chapter 5. SCALING STUDY OF BOIL-OFF PROCESS

IN THE CORE

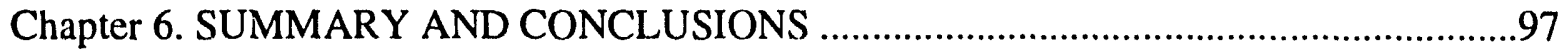




\section{LIST OF FIGURES}

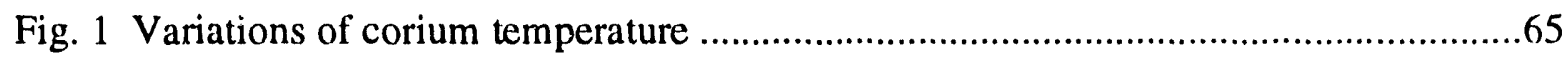

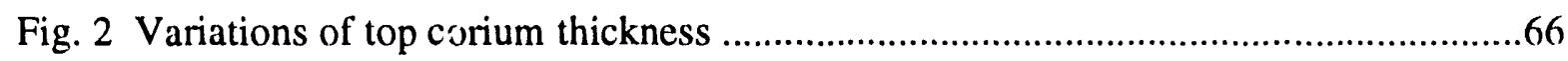

Fig. 3 Variations of bottom corium thicknes; ...................................................................67

Fig. 4 Comparison of the measured mixture level with the predictions by SCDAP and the present method ......................................................................91

Fig. 5 Comparison of the measured fuel temperature at $0.35 \mathrm{~m}$ with the predictions by SCDAP and the present method

Fig. 6 Comparison of the measured fiel temperature at $0.5 \mathrm{~m}$ with the predictions by SCDAP and the present method

Fig. 7 Comparison of the measured fuel temperature at $0.7 \mathrm{~m}$ with the predictions by SCDAP and the present method

Fig. 8 Comparison of fraction of heat loss by several heat transfer mechanism at $0.5 \mathrm{~m}$ predicted by the present method

Fig. 9 Comparison of the measured steam temperature at $0.5 \mathrm{~m}$ with the predictions by SCDAP and the present method 


\section{LIST OF TABLES}

Table 1 Sample calculations for various parameters

in corium dispersion ....................................................................................

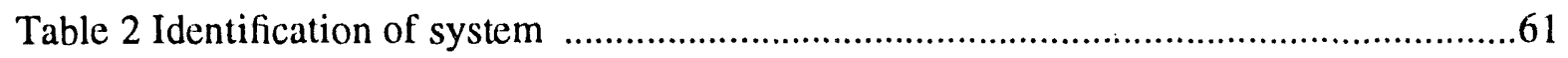

Table 3 Initial and boundary conditions and interfacial

conditions between subsystems

Table 4 Potentially important mechanisms and rank .....................................................63

Table 5 Typical severe accident parameters ....................................................................64

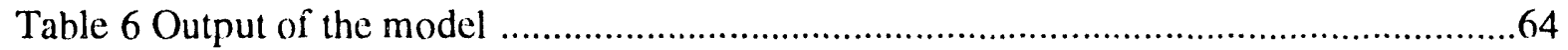




\section{ACKNOWLEDGEMENT}

This work was performed under the auspices of U.S. Nuclear Regulatory Commission under the research grant No. NRC-04-89-361. The authors would like to express their sincere appreciation for the encouragement, support and technical comments on this program from Drs. N. Zuber, R. Lee and F. Eltawila of NRC. 


\section{INTRODUCTION}

Accident sequences which led to severe core damage and to possible release of radioactive fission products into the environment have a very low probability. However, the interest in this area increased significantly due to the occurrence of the small break loss-of-coolant accident at TMI-2 which led to partial core damage and of the Chernobyl accident in the USSR which led to extensive core disassembly and significant release of fission products over several countries. In particular, the latter accident raised the international concern on the potential consequences of severe accidents in nuclear reactor systems. Thus, it is necessary to assess accurately the risk from such accidents involving severe core damages.

Severe accidents in light water reactors (LWRs) are characterized by an occurrence of multi-phase flow with complicated phase changes, chemical reactions and various bifurcation phenomena. A good understanding of the thermohydraulics of multi-phase flow is essential in several areas related to these accidents [1.1-5] as listed below.

1. Accident progressions which may lead to severe core damages can only properly be assessed by accurate two-phase flow models and safety codes supported by experimental data and good understanding of scaling laws.

2. After significantly exceeding the design limit in terms of the cladding temperature, the core degradation and material relocation become possiblc. Modeling of cladding and fuel melting, oxidation and hydrogen generation, fission product release, natural circulation of steam, material relocation, freezing of molten material, blockage formation and interaction of various materials and coolant become necessary. In this stage, the first line of defense against the release of fission products is breached.

3. The second line of defence is the reactor pressure vessel (RPV). However, the lower head of the RPV may fail due to the molten core materials and debris coming in direct contact with it. This leads to an extensive release of the core material and fission products into the containment atmosphere. In terms of accident management, the assessment of coolability 
at this stage is critical. For this purpose, a good understanding of thermohydraulics related to these phenomena is essential.

4. The last line of defense is the reactor containment building. It is basically designed for loads resulting from LOCAs. During a severe accident, the containment wall may be exposed to jets of molten core materials, core-concrete reactions, fuel-coolant interaction, hydrogen combustion, heating of containment atmosphere, and thermal and pressure loading. The consequence of these loadings determines the effectiveness of the last defense in line

In order to analyze various phenomena related to severe accidents, the NRC established the Severe Fuel Damage and Source Term (SFD/ST) Research Program. The program consists of two extensive efforts, namely the Severe Accident Code Development Program and supporting various experimental programs. However, at present, large uncertainties exist in modeling and analyzing these complicated multi-phase flow phenomena.

Efforts to establish proper mitigating actions require an ability to analyze a postulated severe accident with sufficient accuracy. Since the full scale tests are not possible, thermal-hydraulic models and accident analysis computer codes are used to evaluate the effectiveness of the plant protection systems and operator actions. For this purpose, the accuracy of computer codes, code applicability, reliability of multiphase flow models and scaling criteria should be addressed in sufficient detail.

The present research is focused on the development of a systematic and practical method to establish scaling criteria for severe accident phenomena. In view of the inherent difficulties associated with full-scale testing, scaled down experiments have been performed for severe accident phenomena. These included small scale experiment intended for developing physical understandings and correlations as well as integral experiments for overall effects. The ability to predict multiphase flow phenomena depends on the availability of experimental data and of mathematical models which can be used to describe a physical process with a required degree of 
accuracy. It is essential that the various multiphase flow characteristics and processes be formulated on a correct physical basis and supported by experiment data. For this purpose, specially designed experiments are required which must be conducted in conjunction with and in support of analytical study.

However, one of the most significant shortcomings in the analyses of severe accidents is the lack of reliable scaling criteria for various multi-phase flow phenomena. Only very recently, the technical program group sponsored by the Nuclear Regulatory Commission performed a comprehensive study on the scaling method for severe accidents [1.6].

Scaling criteria and similarity analyses are essential for

1) designing scaled down experiments

2) evaluating data and extrapolating the data to prototype conditions, and,

3) developing correctly scaled models. In other words, the scaling criteria bridge between experimental data and predictive models applicable to prototypic conditions.

The scaling laws for single-phase flow have been well established and modeling using these criteria has long been an accepted practice. The importance of scaling criteria for two-phase flow system has also been recognized [1.7-14] for some time. The reasons for the desire to use scaled experiments arise from the condensation of cost, time and simplicity as well as a need for visualization. Thus the lower pressure, temperature, and heat fluxes, combined with the transparency of model fluids, also provide benefits in the nuclear safety research.

There are several methods available to develop scaling laws for a particular system of interest [1.14]. These may be classified as below:

1) Method based on Buckingham's $\pi$ Theorem: When the governing parameters involved in a phenomenon are known or can be guessed, while the physical laws governing these variables are not known, Buckingham's $\pi$ Theorem can be used to obtain nondimensional parameters. 
2) Method based on Physical Laws: When the physical laws governing a phenomenon are available, these equations can be made non-dimensional by choosing proper scales for various physical dimensions involved in the equations. From these equations similarity groups which have definite physical significances can be obtained.

3) Method based on Perturbation Technique: When the equation describing a phenomenon in a system of interest can be solved under small perturbations, similarity laws governing the system can be obtained from the dynamic response.

The application of the first method to general two-phase flows is not very useful because of a large number of parameters required to describe them. Consequently, its application should be limited to certain particular phenomena in which the governing parameters can be significantly reduced, as discussed by Boure [1.7]. It can be said that most of scaling parameters in conventional two-phase flow on pressure drops, boiling heat transfer and critical heat flux have been obtained in this manner [1.7-11].

The second method based on the known physical laws is useful to examine the relative importance of various physical effects and mechanisms existing in the system as well as to define the boundary and initial conditions. The most important aspect is to choose proper scales for various effects and physical dimensions. However, this is not always simple, because in two-phase flow systems the variables may change over considerably wide ranges due to several different mechanisms. It can be said that the scaling criteria obtained from this method are more locally oriented than system oriented because of the above difficulties.

The third method is based on the perturbation method applied to governing differential equations. From the integral of the system, scaling criteria can be obtained [1.13]. Recently, considerable advances have been made in the area of scaling criteria for nuclear reactor systems under two-phase flow condition by Ishii and coworker [1.15-20] by applying this method. The focus of this NRC sponsored study was the two-phase flow scaling for LOCAs. This scaling method is a significant improvement over the classical scaling approach based on the power to 
volume ratio which is widely used in the area of severe accident simulation experiments. The newly developed criteria have been used for the design of the ANL scaled down experiments [1.21-22] and SRI-2 sponsored by EPRI, the conceptual study of new integral test facilities [1.23], and the evaluation of scaling preservation in the safety analyses codes [1.24].

In contrast, such scaling criteria have never been developed for the analyses of severe accidents. Consequently, systematic evaluation of physical models and experimental data in terms of scaling effects has not been carried out. If one recalls that in engineering experiments or tests, the scaling criteria are the most important starting point, the lack of such scaling criteria in the area of severe accident analyses significantly reduces the reliability and accuracy of the predictive methods.

In order to evaluate important physical parameters, to compare various experimental data and to develop correctly scaled models, a well established systematic scaling method is needed. In view of this, a new scaling method is developed for very complicated phenomena such as severe accident phenomena. This stepwise integral scaling method is based on the integral response of a system and subcomponents. As the name indicates, the scaling analyses is carried out by starting from the most important transport process then progressing into secondary phenomena. A detailed description of this new method is given in the next section.

In order to demonstrate the applicability and flexibility of the stepwise integral scaling method, three cases studied have been made with varying sophistications. These are

1) corium dispersion during the direct containment heating problem,

2) corium spreading in BWR MARK I containment, and

3) incore boil-off and heating process.

The results of these studies are presented in Sections III, IV and V. 
References

1.1 J.T.Han and G.P.Mario, "Severe Accident Code Development Program," Thirteenth Water Reactor Safety Research Information Meeting. Gaithersburg, Oct. 22-25, 1985, NUREG/CP-0072, Vol.6, p.339.

1.2 J.Rhode and E.F.Hicken, "Thermal Hydraulic in Severe Accidents," Proc. 2nd Int. Topical Meeting on Nucl.Power Plant Thermal Hydraulic and Operations, April 15-17, 1986, Tokyo, p 6-1.

1.3 C.M.Allison, E.R.Carlson and R.H.Smith, "SCDAP: A Computer Code for Analyzing Light Water Reactor Severe Core Damage," Proc. Int. Meeting on LWR Severe Accident Evaluation, Aug. 28-Sept. 1, Cambridge, Mass., Vol.1, 5.1-1 to 5, 1983.

1.4 W.J.Camp,et al., "MELPROG-PWR/MODO A Mechanistic Code for Analysis of Reactor Core Melt Progression and Vessel Attack under Severe Accidents," NUREG/CR-4684, 1987.

1.5 M.A. Kenton and R.E.Henry, "The MAAP-PWR Severe Accident Analysis Code," Proc. Int. Meeting on LWR Severe Accident Evaluation, Aug. 28-Sept. 1, Cambridge, Mass., Vol.1, 7.3-1 to $8,1983$.

1.6 D.W.Akers, C.S.Olsena and R.V.Stain, "TMI-2 Lower Vessel Debris Examinations," Proc. 14th Water Reactor Safety Inf. Meeting, NUREG/CP-0082, Vol.6, p 1-18, Gaithersburg, Oct. 27-31, 1986.

1.7 J.A.Boure, "A Method to Develop Similarity Laws for Two-Phase Flow," ASME paper No. 70-HT-25,1970.

1.8 R.W.Lockhard and R.C.Martinelli, "Proposed Correlation of Data for Isothermal Twophase, Two-component Flow in Pipes," Chem. Eng. Progress, Vol.45, p.39, 1949. 
1.9 P.G.Barnett, "A Comparison of the Accuracy of Some Correlations for Burn-out in Annuli and Rod Bundles," UKAEA Report AEEW R558, 1968.

1.10 S.Y.Ahmad, "Fluid to Fluid Modeling of Critical Heat Flux: A Compensated Distorted Model," Int. J. Heat Mass Transfer, Vol.16, p.641, 1973.

1.11 L.S.Tong, F.E.Motley, and J.O.Cermak,"Scaling Law of Flow Boiling Crisis," 4th Int. Heat Transfer Conf., Paris, B6.12, 1970.

1.12 M.Ishii, "Thermo-fluid Dynamic Theory of Two-phase Flow," Eyrolles, Paris, 1975.

1.13 M.Ishii and N.Zuber, "Thermally Induced Two-phase Flow Instabilities in Two-phase Mixture," 4th International Heat transfer Conference, B5.11, 1970.

1.14 M.Ishil and O.C.Jones, "Derivation and Application of Scaling Criteria for Two-phase Flow," Proc. NATO Advanced Study Institute, Istanbul, Vol.1.1, p163, 1976

1.15 M.Ishii and I.Kataoka, "Similarity Analysis and Scaling Criteria for LWRs under Singlephase and Two-phase Natural Circulation," NUREG/CR-3267, ANL-83-32, 1983.

1.16 G.Kocamustafaogullari and M.Ishii, "Scaling Criteria for Two-phase Flow Natural and Forced Convection Loop and Their Application to Conceptual 2 X 4 Simulation Loop Design," ANL-83-61, NUREG/CR-3420. 1983.

1.17 G.Kocamustafaogullari and M.Ishii, "Reduced Pressure and Fluid to Fluid Scaling Laws for Two-phase Flow Loop, "NUREG/CR-4584, ANL-86-19,1986.

1.18 M.Ishii and I.Kataoka, "Scaling Laws for Thermal-hydraulic System under Single Phase and Two-phase Natural Circulation," Nucl. Eng. and Design, Vol.81, 411-425, 1984.

1.19 G.Kocamustafaogullari and M.Ishii, "Scaling Criteria for Two-phase Flow Loop and Their Application to Conceptual 2 X 4 Simulation Loop Design," Nucl. Tech., Vol.65, 146-160, 1984. 
1.20 G. Kocamustafaogullari and M.Ishii, "Scaling Criteria for Two-phase Flow Transient using Reduced Pressure System and Stimulant Fluid," Nucl. Eng. and Design, Vol.104, 121-132, 1987.

1.21 S.B.Kim and M.Ishii, "Flow Visualization Experiment on Hot-leg U-bend, Two-phase Natural Circulation Phenomena," NUREG/CR-4621, ANL-86-27, 1986.

1.22 J.T.Hsu and M.Ishii," Experimental Study on Two-phase Natural Circulation and Flow Termination in a Loop," NUREG/CR-4682, ANL-86-32, 1986.

1.23 K.G.Condie, T.K.Larson and C.B.Davis, "Evaluation of Scaling Concept for Integral System Test Facilities," ANS Proc. 24th National Heat Transfer Conference, 3-12, Aug. 912, Pittsburgh, 1987.

1.24 T.K.Larson and R.A.Dimenna, "Preservation of Natural Circulation Similarity Criteria in Mathematical Model," ANS Proc. 24th National Heat Transfer Conference, 3-12, Aug. 912, Pittsburgh, 1987. 


\section{DESCRIPTION OF STEPWISE INTEGRAL SCALING METHOD}

In the proposed method, first of all, two identifications are needed : system identification and mechanism identification. Whole system is divided into subsystems with several components. The initial and boundary conditions of the system are identified in order to isolate the present system and the present problem from other systems and other part of the accident scenario. Also, through the identification of interfacial conditions between subsystems, each subsystem can be separately dealt with.

The whole transient is divided into several stages according to time sequence and the transition of dominant mechanisms to characterize each stage. Then, potentially important mechanisms and bifurcation phenomena are identified for each stage and each subsystem. Transition criteria between stages and the characteristic time constants of each mechanism are identified. The latter will give an estimation time required to complete the plausible mechanism and, as a result, become an important factor in determining which mechanism is dominant. Also, the most critical parameters for each stage are identified which we are most concerned with from the safety point of view. Then, as initial guess, each potential important mechanism is ranked in terms of relative importance in view of the most critical parameters, using the transition criteria, bifurcation criteria, and characteristics time constants as well as engineering judgement and literature survey. As a final step of the phenomena identification, we determine which transfer process dominantly governs each stage ( hydraulic-, thermal-, chemical-, dominant transfer process). If the strong coupling among them exists, combine them (thermalhydraulic-, thermal-chemical-, or thermal-hydraulic-chemical-transfer process ).

After taking the identification step, scaling analysis is done step by step. Starting from the most dominant mechanism for the first stage and the first subsystem, its integral rate equations including initial and boundary conditions are obtained. These balance equations are solved analytical or expressed as nonlinear integral response functions for the most critical parameters. 
Then, in order to obtain integral scaling parameters, nondimensionalize the integral response functions, the transition criteria, the bifurcation criteria, and the characteristic time constants selecting reference conditions so that they may reduce the number of scaling parameters. The reasonable accuracy of the integral response functions should be checked using proper experimental data and/or well-verified software. Based on the integral response functions, the corrections of the initial guess on the order of relative of various mechanisms are obtained.

In the second step, the above step for the next dominant mechanism is repeated independently of the first step but results from the first step may be used in this step. Thus, we check how strong feedback exists between the two mechanisms. If strong enough, we may need to combine analysis. This step should be repeated until all the possible major mechanisms are considered. The above procedure continues until all the stages and subsystems are considered.

The whole set of scaling parameters are generated as a final product of the above stepwise procedure. After the procedure two questions should be answered :

1. Is the same relative importance of each scaling parameter preserved for the prototype and its scaled-down systems?

2. Is the same sensitivity of the scaling parameters to the changes in boundary and initial conditions preserved for the two systems?

If all the requirement of similarity can not be satisfied, possible scale distortion is carefully investigated based on the relative importance of each scaling parameter. Now, we can develop desirable experimental conditions with given design constraints for the scaled-down system. Finally, we need to check whether a separate-effect test is needed examining the uncertainties of dominant mechanisms, transition criteria, bifurcation criteria, and characteristic time constants. 


\section{SCALING STUDY OF CORIUM DISPERSION IN DCH}

The stepwise integral scaling method explained above is applied to the corium dispersion in the reactor cavity in DCH. Thus the subsystem is the reactor cavity with the reactor vessel break as the upstream boundary. The previous studies for the DCH problem indicated that the most significant factor affecting the containment heating and pressurization was the degree of the molten corium dispersion. This is because the heat transfer and chemical reactions which may lead to the containment overpressurization are basically proportional to the available surface area of the molten corium.

Therefore, for the scaling study the corium dispersion is taken as the most important phenomenon to be studied in detail in the reactor cavity. For the molten corium dispersion and corium transport, the following four mechanisms are critical.

i) Cori im discharge and corium jet disintegration

ii) Liquic' corium spread-out upon impact of the jet or droplet

iii) Liquid mass transport due to inertia, pressure and shear force

iv) Entrainment and drop formation by streaming gas

These are studied by using the stepwise integral scaling method and starting from the upstream event.

\subsection{Initial Corium Jet Break-up}

The molten corium jet can disintegrate into droplets after the discharge from the reactor vessel break. The corium discharge can be in a form of a single phase jet or twophase jet due to the depressurization or punch through of the gas flow over the liquid corium surface in the reactor vessel. Several possible mechanisms and jet disintegration length are discussed below. The comparison of the jet disintegration length with the 
height below the reactor vessel gives the base to determine whether the molten corium disintegrates before impinging on the floor or not. Obviously, if the break-up length, $L_{B}$, is much smaller than the height, then it is expected that the jet disintegrates into small droplets during the vertical downward motion below the break. Hence it is important to know the break-up length.

3.1.1 Single Phase Jet Breakup. The single phase liquid jet can break-up in two major modes depending on the relative velocity between the liquid and gas phases, Obot and Ishii [3.1].

3.1.1.1 Jet Surface Hydrodynamic Instability. Obot and Ishii [3.1] showed that for a relatively small gas Weber number range given by

$$
W e_{g r} \equiv \frac{\rho_{g} v_{r}^{2} D_{J}}{\sigma}<3.5
$$

the jet break up length $L_{B}$ is given by

$$
\frac{L_{B}}{D_{J}}=595 \sqrt{\frac{\mu_{f} v_{f J}}{\sigma}}
$$

where $v_{r}, v_{f J}$ and $D_{J}$ are the relative velocity, jet velocity and jet initial diameter.

3.1.1.2 Jet Surface Break-up due to Relative Motion. When the relative velocity is high, $W e_{g r}>3.5$, the break-up length can be significantly reduced [3.1] and is given by

$$
\frac{L_{B}}{D_{J}}=1110 \sqrt{\frac{\mu_{f} v_{f J}}{\sigma}}\left(W e_{g r}\right)^{-0.5}
$$

These correlations indicate that the capillary number $\frac{\mu_{f} v_{f J}}{\sigma}$ and gas Weber number scale the jet break-up. The time constant is $L_{B} / v_{f J}$.

3.1.2 Two-phase Jet Break-up. When the jet consists of two phases due to either the 
gas blow through or gas generation the effect of the void fraction should be considered, Denten and Ishii [3.2] In this case

$$
\frac{L_{B}}{D_{J}}=595 \sqrt{\frac{\mu_{f} j_{J}}{\sigma}}\left(1-\frac{\alpha_{J}}{0.854}\right]^{1.22}
$$

for

$$
W e_{g r}=\frac{\rho_{g} j_{J}^{2} D_{J}}{\sigma}<3.5
$$

where $j_{J} \equiv \alpha_{J} v_{g J}+\left(1-\alpha_{J}\right) v_{f J}$. Here $\alpha_{J}$ and $v_{g J}$ are the void fraction and gas velocity at the jet discharge point. For higher relative velocity, $W e_{g r}>3.5$

$$
\frac{L_{B}}{D_{J}}=1110 \sqrt{\frac{\mu_{f} j_{J}}{\sigma}}\left(W e_{g r}\right)^{-0.5}\left[1-\frac{\alpha_{J}}{0.854}\right]^{1.22}
$$

These correlations indicate that the existence of void accelerates the jet disintegration significantly.

3.1.3 Jet Break-up Droplet Diameter. The second phenomenon of importance for the corium jet disintegration is the resultant droplet size. For the DCH problem the droplet size is the key in determining the degree of chemical reaction, heat transfer and corium transport. In the following, the droplet size from the disintegrating jet is discussed in terms of the primary jet disintegration and subsequent droplet disintegration. The correlations given below are applicable both for the single and two-phase jet disintegration. By modifying the annular droplet size correlation of Katanka, Ishii and Mishima [3.3] the mean droplet size in the disintegrated jet flow is given by De Jarlais, Ishii and Linehan [3.4] by

$$
d=0.028 \frac{\sigma}{\rho_{g} \nu_{r}^{2}}\left(\operatorname{Re}_{J}\right)^{1 / 2}\left[\frac{\rho_{g}}{\rho_{f}}\right]^{1 / 3}
$$

and the maximum, size is given from the maximum $\log$ normal distribution as $d_{\max }=3.13 d$. This criterion roughly corresponds to the Weber number criterion of 12 . 
3.1.4 Secondary Disintegration of Jet Droplet. When the jet disintegrates, the initial droplet size is given by the above correlation. However, often these initial droplets can be relatively large and may not be stable. The droplets from the jet can further disintegrate under two conditions. 'These are

(i) Existence of Extremely High Gas Turbulence such as Shock Waves

(ii) Exceeding of Spherical Limit

During the molten corium discharge phase, the first mechanism is unlikely. Under extreme conditions such as the sudden exposure of droplets to shock waves, the disintegration Weber number can be as low as 2 or 3 . However, the condition around the disintegrated jet before the gas blow down phase does not meet such extreme gas turbulences requirement. The second mechanism indicates that if the initial droplet size given by the above correlation far exceeds the spherical stable drop size limit, then droplets will further disintegrate to reach this stability limit. The spherical limit is given by

$$
d_{s l}=4\left[\frac{2 \sigma}{g \Delta \rho}\right]^{1 / 2}\left(N_{\mu g}\right]^{1 / 3}
$$

where the gas viscosity number, $N_{\mu g}$ is defined by

$$
N_{\mu g}=\frac{\mu_{g}}{\left[\rho_{g} \sigma \sqrt{\sigma / g \Delta \rho}\right]^{1 / 2}}
$$

\subsection{Corium Drop or Jet Impingement Phenomena}

In the above, the criteria for the jet break-up length and resultant droplet size are discussed. The next phenomenon of interest is the vertical impingement of the intact jet or the disintegrated jet in the form of droplet flow. The main question here is whether the impinging liquid mass spreads out coherently over the cavity wall or bounces back into the cavity space. The phenomena after the drop or jet impingement at the cavity fkoor can be scaled by the impact Weber number defined by 


$$
W e_{i m}=\frac{\rho_{f} v_{f j}^{2} d}{\sigma}
$$

where $d$ is the drop or jet diameter.

For $W e_{i m}>80$, the drop or jet will spread out as a liquid film due to large inertia overcoming the surface tension effect to recover. When $W e_{i m}<30$, the droplets bounce back after the impingement, Bolle and Moureau [3.5].

\subsection{Corium Spread Out Over Cavity Wall}

Under a prototypic condition the above criterion for the corium spread out is most likely satisfied. Then it is important to know the thickness and velocity of the molten corium film. For this purpose, several different length scales for the film thickness are considered below. From the continuity relation, and assuming that the magnitude of the velocity remains constant during the impingement, the initial film thickness $\delta_{i}$ at the vicinity of the impingement point is given by

$$
\frac{\delta_{i}}{D_{J}}=0.25
$$

The order of the lower limit of the corium film thickness is estimated by the symmetric spread of the liquid film with the constant liquid film velocity. The length scale for the extent of the film spread is taken as the hydraulic diameter of the cavity, $D_{h}$. Then

$$
\delta_{\min }=\frac{D_{J}^{2}}{4 D_{h}}
$$

It is noted that instead of $D_{h}$, other length scale may be used here, however for the present study $D_{h}$ is satisfactory.

The maximum thickness is obtained by assuming the entire corium mass accumulated 
on the floor. Thus

$$
\delta_{\max }=\frac{M_{c o r}}{\rho_{f} A_{f}}
$$

where $M_{c o r}$ and $A_{f}$ are the total corium discharge mass and cavity floor area.

Another reference film thickness can be obtained by assuming that the all molten corium spreads over the entire cavity surface. In this case

$$
\delta_{c}=\frac{M_{c o r}}{\rho_{f} A_{W}} \sim \frac{M_{c o r}}{\pi \rho_{f} D_{h} L_{c}}
$$

where $A_{W}$ and $L_{c}$ are the cavity wall area and cavity length.

\subsection{Estimate of Cavity Conditions}

In order to evaluate the molten corium dispersion in the reactor cavity, it is necessary to specify the global cavity conditions in terms of the liquid and gas flows. These parameters can be estimated from the geometry and boundary conditions.

In the above, several length scales for the corium film thickness have been obtained. Typical values for these are calculated in Table 1 by considering the following reference conditions.

In the following analysis, the typical film thickness of $\delta_{f}=\delta_{i}$ is assumed over the entire cavity welted perimeter. Then from the continuity condition, the film velocity is given by

$$
v_{f}=\frac{D_{J}^{2} v_{f J}}{4 D_{h} \delta_{f}}
$$

The film Reynolds number is defined by

$$
R_{e f}=\frac{\rho_{f} j_{f} D_{h}}{\mu_{f}}=\frac{4 \rho_{f} \delta_{f} v_{f}}{\mu_{f}}
$$


If the film is only on the floor of the cavity, the velocity $v_{f}$ and $R_{e f}$ should be about $\pi$ times the values given above. Because of the relatively high initial film velocity (in the order of $40 \mathrm{~m} / \mathrm{s}$ ), the liquid corium can climb up the side walls and may even cover the ceiling of the cavity. The actual values should be somewhere between them.

The gas flow conditions are estimated along the analysis proposed by Henry [3.6]. By assuming the choked flow for the gas discharge following the corium discharge, the pressure at the throat is given by

$$
p_{t} \sim 0.6 p_{v}
$$

and the choked flow velocity by

$$
v_{g t}=\sqrt{\frac{R T}{M_{W}}}
$$

From the ideal gas at the isothermal condition

$$
\rho_{g^{\prime}}=0.6 \mathrm{fv}
$$

The unlimited isothermal expansion can give the maximum velocity of twice the discharge velocity. The cavity gas initial velocity before entrainment can be given from the continuity relation and the cavity pressure. Thus

$$
v_{g c}=\frac{0.6 p_{v}}{p_{c o}}\left[\frac{A_{v}}{A_{c}}\right]\left[\frac{R T}{M_{W}}\right]^{0.5}
$$

where $A_{v}$ and $A_{c}$ are the vessel break area and cavity flow area. $p_{c o}$ is the cavity initial pressure.

This equation indicates that the cavity gas velocity is a strong function of the cavity pressure.

\subsection{Flow Regime in Cavity}

When the molten corium spreads out in the reactor cavity, three different two-phase flow regimes are possible. These are stratified wavy flow, slug flow and annular flow. In 
order to identify the most possible flow regime, the transition criteria between these regimes are examined. The onset of slugging from horizontal stratified wavy flow is given by the following form (Wallis and Dobson [3.7]; Mishima and Ishii [3.8]; Taitel and Dukler [3.9]):

$$
v_{r} \geq 0: 5 \sqrt{\Delta \rho g h_{g} / \rho_{g}}
$$

In the Taitel and Dukler correlation, the constant of 0.5 is replaced by a function of the void fraction which approaches unity as the relative film thickness becomes smaller.

The transition to annular flow either from the stratified wavy or slug flow is determined by the entrainment process. Thus if the gas (or relative) velocity exceeds the onset of entrainment velocity, the entrainment of wave crests or liquid slugs occurs. In case of slug flow, this leads to the elimination of liquid slugs. Since the part of entrained droplets are deposited on the wall surface, the onset of entrainment leads to the formation of annular flow with liquid wetting the whole surface. However, due to the gravity effect it is expected that the liquid film thickness at the cavity floor is much larger than those at the side wall and ceiling. The criterion for the annular flow transition is discussed below in terms of the entrainment process.

\subsection{Corium Entrainment and Droplet Size}

The most likely flow regime in the cavity is the film flow. In this case the droplet entrainment becomes the most important mechanisms to disperse the molten corium mass. The onset of entrainment, entrainment rate and entrained droplet size are discussed below. The onset of entrainment criteria is given (Ishii and Grolmes [3.10]) by

$$
\frac{\mu_{f} v_{r}}{\sigma} \sqrt{\frac{\rho_{g}}{\rho_{f}}} \geq N_{\mu}^{0.8}
$$

where the viscosity number is defined as

$$
N_{\mu} \equiv \frac{\mu_{f}}{\left(\rho_{f} \sigma \sqrt{\sigma /(g \Delta \rho)}\right)^{1 / 2}}
$$


The entrainment rate from the film is given (Kataoka and Ishii, 1982) by

$$
\frac{\varepsilon D_{h}}{\mu_{f}}=6.6 \times 10^{-7}\left(\operatorname{Re}_{f} W e\right)^{0.925}\left[\frac{\mu_{g}}{\mu_{f}}\right]^{0.26}
$$

where

$$
\operatorname{Re}_{f}=\frac{\rho_{f} j_{f} D_{h}}{\mu_{f}}, W e=\frac{\rho_{g} j_{g}^{2} D_{h}}{\sigma}\left[\frac{\Delta \rho}{\rho_{g}}\right]^{1 / 3}
$$

Here $D_{h}$ is the hydraulic diameter of the cavity. The initial drop size is

$$
d=0.028 \frac{\sigma}{\rho_{g} \nu_{r}{ }^{2}} \operatorname{Re}_{f}^{-1 / 6} \operatorname{Re}_{g}{ }^{2 / 3}\left(\frac{\rho_{g}}{\rho_{f}}\right)^{-1 / 3}\left(\frac{\mu_{g}}{\mu_{f}}\right)^{2 / 3}
$$

However subsequent disintegration may occur if

$$
W e_{d} \equiv \frac{\rho_{g}\left(v_{g}-v_{f d}\right) 2 d}{\sigma}>12
$$

It is noted that drop size can be as small as $W e_{d}=1.7-2.5$ if very high gas turbulence exists. Under the reactor cavity condition, the criterion of the Weber number at 12 is more likely than the later criterion. Furthermore, for the droplet to disintegrate beyond the initial entrainment drop size, a sufficient interaction time should exist between drops and the gas flow.

\subsection{Various Time Constant}

Several time constants are important to the analysis of the corium dispersion in the reactor cavity. These are listed below.

$$
\text { Corium Discharge Time } \tau_{c d}=\frac{M_{c o r}}{\pi \rho_{f} D_{J}^{2} v_{f J} / 4}
$$




$$
\text { Primary System Blow Down Time } \tau_{p r}=\frac{V_{p r}}{0.6 \pi D_{J}^{2} v_{g t} / 4}
$$

Corium Film Transport Time $\tau_{f}=\frac{L_{c}}{v_{f}}$

Corium Entrainment Time $\tau_{e}=\frac{\delta_{f} \rho_{f}}{\varepsilon}$

The latter two time constants are particularly important in determining the dominant transport mode of the corium out of the reactor cavity.

\subsection{Discussion of Results}

The above scaling study is applied to the following typical reference conditions, see Table 1 .

Cavity geometry :Zion

Reactor Vessel Break Size $: 20 \mathrm{~cm}$ diameter

Molten Corium Mass $\quad: 134$ tones

Vessel Pressure $\quad: 7 \mathrm{MPa}(1000 \mathrm{psia})$

Cavity Pressure $\quad: 0.1 \mathrm{MPa}(15 \mathrm{psia})$

Relative to the above prototypic conditions, several models and simulation experiments are considered. At full scale and full pressure, a water-air system which simulates the molten corium-steam system is considered. For the $1 / 10$ linear scale-down model, the following cases are considereú for sample calculations.

Corium-Steam (full pressure, $7 \mathrm{MPa}$ ) 
Water-Air $\quad$ (reduced pressure, $1.4 \mathrm{MPa}, 200 \mathrm{psia}$ )

Wood Metal-Air (reduced pressure, $1.4 \mathrm{MPa}, 200 \mathrm{psia}$ )

The break size for the liquid discharge is geometrically scaled, thus it is $2 \mathrm{~cm}$ diameter. However, in order to see the parametric effects of the gas flow as well as to compensate for the reduced pressure in the vessel, several enlarged flow area for the gas jet with the increment of twice, three times, five times and seven times are considered in the sample calculations. See Table 1.

\subsubsection{Prototypic Case}

When the reference conditions are applied to the phenomenological models used in the scaling study, the following results are obtained. The molten corium discharge at the velocity of $39 \mathrm{~m} / \mathrm{s}$. The disintegration length for the single and two-phase jets are $6 \mathrm{~m}$ and $1.6 \mathrm{~m}$, respectively. Thus the corium jet tends to disintegrate before reaching the floor of the cavity in the case of two-phase flow. The void fraction of 0.5 is used for this prediction. Since the jet velocity is high, the second mode of disintegration due to the relative motion is applicable. The resultant droplet mean diameter is $4.1 \mathrm{~mm}$ with the maximum size of $12.8 \mathrm{~mm}$. The ultimate spherical limit is $1.45 \mathrm{~mm}$.

The value of the impingement Weber number far exceeds the spreading limit of 80 . Thus both the coherent jet and droplets spread out upon impingement to the floor and form a corium liquid film rather than bouncing back and form a dispersed droplet flow. This indicates that most of the mass that is discharged as a jet and mostly disintegrated into droplets reforms a coherent liquid film upon impingement to the floor. Therefore, for the corium dispersion in the cavity, the liquid film entrainment becomes the most important mechanism. The duration of the entrainment depends on the liquid film residence time in the cavity. Hence the liquid film motion and transport out of the cavity is also important.

For estimating the film motion, the film thickness and velocity are essential. Several 
reference values for the film thickness are given below.

$\begin{array}{ll}\text { Initial Thickness } & \delta_{i}=5 \mathrm{~cm} \\ \text { Minimum Thickness } & \delta_{\min }=0.4 \mathrm{~cm} \\ \text { Maximum Thickness } & \delta_{\max }=41 \mathrm{~cm} \\ \text { Whole Wall Static Spreading } & \delta=9 \mathrm{~cm}\end{array}$

The initial film velocity is very high at $39 \mathrm{~m} / \mathrm{s}$. Furthermore, complicated three dimensional motion and mixing due to the geometry of the cavity is expected. Because of these, some of the liquid can climb up the side walls and may even flow over the ceiling of the cavity. In the subsequent analysis, a typical film thickness of $5 \mathrm{~cm}$ is assumed over the entire cavity wetted perimeter. This value is chosen in view of the initial thickness and the average between the minimum thickness and whole wall static spreading thickness. The corresponding average film velocity is $3.2 \mathrm{~m} / \mathrm{s}$ in the axial direction from the continuity relation. The actual flow should have a very complicated three dimensional pattern. If most of the liquid flows only over the cavity floor then the velocity is about 10 $\mathrm{m} / \mathrm{s}$. With the film velocity of $3.2 \mathrm{~m} / \mathrm{s}$, the film residence time is in the order of 6.5 seconds. The jet discharge time for 134 tons of the molten corium from the $20 \mathrm{~cm}$ break is about $12 \mathrm{sec}$.

When the liquid starts to flow as a film, three different regimes are possible as discussed previously. The stratified to slug flow transition criterion gives the required gas velocity of $300 \mathrm{~m} / \mathrm{s}$, which is about twice the expected gas velocity. However, the more important transition is that to the annular flow, which is determined by the entrainment process. As shown below, for the case of the sample calculation the onset of entrainment velocity is exceeded by the expected gas velocity. Hence these two transition criteria indicate that the most possible flow regime in the cavity is the annular flow with thicker film at the bottom of the cavity and thinner film at the sides and ceiling.

The entrainment of liquid from the film is governed by the relative velocity and film Reynolds number. The minimum relative velocity required for the onset of the 
entrainment is given by $v_{r}$ in Table 1 . The steam velocity in the cavity of $136 \mathrm{~m} / \mathrm{s}$ far exceeds this onset of entrainment velocity of $88 \mathrm{~m} / \mathrm{s}$ at the assumed cavity pressure of 0.1 $\mathrm{MPa}$. Thus significant entrainment of the film into droplets is expected. The calculated entrainment rate is $3.07 \mathrm{~g} / \mathrm{cm}$. At this rate, the characteristic time constant is 14.7 seconds. This value should be compared with the film residence time of 6.5 seconds. The two characteristic time constants indicate that the film transport and entrainment mechanisms are in the same order of magnitude. A little less than one half of the molten corium is expected to be entrained by the streaming gas and the remaining mass discharged from the cavity to the lower compartment as a liquid film.

The mean droplet size from the entrainment is $6.6 \mathrm{~mm}$, which is rather large. The subsequent disintegration due to the relative motion between the droplets and gas flow may be possible. When the free stream gas velocity and Weber number of 12 are used, the droplet stability criterion gives a diameter of about $1.1 \mathrm{~mm}$. The very high entrainment rate shown above will certainly slow down the gas flow, specially in the boundary layer region, since the entrainment process and subsequent acceleration of droplets require considerable momentum transfer from the gas to liquid. When the one half of the free stream velocity is used as a mean gas velocity in the droplet boundary layer, the criterion gives the droplet the size of $0.44 \mathrm{~mm}$. Thus it is expected that the size of droplets is in the range of 0.44 to $6.6 \mathrm{~mm}$.

The significant effects of the cavity pressure on the gas velocity and the entrainment process should be noted. For example, if the cavity pressure is $0.3 \mathrm{MPa}$ or three times the pressure in the sample calculation, the entrainment rate is reduced by a factor of four. The corresponding characteristic time for entrainment is 58 seconds, which is much larger than the film residence time of 6.5 seconds. In that case the corium dispersion is considerably reduced.

The break size has also very strong effects on the corium dispersion. The sample calculations are carried out by assuming the diameter of the break to be $20 \mathrm{~cm}$. The 
increase in the break size shortens both the corium and gas discharge time. However, the most important effect is on the cavity gas velocity. For example, a twice larger diameter for the break leads to four times larger gas velocity and nearly four times larger entrainment rate. In that case, the entrainment becomes the dominant corium transport process.

\subsubsection{Scaled Experiments}

It should be also emphasized that the above results are obtained from the existing phenomenological models based on experimental data far from the prototypic DCH conditions. Most of the data base are obtained in standard air-water systems with a relatively small hydraulic diameter of 1 to $2 \mathrm{~cm}$. Only the onset of entrainment criterion has a relatively larger data base with $D_{h}$ ranging from 1 to $15 \mathrm{~cm}$. Hence there is a great uncertainty in predicting the corium dispersion in the $\mathrm{DCH}$ problem. Two main reasons for this deficiency are:

(1) Mechanism of corium dispersion are not well understood.

(2) Large uncertainty in the scale-up capability of the available droplet entrainment correlations.

In view of these, well scaled and focused separate effect experiments on the corium dispersion phenomena may be required. These separate effect experiments should be focused on understanding of the mechanisms of the liquid dispersion and establishing data base which can be used to develop phenomenological models applicable to prototypic conditions. For this purpose several scaled down experiments and simulation experiments are evaluated as a demonstration of the bottom-up scaling method. The results are summarized and compared to the hypothetical prototypic conditions in Table 1.

In the sample calculations, three different cases are considered. The most important phenomena of liquid entrainment and droplet size are discussed below.

i) Corium-Steam ( $1 / 10$ scale, full $7 \mathrm{MPa}$ pressure) 
The entrainment rate is $0.43 \mathrm{~g} / \mathrm{cm}^{2} \mathrm{~s}$ and the droplet size is $2.09 \mathrm{~mm}$. The entrainment rate is roughly $1 / 7$ of the prototypic case, thus the entrainment time is $10 \mathrm{sec}$, which is comparable to the realistic case. The liquid film transport velocity is essentially the same, at $3.2 \mathrm{~m} / \mathrm{s}$, thus the film transport time is reduced by a factor of 10 which is the linear scale rate. Hence the relative significance of the entrainment is reduced by a factor of 7 in this system. This is a significant scale distortion. The droplet size is reduced by a factor of 3 . In comparison the system dimension is reduced by a factor of 10 . Thus there is a scale distortion in the surface area by a factor of 3.

ii) Water-Air (1/10 scale, reduced pressure $1.4 \mathrm{MPa}, 5$ times break area for gas) The entrainment rate is $0.52 \mathrm{~g} / \mathrm{cm}^{2} \mathrm{~s}$ and the droplet size is $0.30 \mathrm{~mm}$. The entrainment rate is about 1/6 of the prototypic case, and the entrainment time is $1 \mathrm{sec}$. Here the smaller density of the water has a very strong effect. The entrainment time is reduced by a factor of 15 . The liquid film transport velocity is $4 \mathrm{~m} / \mathrm{s}$, which is comparable to the prototype. Hence the film transport time is reduced by a factor of 12.5. Therefore, the ratio of the entrainment time to the transport time is distorted by a factor of only 1.2. The entrainment is slightly accelerated in this system, but overall the agreement is good. The droplet size is reduced by a factor of 22 . In comparison the system dimension is reduced by a factor of 10 . However, this distortion can be eliminated if the break area for the gas is three times the scaled value. In this case the droplet size is $0.6 \mathrm{~mm}$, which is about $1 / 10$ of the realistic case. Then the geometrical scales are well matched between the system scale and the internal scale (droplet size).

iii) Wood Metal-Air (1/10 scale, reduced pressure 1.4 MPa, 5 times break area for gas) The entrainment rate is $0.38 \mathrm{~g} / \mathrm{cm}^{2} \mathrm{~s}$ and the droplet size is $1.6 \mathrm{~mm}$. The entrainment rate is roughly $1 / 8$ of the prototypic case. The corresponding entrainment time is 10.6 sec., which is comparable to the reactor case. The liquid transport velocity is $1.44 \mathrm{~m} / \mathrm{s}$, hence the liquid film transport time is reduced by a factor of 5 . Therefore, 
the ratio of the entrainment time to the transport time is increased by a factor of 3.6. This implies that the relative importance of the entrainment is significantly reduced. The droplet size is reduced by a factor of 4 , which should be compared to the linear system scale down factor of 10 . Hence the internal surface area is reduced relative to the system surface area by a factor of 2.5 . It is noted that this system behavior is similar to the 1/10 scale corium-steam system. Furthermore, by reducing the break area for gas flow, the droplet size can be increased to about $3 \mathrm{~mm}$, which is much closer to the physical dimension of the droplet in the reactor case than that in the water-air system.

The above sample calculations demonstrate the usefulness of the bottom-up scaling method in evaluating various possible experimental conditions. It is noted, however, the numbers obtained for various parameters are based on the best available phenomenological models and correlations. As mentioned above, the data base for these correlations at the prototypic conditions is missing. Hence the verification of both the phenomena and correlations at conditions similar to the reactor conditions is necessary. Furthermore, the present discussion has been limited to the hydrodynamic effects in the corium dispersion. The effects of water in the cavity or the solid materials in the molten corium have not been addressed here. Both of these efiects can have a significant influence on the corium dispersion phenomena. These should also be evaluated by further researches. However, the methodology of the bottom-up scaling and its effectiveness in analyzing the key phenomena are clearly demonstrated.

Nomenclature

$A_{C} \quad$ reactor cavity flow area $\quad N_{\mu} \quad$ viscosity number based on liquid 


$\begin{array}{llll}A_{f i} & \text { cavity flow area } & N_{\mu g} & \text { viscosity number based on gas } \\ A_{V} & \text { vessel break area } & P_{t} & \text { break throat pressure } \\ A_{W} & \text { cavity whole wall area } & P_{v} & \text { vessel pressure } \\ \mathrm{d} & \text { droplet diameter } & \mathrm{R} & \text { universal gas constant } \\ d_{\text {max }} & \text { maximum droplet diameter } & \mathrm{Re}_{f} & \text { Reynolds number of film } \\ d_{s l} & \text { spherical limit droplet diameter } & \mathrm{Re}_{J} & \text { Reynolds number of jet } \\ D_{h} & \text { cavity hydraulic diameter } & \mathrm{T} & \text { temperature } \\ D_{J} & \text { discharge jet diameter } & v_{f J} & \text { liquid jet velocity } \\ \mathrm{g} & \text { gravity } & v_{g t} & \text { gas discharge throat velocity } \\ h_{g} & \text { height above corium film } & v_{r} & \text { relative velocity } \\ j_{f} & \text { liquid volumetric flux } & V_{p r} & \text { volume of primary system } \\ j_{J} & \text { total volumetric flux of jet } & \text { We } & \text { Weber number of entrainment } \\ L_{B} & \text { jet break-up length } & W e_{d} & \text { droplet Weber number } \\ L_{c} & \text { cavity total length } & W e_{g r} & \text { gas Weber number } \\ M_{c o r} & \text { total corium mass discharged } & & \text { based on relative velocity } \\ M_{W} & \text { gas molecular weight } & W e_{i m} & \text { impact Weber number } \\ & & & \end{array}$

Greek Letters

$\alpha_{J} \quad$ jet void fraction

$\Delta \rho \quad$ density difference

$\delta_{c} \quad$ corium thickness from whole wall static spreading

$\delta_{i} \quad$ initial corium film thickness

$\delta_{\min } \quad$ minimum corium film thickness

$\delta_{\max } \quad$ maximum corium film thickness

$\delta_{f} \quad$ corium film thickness in cavity

$\varepsilon \quad$ entrainment rate 


$\begin{array}{ll}\mu_{f} & \text { viscosity of liquid } \\ \mu_{g} & \text { viscosity of gas } \\ \rho_{f} & \text { density of liquid } \\ \rho_{g} & \text { density of gas } \\ \sigma & \text { surface tension }\end{array}$

References

3.1 N.T. Obot and M. Ishii, "Two-phase Flow Regime Transition Criteria in Post Dryout Region Based on Flow Visualization Experiments", Int. J. Heat Mass Transfer, 31, 2559-2570, 1989.

3.2 J.G. Denten and M. Ishii, "Flow Visualization Study of Post Critical Heat Flux Region for Inverted Bubbly, Slug and Annular Flow Regime", NUREG/CR-5171, ANL-88-27, 1988.

3.3 I. Kataoka, M. Ishii, and K. Mishima, "Generation and Size Distribution of Droplet in Annular Two-phase Flow", J. Fluid Eng., 105, 230-238, 1983.

3.4 G. DeJarlais, M. Ishii, and J. Linehan, "Hydrodynamic Stability of Inverted Annular Flow in Adiabatic Simulation", J. of Heat Transfer, 108, 84-92, 1986.

3.5 L. Bolle and J.C. Moureau, "Spray Cooling of Hot Surfaces", Multiphase Science and Technology 1 (Edited by G.F. Hewitt, J.M. Delhaye and N. Zuber), 1-98, 1982.

3.6 R. Henry, "An Evaluation of Fission Product Release Rates During Debris Dispersal", Proc. ANS International Topical Meeting - Probability, Reliability and Safety Assessment 1, April 2-7, 375-383, 1989.

3.7 G.B. Wallis and J.E. Dobson, "The Onset of Slugging in Horizontal Stratified AirWater Flow", Int. J. Multiphase Flow, 1, 173-183, 1973.

3.8 K. Mishima and M. Ishii, "Theoretical Prediction of Onset of Horizontal Slug Flow", J. Fluids Engineering, 102, 441-445, 1980. 
3.9 Y. Taitel and A.E. Dukler, "A Model for Predicting Flow Regime Transition in Horizontal and Near Horizontal Gas-Liquid Flow", AIChE J., 22, 47-55, 1976.

3.10 M. Ishii and M.A. Grolems, "Inception Criteria for Droplet Entrainment in Twophase Concurrent Film Flow", AIChE, 21, 308-318, 1975.

3.11 I. Kataoka and M. Ishii, "Mechanism and Correlation of Droplet Entrainment and Deposition in Annular Two-phase Flow", NUREG/CR-2885, ANL-82-44, 1982. 
Table 1. Sample calculation for various parameters in corium dispersion




Table 1. (continued)

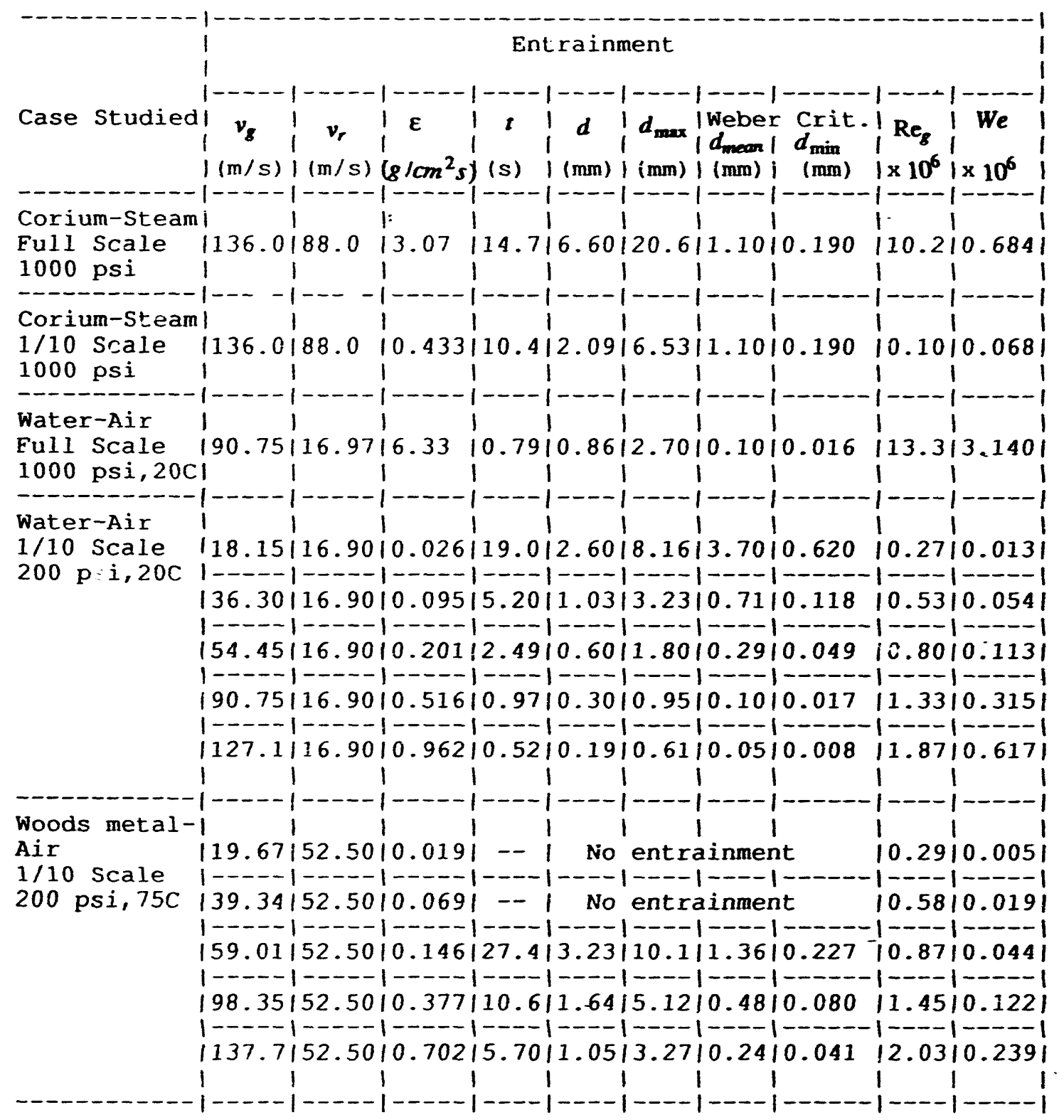




\section{SCALING STUDY OF SPREADING OF MOLTEN CORIUM IN MARK-1 BOILING WATER REACTORS}

\subsection{Introduction}

Previous containment analysis of BWR MARK-1 has considered the $\gamma$-mode of containment failure, that is, overpressure failure of the drywell liner as the dominant mode. However, a possible mode of early containment failure has been identified [4.1]. In this mode the possible rapid spreading of the melt onto the drywell floor following the ejection of core melt materials causes thermal attack by the high-temperature corium through the direct contact of the molten corium with the steel liner.

Several experimental and analytical investigations have been performed in order to deal with the safety concern of the mode. The mechanism of melt spreading was experimentally studied by BNL [4.2]. Their studies revealed five melt spreading flow regimes characterized by hydrodynamically-limited and heat transfer-limited phenomena. Based on their observation, a single parameter dimensionless correlation was suggested for identifying the spreading regimes. Issues on the dynamic interactions between the corium and water were studied by Fauske Associates [4.3]. Their experiments designed with a one-tenth liner scale for geometry used iron thermite as a corium simulant. They reported that the most important part of the experiments is energy removal rates provided hy water and quenching rates far exceeded critical heat flux values in early transients. The thermal response of the shell was studied by ORNL using the three-dimensional transient heat transport computer code, HEATING-6 [4.4]. They found out that the most important parameters are melt superheat, melt depth, and melt-to-crust heat transfer coefficients. A detailed computer code for analysis of spreading of the molten corium is under development at ANL [4.5]. Their scoping calculation showed that the prediction of corium penetration is strongly sensitive to the superheat of corium hut weakly sensi-

tive to the volumetric heat source in the corium. Kazimi evaluated the cooling of the 
spreading corium and the heat transfer to the liner using his simple model [4.6]. He devised the map showing the regions of unlikely liner failure in terms of pour rate, pour superheat, pour material, and the presence of water. Moody developed a simplified theoretical method for estimating the maximum temperature of the shell considering the relative importance of each phenomenon through nondimensional analysis [4.7]. They found that the maximum shell temperature is directly proportional to the volumetric heat generating rate and water cooling is effective in preventing temperatures from reaching the shell melting value.

In view of complexities of phenomena involved in the mode we need properlyscaled experiments for studying interactions between spreading and crust formation by cooling. In order to generate scaling criteria, several studies have been performed on the base of Buckingham's $\pi$ theorem [4.8-10], the meunod of nondimensional differential equation [4.11], and the integral method [4.12-13].

The most extensively used scaling approach is Buckingham's $\pi$ theorem. Its application to the present problem is not very useful because of its main characteristics requiring to guess governing parameters and generating too many similarity groups without clear physical meanings. The method of nondimensional differential equations based on physical conservation laws is very useful to provide similarity groups with physical significance. For muitiphase flow this method is applicable only for local scaling due to a large change of scales over wide ranges. The integral method has heen sucessfully used for scaling analysis of LOCA. In this method differential equations are integrated over system implementing initial and boundary conditions in order to ohtain integral response function. Therefore, scaling criteria generated from nondimensionalized integral response function are applicable for system. However, it is very difficult to apply this method to a problem with poorly understood and very complicaled phenomena hecause of difficulties in obtaining its integral response function. As a result, a new scaling method called stepwise integral scaling approach described in Chapter II is applied to generating scaling criteria for the present problem. 


\subsection{Application of The Proposed Method}

\subsubsection{Identification of system}

Whole system is divided into three subsystems as shown in Table 2 : vessel subsystem, floor subsystem, and shell subsystem. Each subsystem has its own components. For example, the floor subsystem consists of 4 components : sump, inpedestal floor, doorway, and expedestal floor. Through identifying initial and boundary conditions, and interfacial conditions between subsystems as shown in Table 3, the problem can be separated from in-vessel accident scenario and each subsystem can be separately dealt with. Five possible bifurcation phenomena are identified : critical flow (hydraulic jump phenomena), film boiling and quenching, solidification, crust stability, and minimum corium thickness for spreading. Concrete ablation and stable crust formation are identified as important feedback mechanisms. Steam and gas produced by concrete ablation chemically react with metallic components in the corium and produce chemical energy. More ablation is possible due to an increase in the corium temperature by the produced chemical energy. However, more cooling on the top of the corium is expected by bubble agitation and corium entrainment. Stable top crust formation considerably retards spreading and, as a result, thickens crust. Stable bottom crust formation can generate mixed results : no chemical energy and no enhancement of water cooling.

Twenty-nine potentially important phenomena are identified and ranked as shown in Table 4. Spreading and crust formation are considered as phenomena with high relative importance.

These phenomena are grouped and sequence of analysis is decided according to their importance and order of events. Three group mechanisms are identified : spreading group mechanism, water-corium-concrete interactions and corium-shell interactions. Here, the former two group mechanisms are studied.

\subsubsection{Spreading Group Mechanism}


The spreading group mechanism is chosen as the most important group mechanism because it consists of main driving mechanisms to transfer the molten corium to the shell. In the first step spreading and filling phenomena in the sump, inpedestal floor, doorway, and expedestal floor are analyzed to generate scaling parameters governing the spreading group mechanism. As only mass and momentum transfer are considered, scaling parameters involved in the hydrodynamics of the molten corium can be generated.

\section{In the sump}

It can be thought that the molten corium leaving the reactor vessel first fills the sump below it. The filling mechanism in the sump is simply modeled using mass balance

$$
\frac{\mathrm{dh}_{\mathrm{su}}}{\mathrm{dt}}=\frac{\mathrm{Q}_{\mathrm{p}}}{\pi \mathrm{R}_{\mathrm{su}}^{2}\left(1-\alpha_{\mathrm{su}}\right)},
$$

where $h_{s u}$ and $\alpha_{s u}$ : corium thickness and averaged void fraction in the sump, respectively,

$\mathrm{R}_{\mathrm{su}}$ : radius of the sump,

$\mathrm{Q}_{p}$ : volumetric pouring-out rate of the corium from the reactor vessel.

Equation (4.1) is nordimensionalized using the following nondimensional variables and parameters :

$$
\mathrm{t}^{*}=\frac{\mathrm{t}}{\tau_{\mathrm{p}}}, \mathrm{h}_{\mathrm{su}}^{*}=\frac{\mathrm{h}_{\mathrm{su}}}{\mathrm{H}_{\mathrm{su}}}, \mathrm{N}_{\mathrm{su}}=\mathrm{Q}_{\mathrm{p}} \frac{\tau_{\mathrm{p}}}{\mathrm{V}_{\mathrm{su}}}, \frac{\mathrm{dh}_{\mathrm{su}}^{*}}{\mathrm{dt}}=\frac{\mathrm{N}_{\mathrm{su}}}{\left(1-\alpha_{\mathrm{su}}\right)},
$$

where $\tau_{p}$ : time interval in which pouring-out of the corium from the reactor vessel continues,

$\mathrm{V}_{\mathrm{su}}$ : volume of the sump,

$\mathrm{N}_{\mathrm{su}}$ : dimensionless sump number.

The dimensionless sump number $\mathrm{N}_{\mathrm{su}}$ represents the ratio of the total volume of the pouring-out corium to the total sump volume, noting that

$$
(M / \rho)=Q_{p} \tau_{p}
$$


where $M$ and $\rho$ : total mass and density of the pouring-out corium, respectively.

If the sump is covered by steel plates during operation, the corium will initially flow over the cover plates. If the time constant related to their complete melting is large enough compared to the time constant of corium spreading, the scaling analysis of the sump can be simply neglected. However, for the short melting time constant the effect of the cover plates on scaling analysis can be neglected. Let us define the subscript $R$ as the ratio between the model and the prototype in the following generalized form :

$$
\Psi_{\mathrm{R}}=\frac{\Psi_{\mathrm{m}}}{\Psi_{\mathrm{p}}}=\frac{\Psi \text { for model }}{\Psi \text { for prototype }} .
$$

Similarity between the model and the; prototype requires that $\Psi_{\mathrm{R}}$ should be equal to 1 . For similarity in the sump,

$$
\left(\mathrm{N}_{\mathrm{su}}\right)_{\mathrm{R}}=\left(\frac{\mathrm{M}}{\rho}\right)_{\mathrm{R}} /\left(\mathrm{V}_{\mathrm{su}}\right)_{\mathrm{R}}=1 .
$$

\section{In the Inpedestal Region}

After the sump is filled with the molten corium, spreading over the inpedestal floor is mainly governed by two competing forces : gravitational force and surface tension. Gravitational force on the spreading corium is produced by the difference of corium thickness between upstream and downstream. If the gravitational force hecomes low enough to balance surface tension on the leading edge of the spreading corium, the corium will uniformly spread maintaining its minimum thickness. Therefore, spreading over the floor is divided into two regimes : gravitational force-dominated spreading and surface tension-dominated spreading.

After the front of the corium reaches the wall of the floor, filling is a more dominant phenomenon than spreading in the same way as water pours into the large empty-flat bowl. It can be observed that first water spreads out and then its height in the bowl almost instantaneously increases. 


\section{Gravitational force-dominant spreading}

Boundary conditions at the radius of the sump $R_{\text {su }}$ such as corium velocity and thickness are needed for gravitational force-dominant spreading over the inpedestal floor. After the sump is filled with the pouring-out molten corium, its height $h_{p}$ continues to increase without any spilling over the sump until gravitational force resulting from the potential difference between $h_{p}$ and $h_{s}$ overcomes the surface tension on the leading edge of the corium. After then, the volumetric flow rate leaving the sump region $Q_{s}$ continues to increase until it becomes equal to $Q_{p}$. The corium velocity at $R_{s}, v_{s}$, can he approximately obtained using Bernoulli's equation:

$$
v_{s}=\sqrt{2 g\left(h_{p}-h_{s}\right)} \text {. }
$$

The volumetric flow rate at $R_{s}, Q_{s}$, is expressed as

$$
Q_{s}=2 \pi R_{s u} h_{s} \sqrt{2 g\left(h_{p}-h_{s}\right)} \text {. }
$$

At the maximum draining rate from the sump region, which is equal to $Q_{p}$, the following relationship between $h_{s}$ and $h_{p}$ can be obtained differentiating Eq.(4.7) with $h_{s}$ :

$$
h_{s}=\frac{2}{3} h_{p}
$$

Putting Eq.(4.8) into Eq.(4.7) yields

$$
\begin{aligned}
& h_{s}=a_{1}\left(Q_{p} / R_{s u}\right)^{2 / 3}, \\
& v_{s}=a_{2}\left(Q_{p} / R_{s u}\right)^{1 / 3},
\end{aligned}
$$

where $a_{1}=\left(1 / 4 \pi^{2} g\right)^{1 / 3}, a_{2}=(g / 2 \pi)^{1 / 3}$.

As noticed later, Eqs. (4.9) and (4.10) are equivalent to the critical conditions for open channel flow. Corium spreading is expected to be analyzed by equations governing the dynamics of open channel flow. Since spreading is at quasi-steady at the maximum draining rate from the sump, the following steady-state macroscopic mass and 
momentum balance equations for a fixed control volume are used:

$$
\text { mass : } \int_{A} \rho \vec{v} \cdot \vec{n} d A=0 \text {, }
$$

$$
\text { momentum : } \int_{A} \rho \vec{V} \vec{V} \cdot \vec{n} d A=\int_{V} \rho \vec{g} d V+\int_{A} \vec{c}_{(n)} d A,
$$

where $A$ and $V$ : control surface and volume, respectively,

$\overrightarrow{\mathfrak{t}}_{(\mathrm{n})}$ : stress vector acting on the control surface.

Then, Eq.(4.11) becomes

$$
h \frac{d<v>}{d r}+\left\langle v>\frac{d h}{d r}+\frac{\langle v\rangle h}{r}=0,\right.
$$

where $\langle v\rangle=\int_{0}^{h} v d z / \int_{0}^{h} d z$.

Equation (4.13) is the other expression of steady-state mass balance

$$
\mathrm{Q}_{\mathrm{p}}=2 \pi \mathrm{rh}\langle\mathrm{v}\rangle .
$$

Integrating Eq.(4.12) over the control surface and control volume yields

$$
\begin{aligned}
& {\left[1-\frac{\mathrm{C}}{\cos \delta} \mathrm{N}_{\mathrm{Fr}}\right] \frac{\mathrm{dh}}{\mathrm{dr}}+\frac{\mathrm{h}}{2 \cos \delta} \frac{\mathrm{d}}{\mathrm{dr}} \cos \delta} \\
& =\frac{\mathrm{C}}{\cos \delta} \frac{\mathrm{h}}{\mathrm{r}} \mathrm{N}_{\mathrm{Fr}}+\tan \delta-\frac{1}{2 \cos \delta} \mathrm{f}_{\mathrm{Fr}},
\end{aligned}
$$

where $\mathrm{N}_{\mathrm{Fr}}$ : Froude number defined as $\mathrm{N}_{\mathrm{Fr}}=\langle\mathrm{v}\rangle^{2} / \mathrm{gh}$,

$$
\begin{aligned}
& \delta \text { : floor angle, } \\
& \mathrm{f} \text { : wall friction coefficient. }
\end{aligned}
$$

According to the Manning correlation [4.15] for friction coefficients in open channel flow, $f$ can be expressed as 


$$
f=a_{f} \frac{n^{2}}{h^{1 / 3}},
$$

where $\mathrm{a}_{\mathrm{f}}$ : constant

$\mathrm{n}^{2}:$ coefficient depending on the material of the substrate and its roughness.

Let us nondimensionalize Eq.(4.15) for turbulent flow and the flat surface of the floor using the following nondimensional variables and parameters:

$$
\begin{aligned}
& r^{*}=\frac{r}{r_{r}}, h^{*}=\frac{h}{h_{r}},\langle v\rangle^{*}=\frac{\langle v\rangle}{\langle v\rangle_{r}}, \\
& \left(N_{F r}\right)^{i n}=\frac{\langle v\rangle_{r}^{2}}{g h_{r}},\left(N_{G}\right)^{i n}=\frac{h_{r}}{R i n},\left(N_{f}\right)^{i n}=\frac{n_{i n}^{2} r_{r}}{h_{r}^{4 / 3}} \\
& {\left[1-\left(N_{F r}\right)^{i n} \frac{1}{r^{* 2} h^{* 3}}\right] \frac{d h^{*}}{d r^{*}}=} \\
& \left(N_{F r}\right)^{i n} \frac{1}{r^{* 3} h^{* 2}}-a_{f}\left(N_{f}\right)^{i n}\left(N_{F r}\right)^{i n} \frac{1}{h^{* 3 \frac{1}{3}} r^{* 2}},
\end{aligned}
$$

where $R_{\text {in }}$ and $n_{\text {in }}$ : radius and coefficient of the inpedestal floor.

The subscript $r$ denotes the reference value.

As Eq.(4.17) is a nonlinear differential equation, its integral response function is expressed in the following nonlinear form:

$$
h^{*}=h_{s}^{*}+\int_{r_{s}^{*}}^{r^{*}} f_{2}\left[h^{*}\left(r^{*}\right), r^{*},\left(N_{F r}\right)^{\text {in }},\left(N_{f}\right)^{\text {in }}\right] d r^{*}
$$

where the subscript $s$ represents properties at $R_{s}$, and $h_{s}^{*}$ and $r_{s}^{*}$ are defined as $h_{s}^{*}=\frac{h_{s}}{h_{r}}$ and $r_{s}^{*}=\frac{R_{s u}}{R_{i n}}$, respectively.

Based on Eq.(4.18), similarity between the prototype and the model for corium spreading over the inpedestal floor can be maintained if the following boundary conditions and scaling parameters are satisfied: 
boundary conditions:

$h_{s}^{*}=\frac{h_{s}}{h_{r}}, r_{s}^{*}=\frac{R_{s u}}{r_{r}}=\left(N_{G}\right)^{\text {in }}, r_{i n}^{*}=\frac{R_{\text {in }}}{r_{r}}$

scaling-parameters:

$\left(\mathrm{N}_{\mathrm{Fr}}\right)^{\text {in }},\left(\mathrm{N}_{\mathrm{f}}\right)^{\text {in }}$

If $R_{i n}, h_{s}$, and $v_{s}$ are used for reference values of $R_{i n}, h_{r}$, and $v_{r}$, respectively, $h_{s}^{*}, r_{i n}^{*}$, and $\left(\mathrm{N}_{\mathrm{Fr}}\right)^{\text {in }}$ become 1 . Then, the following two scaling parameters are required to be satisfied for similarity:

$$
\begin{aligned}
& \left(N_{G}\right)_{R}^{\text {in }}=\left[\frac{R_{\text {su }}}{R_{\text {in }}}\right]_{R}=1, \\
& \left(N_{f}\right)_{R}^{\text {in }}=\left[\frac{n_{\text {in }}^{2} R_{\text {in }}}{h_{s}^{4 / 3}}\right]_{R}=1 .
\end{aligned}
$$

The scaling parameter related to the time constant of spreading can be obtained using the following nondimensional characteristic equation which represents the propagation of mass and momentum of the spreading corium:

$$
\frac{\mathrm{dr}^{*}}{\mathrm{dt}^{*}}=\left(\mathrm{N}_{\mathrm{d}}\right)^{\mathrm{in}}\langle\mathrm{v}\rangle^{*}
$$

where $\left(\mathrm{N}_{\mathrm{d}}\right)^{\text {in }}$ : nondimensional dynamic time constant in the inpedestal floor defined as

$$
\begin{aligned}
& \left(N_{d}\right)^{\text {in }}=\frac{\tau_{r}}{\tau_{d}^{\text {in }}} \\
& \tau_{d}^{\text {in }}=\frac{R_{\text {in }}}{v_{r}} \\
& t^{*}=\frac{t}{\tau_{r}}
\end{aligned}
$$




\section{DESCRIPTION OF STEPWISE INTEGRAL SCALING METHOD}

In the proposed method, first of all, two identifications are needed : system identification and mechanism identification. Whole system is divided into subsystems with several components. The initial and boundary conditions of the system are identified in order to isolate the present system and the present problem from other systems and other part of the accident scenario. Also, through the identification of interfacial conditions between subsystems, each subsystem can be separately dealt with.

The whole transient is divided into several stages according to time sequence and the transition of dominant mechanisms to characterize each stage. Then, potentially important mechanisms and bifurcation phenomena are identified for each stage and each subsystem. Transition criteria between stages and the characteristic time constants of each mechanism are identified. The latter will give an estimation time required to complete the plausible mechanism and, as a result, become an important factor in determining which mechanism is dominant. Also, the most critical parameters for each stage are identified which we are most concerned with from the safety point of view. Then, as initial guess, each potential important mechanism is ranked in terms of relative importance in view of the most critical parameters, using the transition criteria, bifurcation criteria, and characteristics time constants as well as engineering judgement and literature survey. As a final step of the phenomena identification, we determine which transfer process dominantly governs each stage ( hydraulic-, thermal-, chemical-, dominant transfer process). If the strong coupling among them exists, combine them (thermalhydraulic-, thermal-chemical-, or thermal-hydraulic-chemical-transfer process ).

After taking the identification step, scaling analysis is done step by step. Starting from the most dominant mechanism for the first stage and the first subsystem, its integral rate equations including initial and boundary conditions are obtained. These balance equations are solved analytical or expressed as nonlinear integral response functions for the most critical parameters. 
Then, in order to obtain integral scaling parameters, nondimensionalize the integral response functions, the transition criteria, the bifurcation criteria, and the characteristic time constants selecting reference conditions so that they may reduce the number of scaling parameters. The reasonable accuracy of the integral response functions should be checked using proper experimental data and/or well-verified software. Based on the integral response functions, the corrections of the initial guess on the order of relative of various mechanisms are obtained.

In the second step, the above step for the next dominant mechanism is repeated independently of the first step but results from the first step may be used in this step. Thus, we check how strong feedback exists between the two mechanisms. If strong enough, we may need to combine analysis. This step should be repeated until all the possible major mechanisms are considered. The above procedure continues until all the stages and subsystems are considered.

The whole set of scaling parameters are generated as a final product of the above stepwise procedure. After the procedure two questions should he answered :

1. Is the same relative importance of each scaling parameter preserved for the prototype and its scaled-down systems?

2. Is the same sensitivity of the scaling parameters to the changes in boundary and initial conditions preserved for the two systems?

If all the requirement of similarity can not he satisfied, possible scale distortion is carefully investigated based on the relative importance of each scaling parameter. Now, we can develop desirable experimental conditions with given design constraints for the scaled-down system. Finally, we need to check whether a separate-effect test is needed examining the uncertainties of dominant mechanisms, transition criteria, bifurcation criteria, and characteristic time constants. 


\section{SCALING STUDY OF CORIUM DISPERSION IN DCH}

The stepwise integral scaling method explained above is applied to the corium dispersion in the reactor cavity in DCH. Thus the subsystem is the reactor cavity with the reactor vessel break as the upstream boundary. The previous studies for the DCH problem indicated that the most significant factor affecting the containment heating and pressurization was the degree of the molten corium dispersion. This is because the heat transfer and chemical reactions which may lead to the containment overpressurization are basically proportional to the available surface area of the molten corium.

Therefore, for the scaling study the corium dispersion is taken as the most important phenomenon to be studied in detail in the reactor cavity. For the molten corium dispersion and corium transport, the following four mechanisms are critical.

i) Corium discharge and corium jet disintegration

ii) Liquid corium spread-out upon impact of the jet or droplet

iii) Liquid mass transport due to inertia, pressure and shear force

iv) Entrainment and drop formation by streaming gas

These are studied hy using the stepwise integral scaling method and starting from the upstream event.

\subsection{Initial Corium Jet Break-up}

The molten corium jet can disintegrate into droplets after the discharge from the reactor vessel break. The corium discharge can be in a form of a single phase jet or twophase jet due to the depressurization or punch through of the gas llow over the liquid corium surface in the reactor vessel. Several possible mechanisms and jet disintegration length are discussed below. The comparison of the jet disintegration length with the 
height below the reactor vessel gives the base to determine whether the molten corium disintegrates before impinging on the floor or not. Obviously, if the break-up length, $L_{B}$, is much smaller than the height, then it is expected that the jet disintegrates into small droplets during the vertical downward motion below the break. Hence it is important to know the break-up length.

3.1.1 Single Phase Jet Breakup. The single phase liquid jet can break-up in two major modes depending on the relative velocity between the liquid and gas phases, Obot and Ishii [3.1].

3.1.1.1 Jet Surface Hydrodynamic Instability. Obot and Ishii [3.1] showed that for a relatively small gas Weber number range given by

$$
W e_{g r} \equiv \frac{\rho_{g} v_{r}^{2} D_{J}}{\sigma}<3.5
$$

the jet break up length $L_{B}$ is given by

$$
\frac{L_{B}}{D_{J}}=595 \sqrt{\frac{\mu_{f} v_{f J}}{\sigma}}
$$

where $v_{r}, v_{f J}$ and $D_{J}$ are the relative velocity, jet velocity and jet initial diameter.

3.1.1.2 Jet Surface Break-up due to Relative Motion. When the relative velocity is high, $W e_{g r}>3.5$, the break-up length can be significantly reduced [3.1] and is given by

$$
\frac{L_{B}}{D_{J}}=1110 \sqrt{\frac{\mu_{f} v_{f J}}{\sigma}}\left(W e_{g r}\right)^{-0.5}
$$

These correlations indicate that the capillary number $\frac{\mu_{f} v_{f J}}{\sigma}$ and gas Weber number scale the jet break-up. The time constant is $L_{B} / v_{f J}$.

3.1.2 Two-phase Jet Break-up. When the jet consists of two phases due to either the 
gas blow through or gas generation the effect of the void fraction should be considered, Denten and Ishii [3.2] In this case

$$
\frac{L_{B}}{D_{J}}=595 \sqrt{\frac{\mu_{f j}}{\sigma}}\left(1-\frac{\alpha_{j}}{0.854}\right)^{1.22}
$$

for

$$
W e_{g r}=\frac{\rho_{g} j j^{2} D_{J}}{\sigma}<3.5
$$

where $j_{J} \equiv \alpha_{J} v_{g J}+\left(1-\alpha_{J}\right) v_{f J}$. Here $\alpha_{J}$ and $v_{g J}$ are the void fraction and gas velocity at the jet discharge point. For higher relative velocity, $W e_{g r}>3.5$

$$
\frac{L_{B}}{D_{J}}=1110 \sqrt{\frac{\mu_{f j J}}{\sigma}}\left(W e_{g r}\right)^{-0.5}\left(1-\frac{\alpha_{J}}{0.854}\right]^{1.22}
$$

These correlations indicate that the existence of void accelerates the jet disintegration significantly.

3.1.3 Jet Break-up Droplet Diameter. The second phenomenon of importance for the corium jet disintegration is the resultant droplet size. For the DCH problem the droplet size is the key in determining the degree of chemical reaction, heat transfer and corium transport. In the following, the droplet size from the disintegrating jet is discussed in terms of the primary jet disintegration and subsequent droplet disintegration. The correlations given below are applicable both for the single and two-phase jet disintegration. By modifying the annular droplet size correlation of Kataoka, Ishii and Mishima [3.3] the mean droplet size in the disintegrated jet flow is given by De Jarlais, Ishii and Linehan [3.4] by

$$
d=0.028 \frac{\sigma}{\rho_{g} v_{r}^{2}}\left(\operatorname{Re}_{J}\right)^{1 / 2}\left[\frac{\rho_{g}}{\rho_{f}}\right]^{1 / A}
$$

and the maximum, size is given from the maximum $\log$ normal distribution as $d_{\max }=3.13 d$. This criterion roughly corresponds to the Weber number criterion of 12 . 
3.1.4 Secondary Disintegration of Jet Droplet. When the jet disintegrates, the initial droplet size is given by the above correlation. However, often these initial droplets can be relatively large and may not be stable. The droplets from the jet can further disintegrate under two conditions. These are

(i) Existence of Extremely High Gas Turbulence such as Shock Waves

(ii) Exceeding of Spherical Limit

During the molten corium discharge phase, the first mechanism is unlikely. Under extreme conditions such as the sudden exposure of droplets to shock waves, the disintegration Weber number can be as low as 2 or 3 . However, the condition around the disintegrated jet before the gas blow down phase does not meet such extreme gas turbulences requirement. The second mechanism indicates that if the initial droplet size given by the above correlation far exceeds the spherical stable drop size limit, then droplets will further disintegrate to reach this stability limit. The spherical limit is given by

$$
d_{s l}=4\left(\frac{2 \sigma}{g \Delta \rho}\right)^{1 / 2}\left(N_{\mu g}\right)^{1 / 3}
$$

where the gas viscosity number, $N_{\mu g}$ is defined by

$$
N_{\mu g}=\frac{\mu_{g}}{\left[\rho_{g} \sigma \sqrt{\sigma / g \Delta} \bar{\rho}\right]^{1 / 2}}
$$

\subsection{Corium Drop or Jet Impingement Phenomena}

In the above, the criteria for the jet break-up length and resultant droplet size are discussed. The next phenomenon of interest is the vertical impingement of the intact jet or the disintegrated jet in the form of droplet flow. The main question here is whether the impinging liquid mass spreads out coherently over the cavity wall or bounces back into the cavity space. The phenomena after the drop or jet impingement at the cavity floor can be scaled by the impact Weber number defined by 


$$
W e_{i m}=\frac{\rho_{f} v_{f j}{ }^{2} d}{\sigma}
$$

where $d$ is the drop or jet diameter.

For $W e_{i m}>80$, the drop or jet will spread out as a liquid film due to large inertia overcoming the surface tension effect to recover. When $W e_{l m}<30$, the droplets bounce back after the impingement, Bolle and Moureau [3.5].

\subsection{Corium Spread Out Over Cavity Wall}

Under a prototypic condition the above criterion for the corium spread out is most likely satisfied. Then it is important to know the thickness and velocity of the molten corium film. For this purpose, several different length scales for the film thickness are considered below. From the continuity relation, and assuming that the magnitude of the velocity remains constant during the impingement, the initial film thickness $\delta_{i}$ at the vicinity of the impingement point is given by

$$
\frac{\delta_{i}}{D_{J}}=0.25
$$

The order of the lower limit of the corium film thickness is estimated by the symmetric spread of the liquid film with the constant liquid film velocity. The length scale for the extent of the film spread is taken as the hydraulic diameter of the cavity, $D_{h}$. Then

$$
\delta_{\min }=\frac{D_{J}^{2}}{4 D_{h}}
$$

It is noted that instead of $\Gamma_{i n}$, other length scale may be used here, however for the present study $D_{h}$ is satisfactory.

The maximum thickness is obtained by assuming the entire corium mass accumulated 
on the floor. Thus

$$
\delta_{\max }=\frac{M_{c o r}}{\rho_{f} A_{f}}
$$

where $M_{c o r}$ and $A_{f}$ are the total corium discharge mass and cavity floor area.

Another reference film thickness can be obtained by assuming that the all molten corium spreads over the entire cavity surface. In this case

$$
\delta_{c}=\frac{M_{c o r}}{\rho_{f} A_{W}} \sim \frac{M_{c o r}}{\pi \rho_{f} D_{h} L_{c}}
$$

where $A_{W}$ and $L_{c}$ are the cavity wall area and cavity length.

\subsection{Estimate of Cavity Conditions}

In order to evaluate the molten corium dispersion in the reactor cavity, it is necessary to specify the global cavity conditions in terms of the liquid and gas flows. These parameters can be estimated from the geometry and boundary conditions.

In the above, several length scales for the corium film thickness have been obtained. Typical values for these are calculated in Table 1 by considering the following reference conditions.

In the following analysis, the typical film thickness of $\delta_{f}=\delta_{i}$ is assumed over the entire cavity welted perimeter. Then from the continuity condition, the film velocity is given by

$$
v_{f}=\frac{D_{J}^{2} v_{f J}}{4 D_{h} \delta_{f}}
$$

The film Reynolds number is defined by

$$
R_{e f}=\frac{\rho_{f} j_{f} D_{h}}{\mu_{f}}=\frac{4 \rho_{f} \delta_{f} v_{f}}{\mu_{f}}
$$


If the film is only on the floor of the cavity, the velocity $v_{f}$ and $R_{e f}$ should be about $\pi$ times the values given above. Because of the relatively high initial film velocity (in the order of $40 \mathrm{~m} / \mathrm{s}$ ), the liquid corium can climb up the side walls and may even cover the ceiling of the cavity. The actual values should be somewhere between them.

The gas flow conditions are estimated along the analysis proposed by Henry [3.6]. By assuming the choked flow for the gas discharge following the corium discharge, the pressure at the throat is given by

$$
p_{t} \sim 0.6 p_{v}
$$

and the choked flow velocity by

$$
v_{g t}=\sqrt{\frac{R T}{M_{W}}}
$$

From the ideal gas at the isothermal condition

$$
\rho_{g t}=0.6 \rho_{\nu}
$$

The unlimited isothermal expansion can give the maximum velocity of twice the discharge velocity. The cavity gas initial velocity before entrainment can be given from the continuity relation and the cavity pressure. Thus

$$
v_{g c}=\frac{0.6 p_{\nu}}{p_{c o}}\left[\frac{A_{\nu}}{A_{c}}\right]\left[\frac{R T}{M_{W}}\right]^{0.5}
$$

where $A_{v}$ and $A_{c}$ are the vessel break area and cavity flow area. $p_{c o}$ is the cavity initial pressure.

This equation indicates that the cavity gas velocity is a strong function of the cavity pressure.

\subsection{Flow Regime in Cavity}

When the molten corium spreads out in the reactor cavity, three different two-phase flow regimes are possible. These are stratified wavy flow, slug flow and annular flow. In 
order to identify the most possible flow regime, the transition criteria between these regimes are examined. The onset of slugging from horizontal stratified wavy flow is given by the following form (Wallis and Dobson [3.7]; Mishima and Ishii [3.8]; Taitel and Dukler [3.9]):

$$
v_{r} \geq 0.5 \sqrt{\Delta \rho g h_{g} / \rho_{g}}
$$

In the Taitel and Dukler correlation, the constant of 0.5 is replaced by a function of the void fraction which approaches unity as the relative film thickness becomes smaller.

The transition to annular flow either from the stratified wavy or slug flow is determined by the entrainment process. Thus if the gas (or relative) velocity exceecis the onset of entrainment velocity, the entrainment of wave crests or liquid slugs occurs. In case of slug flow, this leads to the elimination of liquid slugs. Since the part of entrained droplets are deposited on the wall surface, the onset of entrainment leads to the formation of annular flow with liquid wetting the whole surface. However, due to the gravity effect it is expected that the liquid film thickness at the cavity floor is much larger than those at the side wall and ceiling. The criterion for the annular flow transition is discussed below in terms of the entrainment process.

\subsection{Corium Entrainment and Droplet Size}

The most likely flow regime in the cavity is the film flow. In this case the droplet entrainment becomes the most important mechanisms to disperse the molten corium mass. The onset of entrainment, entrainment rate and entrained droplet size are discussed below. The onset of entrainment criteria is given (Ishii and Grolmes [3.10]) by

$$
\frac{\mu_{f} v_{r}}{\sigma} \sqrt{\frac{\rho_{g}}{\rho_{f}}} \geq N_{\mu}^{0.8}
$$

where the viscosity number is defined as

$$
N_{\mu} \equiv \frac{\mu_{f}}{\left(\rho_{f} \sigma \sqrt{\sigma /(g \Delta \rho)}\right)^{1 / 2}}
$$


The entrainment rate from the film is given (Kataoka and Ishii, 1982) by

$$
\frac{\varepsilon D_{h}}{\mu_{f}}=6.6 \times 10^{-7}\left(\operatorname{Re}_{f} W e\right)^{0.925}\left[\frac{\mu_{g}}{\mu_{f}}\right]^{0.26}
$$

where

$$
\operatorname{Re}_{f}=\frac{\rho_{f} j_{f} D_{h}}{\mu_{f}}, W e=\frac{\rho_{g} j_{g}^{2} D_{h}}{\sigma}\left[\frac{\Delta \rho}{\rho_{g}}\right]^{1 / 3}
$$

Here $D_{h}$ is the hydraulic diameter of the cavity. The initial drop size is

$$
d=0.028 \frac{\sigma}{\rho_{g} v_{r}{ }^{2}} \operatorname{Re}_{f}^{-1 / 6} \operatorname{Re}_{g}^{2 / 3}\left[\frac{\rho_{g}}{\rho_{f}}\right)^{-1 / 3}\left[\frac{\mu_{g}}{\mu_{f}}\right)^{2 / 3}
$$

However subsequent disintegration may occur if

$$
W e_{d} \equiv \frac{\rho_{g}\left(v_{g}-v_{f d}\right) 2 d}{\sigma}>12
$$

It is noted that drop size can be as small as $W e_{d}=1.7-2.5$ if very high gas turbulence exists. Under the reactor cavity condition, the criterion of the Weber number at 12 is more likely than the later criterion. Furthermore, for the droplet to disintegrate beyond the initial entrainment drop size, a sufficient interaction time should exist between drops and the gas flow.

\subsection{Various Time Constant}

Several time constants are important to the analysis of the corium dispersion in the reactor cavity. These are listed below.

$$
\text { Corium Discharge Time } \quad \tau_{c d}=\frac{M_{c o r}}{\pi \rho_{f} D_{J}^{2} v_{f J} / 4}
$$


Primary System Blow Down Time $\tau_{p r}=\frac{V_{p r}}{0.6 \pi D_{J}^{2} v_{g t} / 4}$

Corium Film Transport Time $\tau_{f}=\frac{L_{c}}{v_{f}}$

Corium Entrainment Time $\tau_{e}=\frac{\delta_{f} \rho_{f}}{\varepsilon}$

The latter two time constants are particularly important in determining the dominant transport mode of the corium out of the reactor cavity.

\subsection{Discussion of Results}

The above scaling study is applied to the following typical reference conditions, see Table 1.

Cavity geometry :Zion

Reactor Vessel Break Size $\quad: 20 \mathrm{~cm}$ diameter

Molten Corium Mass $\quad: 134$ tones

Vessel Pressure $\quad: 7 \mathrm{MPa}(1000 \mathrm{psia})$

Cavity Pressure $\quad: 0.1 \mathrm{MPa}(15 \mathrm{psia})$

Relative to the above prototypic conditions, several models and simulation experiments are considered. At full scale and full pressure, a water-air system which simulates the molten corium-steam system is considered. For the $1 / 10$ linear scale-down model, the following cases are considered for sample calculations.

Corium-Steam (full pressure, $7 \mathrm{MPa}$ ) 
Water-Air (reduced pressure, $1.4 \mathrm{MPa}, 200 \mathrm{psia}$ )

Wood Metal-Air (reduced pressure, $1.4 \mathrm{MPa}, 200 \mathrm{psia}$ )

The break size for the liquid discharge is geometrically scaled, thus it is $2 \mathrm{~cm}$ diameter. However, in order to see the parametric effects of the gas flow as well as to compensate for the reduced pressure in the vessel, several enlarged flow area for the gas jet with the increment of twice, three times, five times and seven times are considered in the sample calculations. See Table 1.

\subsubsection{Prototypic Case}

When the reference conditions are applied to the phenomenological models used in the scaling study, the following results are obtained. The molten corium discharge at the velocity of $39 \mathrm{~m} / \mathrm{s}$. The disintegration length for the single and two-phase jets are $6 \mathrm{~m}$ and $1.6 \mathrm{~m}$, respectively. Thus the corium jet tends to disintegrate before reaching the floor of the cavity in the case of two-phase flow. The void fraction of 0.5 is used for this prediction. Since the jet velocity is high, the second mode of disintegration due to the relative motion is applicable. The resultant droplet mean diameter is $4.1 \mathrm{~mm}$ with the maximum size of $12.8 \mathrm{~mm}$. The ultimate spherical limit is $1.45 \mathrm{~mm}$.

The value of the impingement Weber number far exceeds the spreading limit of 80 . Thus both the coherent jet and droplets spread out upon impingement to the floor and form a corium liquid film rather than bouncing back and form a dispersed droplet flow. This indicates that most of the mass that is discharged as a jet and mostly disintegrated into droplets reforms a coherent liquid film upon impingement to the floor. Therefore, for the corium dispersion in the cavity, the liquid film entrainment becomes the most important mechanism. The duration of the entrainment depends on the liquid film residence time in the cavity. Hence the liquid film motion and transport out of the cavity is also important.

For estimating the film motion, the film thickness and velocity are essential. Several 
reference values for the film thickness are given below.

$\begin{array}{ll}\text { Initial Thickness } & \delta_{i}=5 \mathrm{~cm} \\ \text { Minimum Thickness } & \delta_{\min }=0.4 \mathrm{~cm} \\ \text { Maximum Thickness } & \delta_{\max }=41 \mathrm{~cm} \\ \text { Whole Wall Static Spreading } & \delta=9 \mathrm{~cm}\end{array}$

The initial film velocity is very high at $39 \mathrm{~m} / \mathrm{s}$. Furthermore, complicated three dimensional motion and mixing due to the geometry of the cavity is expected. Because of these, some of the liquid can climb up the side walls and may even flow over the ceiling of the cavity. In the subsequent analysis, a typical film thickness of $5 \mathrm{~cm}$ is assumed over the entire cavity wetted perimeter. This value is chosen in view of the initial thickness and the average between the minimum thickness and whole wall static spreading thickness. The corresponding average film velocity is $3.2 \mathrm{~m} / \mathrm{s}$ in the axial direction from the continuity relation. The actual flow should have a very complicated three dimensional pattern. If most of the liquid flows only over the cavity floor then the velocity is about 10 $\mathrm{m} / \mathrm{s}$. With the film velocity of $3.2 \mathrm{~m} / \mathrm{s}$, the film residence time is in the order of 6.5 seconds. The jet discharge time for 134 tons of the molten corium from the $20 \mathrm{~cm}$ break is about $12 \mathrm{sec}$.

When the liquid starts to flow as a film, three different regimes are possible as discussed previously. The stratified to slug flow transition criterion gives the required gas velocity of $300 \mathrm{~m} / \mathrm{s}$, which is about twice the expected gas velocity. However, the more important transition is that to the annular flow, which is determined by the entrainment process. As shown below, for the case of the sample calculation the onset of entrainment velocity is exceeded by the expected gas velocity. Hence these two transition criteria indicate that the most possible flow regime in the cavity is the annular flow with thicker film at the bottom of the cavity and thinner film at the sides and ceiling.

The entrainment of liquid from the film is governed by the relative velocity and film Reynolds number. The minimum relative velocity required for the onset of the 
entrainment is given by $v_{r}$ in Table 1 . The steam velocity in the cavity of $136 \mathrm{~m} / \mathrm{s}$ far exceeds this onset of entrainment velocity of $88 \mathrm{~m} / \mathrm{s}$ at the assumed cavity pressure of 0.1 MPa. Thus significant entrainment of the film into droplets is expected. The calculated entrainment rate is $3.07 \mathrm{~g} / \mathrm{cm}$. At this rate, the characteristic time constant is 14.7 seconds. This value should be compared with the film residence time of 6.5 seconds. The two characteristic time constants indicate that the film transport and entrainment mechanisms are in the same order of magnitude. A little less than one half of the molten corium is expected to be entrained by the streaming gas and the remaining mass discharged from the cavity to the lower compartment as a liquid film.

The mean droplet size from the entrainment is $6.6 \mathrm{~mm}$, which is rather large. The subsequent disintegration due to the relative motion between the droplets and gas flow may be possible. When the free stream gas velocity and Weber number of 12 are used, the droplet stability criterion gives a diameter of about $1.1 \mathrm{~mm}$. The very high entrainment rate shown above will certainly slow down the gas flow, specially in the boundary layer region, since the entrainment process and subsequent acceleration of droplets require considerable momentum transfer from the gas to liquid. When the one half of the free stream velocity is used as a mean gas velocity in the droplet boundary layer, the criterion gives the droplet the size of $0.44 \mathrm{~mm}$. Thus it is expected that the size of droplets is in the range of 0.44 to $6.6 \mathrm{~mm}$.

The significant effects of the cavity pressure on the gas velocity and the entrainment process should be noted. For example, if the cavity pressure is $0.3 \mathrm{MPa}$ or three times the pressure in the sample calculation, the entrainment rate is reduced by a factor of four. The corresponding characteristic time for entrainment is 58 seconds, which is much larger than the film residence time of 6.5 seconds. In that case the corium dispersion is considerably reduced.

The break size has also very strong effects on the corium dispersion. The sample calculations are carried out by assuming the diameter of the break to be $20 \mathrm{~cm}$. The 
increase in the break size shortens both the corium and gas discharge time. However, the most important effect is on the cavity gas velocity. For example, a twice larger diameter for the break leads to four times larger gas velocity and nearly four times larger entrainment rate. In that case, the entrainment becomes the dominant corium transport process.

\subsubsection{Scaled Experiments}

It should be also emphasized that the above results are obtained from the existing phenomenological models based on experimental data far from the prototypic DCH conditions. Most of the data base are obtained in standard air-water systems with a relatively small hydraulic diameter of 1 to $2 \mathrm{~cm}$. Only the onset of entrainment criterion has a relatively larger data base with $D_{h}$ ranging from 1 to $15 \mathrm{~cm}$. Hence there is a great uncertainty in predicting the corium dispersion in the DCH problem. Two main reasons for this deficiency are:

(1) Mechanism of corium dispersion are not well understood.

(2) Large uncertainty in the scale-up capability of the available droplet entrainment correlations.

In view of these, well scaled and focused separate effect experiments on the corium dispersion phenomena may be required. These separate effect experiments should be focused on understanding of the mechanisms of the liquid dispersion and establishing data base which can be used to develop phenomenological models applicable to prototypic conditions. For this purpose several scaled down experiments and simulation experiments are evaluated as a demonstration of the bottom-up scaling method. The results are summarized and compared to the hypothetical prototypic conditions in Table 1.

In the sample calculations, three different cases are considered. The most important phenomena of liquid entrainment and droplet size are discussed below.

i) Corium-Steam (1/10 scale, full 7MPa pressure) 
From Eqs.(4.40) and (4.44)

$$
\begin{aligned}
& {\left[\mathrm{N}_{\mathrm{O}}\right]_{\mathrm{R}}^{\mathrm{ex}}=\left[\frac{\mathrm{w}}{\mathrm{L}_{\mathrm{ex}}}\right]_{\mathrm{R}}=1 ;\left(\mathrm{L}_{\mathrm{ex}}\right)_{\mathrm{R}}=0.1,} \\
& {\left[\mathrm{~N}_{\mathrm{O}}\right]_{\mathrm{R}}^{\mathrm{dw}}=\left[\frac{\mathrm{w}}{\mathrm{L}_{\mathrm{dw}}}\right]_{\mathrm{R}}=1 ;\left(\mathrm{L}_{\mathrm{dw}}\right)_{\mathrm{R}}=0.1 .}
\end{aligned}
$$

The remaining scaling parameters, $\left(\mathrm{N}_{\mathrm{d}}\right)_{\mathrm{R}}^{\mathrm{x}},\left(\mathrm{N}_{\min }\right)_{\mathrm{R}}^{\mathrm{g}}$, and $\left(\mathrm{N}_{\mathrm{dm}}\right)_{\mathrm{k}}^{\mathrm{kx}}$ are automatically satisfied:

$$
\left(N_{d}\right)_{R}^{e x}=\left(N_{\min }\right)_{R}^{e x}=\left(N_{d m}\right)_{R}^{e x}=1 .
$$

While all the geometrical scaling parameters have the same scaling ratio, 0.1 , all the scaling ratios related to the corium thickness have the same but relatively high scaling ratio, 0.54 , resulting from the scaling ratio of the minimum thickness. This relatively high scaling ratio of the corium thickness causes difficulties in thermal scaling because more cooling in the model is needed than that in the prototype due to relatively high thermal capacity and latent heat in the model. For thermal scaling

$$
\begin{aligned}
& {\left[\mathrm{N}_{\text {sup }}\right]_{R}=\left[\frac{\Delta \mathrm{T}_{\text {sup }}}{\Delta \mathrm{T}_{\mathrm{w}}}\right]_{\mathrm{R}}=1 ;\left(\Delta \mathrm{T}_{\text {sup }}\right]_{\mathrm{m}}=65.7 \mathrm{~K},} \\
& {\left[\mathrm{~N}_{\mathrm{hc}}\left(1+\mathrm{N}_{\mathrm{cw}}\right)\right]_{\mathrm{R}}=\left[\frac{\left(\mathrm{h}_{\mathrm{c}}+\mathrm{h}_{\mathrm{w}}\right) \tau_{\mathrm{d}}}{\left(\rho \mathrm{c}_{\mathrm{p}} \mathrm{h}_{\mathrm{r}}\right.}\right]_{\mathrm{R}}=1 ;\left(\mathrm{h}_{\mathrm{c}}+\mathrm{h}_{\mathrm{w}}\right)_{\mathrm{R}}=1.53,} \\
& {\left[\frac{\left(1+\mathrm{N}_{\mathrm{cc}}\right)}{\left(1+\mathrm{N}_{\mathrm{cw}}\right)}\right]=\left[\frac{\mathrm{h}_{\mathrm{w}}+\mathrm{h}_{\mathrm{c}} \frac{\Delta \mathrm{T}_{\mathrm{c}}}{\Delta \mathrm{T}_{\mathrm{w}}}}{\mathrm{h}_{\mathrm{c}}+\mathrm{h}_{\mathrm{w}}}\right]_{\mathrm{R}}=1 ;\left(\mathrm{h}_{\mathrm{w}}+\mathrm{h}_{\mathrm{c}} \frac{\Delta \mathrm{T}_{\mathrm{c}}}{\Delta \mathrm{T}_{\mathrm{w}}}\right]_{\mathrm{R}}=1.53,} \\
& \left(\mathrm{~N}_{\mathrm{sol}}\right)_{\mathrm{R}}=\left[\frac{\mathrm{h}_{\mathrm{fc}} \rho \mathrm{h}_{\mathrm{r}}}{\left(\mathrm{h}_{\mathrm{w}} \Delta \mathrm{T}_{\mathrm{w}}+\mathrm{h}_{\mathrm{c}} \Delta \mathrm{T}_{\mathrm{c}}\right) \tau_{\mathrm{p}}}\right]_{\mathrm{R}}=1 ; \frac{\left(\mathrm{h}_{\mathrm{c}} \Delta \mathrm{T}_{\mathrm{c}}\right)_{\mathrm{m}}}{\left(\mathrm{h}_{\mathrm{w}} \Delta \mathrm{T}_{\mathrm{w}}\right)_{\mathrm{p}}}=6.17 .
\end{aligned}
$$

It is impossible to satisfy the above three cooling requirements simultaneously. As the time constant related to interactions before solidification starts is much shorter than that related to interactions after solidification, it is better to distort the scaling ratios related to thermal convection. 
The scaling ratio of the transition criterion of spreading is automatically satisfied:

$$
\left(N_{i}^{m}\right)_{R}=1 \text {. }
$$

From the transition criterion of water cooling and radiation cooling only,

$$
\left(N_{w d}\right)_{R}=\left[\frac{h_{w d}}{h_{r}}\right]_{R}=1 ;\left(h_{w d}\right)_{R}=0.54 .
$$

The sputtering scaling ratio is very low because of the low solidification temperature of lead:

$$
\left(\mathrm{N}_{\mathrm{sp}}\right)_{\mathrm{R}}=0.11 \text {. }
$$

However, the important thing is whether quenching can take place during the solidification process. By rough estimation, before the top crust thickness reaches $40 \mathrm{~cm}$, quenching will not occur in the model. Table 6 shows the final output of the model. It is noted that the considerable amount of lead and enormous concrete cooling are needed in the model.

References

4.1 G. A. Greene, K. R. Perkins, and S. A. Hodge, "MARK-1 Containment Drywell : Impact of Core / Concrete Interaction on Containment Integrity and Failure of the Drywell Linear," Proc. Int. Symp. Source Term Evaluation for Accident Conditions, Columbus, Ohio, Oct. 28 - Nov. 1, IAEA-SM-281/36, International Atomic Energy Agency, 1986.

4.2 G. A. Greene, C. Finfrock, J. Klages, C. E. Schwarz, and S. B. Burson, "Experimental Studies on Melt Spreading, Bubbling Heat Transfer, and Coolant Layer Boiling," Proc. Sixteenth Water Reactor Safety Information Meeting, Gaitherburg, Maryland, Oct. 24 - 27, 5, pp. 341 - 358, NUREG/CP - 0097, U.S. Nuclear Regulatory Commission, 1988. 
4.3 R. E. Henry, R. J. Hammersley, B. Malinovic, R. Sehgal, and E. L. Fuller, "Experiments Relating to Drywell Shell-Core Debris Interactions," ibid, 5, pp. 317 - 340, 1988.

4.4 T. S. Kress and J. C. Cleveland, "Analysis of the Thermal Response of a BWR MARK-1 Containment Shell to Direct Contact by Molten Core Materials," ibid, 5, pp. 429 - 451, 1988.

4.5 J. J. Sienicki, M. T. Farmer, and B. W. Spencer, " Spreading of Molten Corium in MK I Geometry Following Vessel Meltthrough," Fourth Proc. of Nuclear Thermal Hydraulics, ANS Winter Meeting, Oct. 30 - Nov. 4, Washington, D.C., pp. 128 $138,1988$.

4.6 M. S. Kazimi, "On the Linear Failure Potential in MARK-1 Boiling Water Reactors," Nucl. Sci. \& Eng., 103, 59 - 69, 1989.

4.7 P. J. Moody, R. Muralidharam, and S. S Dua, "MARK-1 Drywell Shell Temperature Response of the MARK-1 Drywell Shell," Proc. Sixteenth Water Reactor Safety Information Meeting, Gaithersburg, Maryland, Oct. 24 - 27, NUREG/CP-(0097, U.S. Nuclear Regulatory Commission 5, 525-550,1988.

4.8 J. A. Boure, "A Method to Develop Similarity Laws for Two Phase Flow," ASME paper No. 70-HT-25, 1970.

4.9 R. W. Lockhart and R. C. Martinelli, "Proposed Correlation of Data for Isothermal Two-Phase, Two-Component Flow in Pipes," Chem. Eng. Progress, 45, 1949.

4.10 S. Y. Ahmad, "Fluid to Fluid Modeling of Critical Heat Flux : A Compensated Distortion Model," Int. J. Heat Mass Transfer,16, 1973.

4.11 B. Spindler, "Rational Simplification of the Equations Governing the Liquid Film Flow over a Plane with Heat Flux at the Wall and Interfacial Phase Change," in Scaling in Two-Phase Flows, Presented at the Winter Annual Meeting of ASME, Chicago, 1980.

4.12 M. Ishii and N. Zuber, "Thermally Induced Flow Instabilities in Two-Phase Mixtures," Proc. 4th Int. Heat Transfer Conf., Paris, Paper B.5, 11, 1970. 
4.13 M. Ishii and I. Kataoka, "Scaling Laws for Thermal-Hydraulic System under Single Phase and Two-Phase Natural Circulation," Nucl. Eng. and Des., 81, 1984.

4.14 G. A. Greene, C. Finfrock, and S. B. Burson, "Phenomenological Studies on Molten Core-Concrete Interactions," Nucl. Eng. Design, 108, 167-177, 1988.

4.15 R. Manning, "On the Flow of Water in Open Channels and Pipes," Trans. Inst. Civ. EngrsR Ireland, 20, :161, 1891.

4.16 P.J. Berenson, "Film Boiling Heat Transfer from a Horizontal Surface," Trans. ASME, Ser. C. 83, 351 - 358, 1961.

4.17 M.L. Corradini, "A Transient Model for the Ablation and Decomposition of Concrete," Nucl. Tech., 62, 263 - 273, 1983. 
Table 2 Identification of System

\begin{tabular}{|c|c|c|c|c|}
\hline Subsystem & Component & \multicolumn{2}{|l|}{ Geometry } & Muterials \\
\hline \multirow{4}{*}{$\begin{array}{c}\text { vessel } \\
\text { subsystem }\end{array}$} & \multirow{2}{*}{ reactor vessel } & location of breach & & \\
\hline & & height from floor & $\mathrm{H}_{\mathrm{rv}}$ & \\
\hline & \multirow{2}{*}{$\begin{array}{l}\text { below-vessel } \\
\text { structure }\end{array}$} & $\begin{array}{l}\text { distributed area } \\
\text { of corium }\end{array}$ & $A_{d}$ & \multirow{2}{*}{$\begin{array}{l}\text { below-vessel } \\
\text { materials }\end{array}$} \\
\hline & & height from floor & $\mathrm{H}_{b v}$ & \\
\hline \multirow{7}{*}{$\begin{array}{c}\text { floor } \\
\text { subsystem }\end{array}$} & \multirow{2}{*}{ sump } & cross-sectional area & $\mathrm{A}_{\mathrm{su}}$ & \multirow{7}{*}{$\begin{array}{l}\text { floor } \\
\text { concrete } \\
\text { materials }\end{array}$} \\
\hline & & height & $\mathrm{H}_{\mathrm{su}}$ & \\
\hline & \multirow{2}{*}{ inpedestal floor } & area & $A_{\text {in }}$ & \\
\hline & & outer radius & $R_{\text {in }}$ & \\
\hline & \multirow{2}{*}{ doorwily } & width & $w_{d w}$ & \\
\hline & & length & $L_{(N)}$ & \\
\hline & expedestal floor & ouler madius & $R_{c x}$ & \\
\hline \multirow{4}{*}{$\begin{array}{c}\text { shell } \\
\text { subsystem }\end{array}$} & \multirow{2}{*}{ shell } & thickness & $\sin$ & \multirow{2}{*}{$\begin{array}{l}\text { shell } \\
\text { materials }\end{array}$} \\
\hline & & angle & $\theta_{\mathrm{sh}}$ & \\
\hline & outer-shell air layer & thickness & $t_{\text {air }}$ & \\
\hline & $\begin{array}{c}\text { ouler-shell } \\
\text { concrete structure }\end{array}$ & lhickness & $t_{\operatorname{cosc}}$ & $\begin{array}{c}\text { outer-shell } \\
\text { concrete materials }\end{array}$ \\
\hline
\end{tabular}


Table 3 Initial and Boundary Conditions and Interfacial Conditions between Subsystems

\begin{tabular}{|c|c|c|c|}
\hline Subsystem & \multicolumn{2}{|c|}{ Initial and boundary conditions } & Interfacial conditions \\
\hline \multirow{3}{*}{$\begin{array}{c}\text { vessel } \\
\text { subsystem }\end{array}$} & pouring-out rate & $\mathrm{Q}_{\mathrm{co}}$ & \multirow{3}{*}{$\mathrm{Q}_{\mathrm{CO}}, \mathrm{T}_{\mathrm{co}}, \mathrm{X}_{\mathrm{cos}}$} \\
\hline & corium temperature & $\mathrm{T}_{\omega}$ & \\
\hline & corium composition & $\mathrm{X}_{\mathrm{co}}$ & \\
\hline \multirow{7}{*}{$\begin{array}{c}\text { floor } \\
\text { subsystem }\end{array}$} & containment pressure & $\mathrm{P}_{\mathrm{Cl}}$ & \multirow{7}{*}{$\begin{array}{l}\text { corium thickness }\left(t_{c o}\right) \\
\text { water thickness }\left(t_{w}\right) \\
\text { heat flux from corium } \\
\text { to shell }\left(q_{c o-* h}^{\prime \prime}\right)\end{array}$} \\
\hline & water content & $\mathrm{M}_{\mathrm{w}}$ & \\
\hline & water temperature & $\mathrm{T}_{w}$ & \\
\hline & \multirow{4}{*}{ component temperature } & $\mathrm{T}_{\mathrm{su}}$ & \\
\hline & & $T_{\text {in }}$ & \\
\hline & & $T_{\text {dw }}$ & \\
\hline & & $\mathrm{T}_{\mathrm{ex}}$ & \\
\hline \multirow{3}{*}{$\begin{array}{c}\text { shell } \\
\text { subsystem }\end{array}$} & \multirow{3}{*}{ component temperature } & $T_{s h}$ & \multirow{3}{*}{$\begin{array}{l}\text { shell temperature }\left(T_{s h}\right) \\
\text { shell stress }\left(\sigma_{s h}\right)\end{array}$} \\
\hline & & $T_{i u r}$ & \\
\hline & & $\mathrm{T}_{\mathrm{osc}}$ & \\
\hline
\end{tabular}


Table 4 Potentially Important Mechanisms and Rank

\begin{tabular}{|c|c|c|c|c|}
\hline $\begin{array}{l}\text { Interacting } \\
\text { Materials }\end{array}$ & $\begin{array}{l}\text { Sub- } \\
\text { Systems }\end{array}$ & \multicolumn{2}{|l|}{ Phenomena } & Rank \\
\hline Water & $\mathrm{S}, \mathrm{I}, \mathrm{D}, \mathrm{E}$ & (1) boiling & $\mathrm{T}$ & 2 \\
\hline \multirow{3}{*}{ Water-Corium } & \multirow{5}{*}{$S, I, D, E$} & (2) entrainment & $\mathrm{H}$ & 2 \\
\hline & & (3) film boiling & $\mathrm{T}$ & 1 \\
\hline & & (4) bubbling & $\mathrm{H}$ & 2 \\
\hline \multirow[t]{2}{*}{ Interface } & & (5) quenching & $\mathrm{T}$ & 1 \\
\hline & & (6) radiation & $\mathrm{T}$ & 1 \\
\hline \multirow{10}{*}{ Corium } & $S$ & (7) filling & $\mathrm{H}$ & 1 \\
\hline & $I$ & (8) spreading & $\mathrm{H}$ & 1 \\
\hline & $E$ & (9) spreading & $\mathrm{H}$ & 1 \\
\hline & $E$ & (10) spreading & $\mathrm{H}$ & 1 \\
\hline & \multirow[t]{6}{*}{$\mathrm{S}, \mathrm{I}, \mathrm{D}, \mathrm{E}$} & $\begin{array}{l}\text { (11) crust formation \& } \\
\text { stability }\end{array}$ & $\mathrm{T}, \mathrm{H}$ & 1 \\
\hline & & (12) bubbling & $\mathrm{H}$ & 2 \\
\hline & & (13) chemical reaction & $\mathrm{C}, \mathrm{T}$ & 2 \\
\hline & & (14) decay heat & $T$ & 2 \\
\hline & & (15) conduction & $\mathrm{T}$ & 3 \\
\hline & & (16) convection & $\mathrm{T}, \mathrm{H}$ & 2 \\
\hline \multirow{2}{*}{$\begin{array}{l}\text { Corium-Concrete } \\
\text { Interface }\end{array}$} & \multirow[t]{2}{*}{$\mathrm{S}, \mathrm{I}, \mathrm{D}, \mathrm{E}$} & (17) film heat transfer & $\mathrm{T}$ & 1 \\
\hline & & (18) radiation & $\mathrm{T}$ & 3 \\
\hline \multirow{3}{*}{ Concrete } & \multirow{3}{*}{$\mathrm{S}, \mathrm{I}, \mathrm{D}, \mathrm{E}$} & (19) ablation & $\mathrm{C}, \mathrm{T}$ & 1 \\
\hline & & (20) conduction & $\mathrm{T}$ & 2 \\
\hline & & (21) melting & $\mathrm{T}$ & 3 \\
\hline \multirow[t]{2}{*}{ Shell } & \multirow[t]{2}{*}{$E$} & (22) conduction & $\mathrm{T}$ & 1 \\
\hline & & (23) melting & $\mathrm{T}$ & 3 \\
\hline \multirow{3}{*}{$\begin{array}{l}\text { Shell-Corium } \\
\text { Interface }\end{array}$} & \multirow{3}{*}{$\mathrm{E}$} & (24) solidification & $\mathrm{T}$ & 1 \\
\hline & & (25) convection & $\mathrm{T}, \mathrm{H}$ & 1 \\
\hline & & (26) conduction & $\mathrm{T}$ & 2 \\
\hline \multirow{3}{*}{$\begin{array}{c}\text { Shell-Air-Concrete } \\
\text { Interface }\end{array}$} & \multirow{3}{*}{$\mathrm{E}$} & (27) radiation & $\mathrm{T}$ & 1 \\
\hline & & (28) air convection & $\mathrm{T}, \mathrm{H}$ & 2 \\
\hline & & $\begin{array}{l}\text { (29) concrete } \\
\text { conduction }\end{array}$ & $\mathrm{T}$ & 3 \\
\hline
\end{tabular}

S : Sump, I : Inpedestal floor

D : Doorway, E: Expedestal floor

$\mathrm{T}$ : Thermal-dominant phenomena

$\mathrm{H}$ : Hydraulic-dominant phenomena

$\mathrm{C}$ : Chemical-dominant phenomena 
Boundary parameters:

$$
\begin{aligned}
\tau_{p} & =40 \min \quad Q_{p}=8.33 \times 10^{-3} \mathrm{~m}^{3} / \mathrm{s} \quad \dot{\mathrm{m}}=75 \mathrm{Kg} / \mathrm{s} \quad M / \rho=20 \mathrm{~m}^{3} \\
M & =1.8 \times 10^{5} \mathrm{Kg}
\end{aligned}
$$

Geometrical parameters:

$\mathrm{R}_{\mathrm{su}}=2 \mathrm{~m} \quad \mathrm{R}_{\mathrm{in}}=4 \mathrm{~m} \quad \mathrm{~L}_{\mathrm{dw}}=0.91 \mathrm{~m} \quad \mathrm{w}=1.03 \mathrm{~m} \quad \mathrm{~L}_{\mathrm{ex}}=2.09 \mathrm{~m}$

$H_{\mathrm{su}}=43 \mathrm{~cm} \quad \mathrm{~V}_{\mathrm{su}}=5.8 \mathrm{~m}^{3}$

Corium parameters:

$$
\begin{aligned}
& \mathrm{k}=30 \mathrm{~W} / \mathrm{mK} \quad \rho=9000 \mathrm{Kg} / \mathrm{m}^{3} \quad \mathrm{C}_{\mathrm{p}}=480 \mathrm{~J} / \mathrm{Kg} \mathrm{K} \quad \mathrm{h}_{\mathrm{fg}}=2.5 \times 10^{5} \mathrm{~J} / \mathrm{Kg} \\
& \mathrm{T}_{\mathrm{s}}=2100 \mathrm{~K} \quad \mathrm{~T}_{\text {sup }}=500 \mathrm{~K} \quad \sigma=1.48 \mathrm{Kg} / \mathrm{s}^{2} \\
& \mathrm{q}^{-}=4 \mathrm{Mw} / \mathrm{m}^{3} \text { before initial generation of bottom crust } \\
& \mathrm{q}^{-}=1 \mathrm{Mw} / \mathrm{m}^{3} \text { after initial generation of bottom crust }
\end{aligned}
$$

Concrete cooling reference parameters:

$\mathrm{T}_{\mathrm{a}}=1670 \mathrm{~K}$

$h_{c}=1940 \mathrm{~W} / \mathrm{m}^{2} \mathrm{~K}$ before initial generation of bottom crust

$h_{c}=1077 \mathrm{~W} / \mathrm{m}^{2} \mathrm{~K}$ after initial generation of bottom crust

Water cooling reference parameters:

$\mathrm{T}_{\mathrm{w}}=373 \mathrm{~K}, \quad \mathrm{~h}_{\mathrm{wd}}=30 \mathrm{~cm}$

$\mathrm{hw}=777.1 \mathrm{~W} / \mathrm{m}^{2} \mathrm{~K}$ before initial generation of bottom crust

$h w=574.5 \mathrm{~W} / \mathrm{m}^{2} \mathrm{~K}$ after initial generation of bottom crust

Table 6 Output of the Model

Geometry:

$$
\mathrm{R}_{\text {sup }}=20 \mathrm{~cm}, \quad \mathrm{R}_{\mathrm{im}}=40 \mathrm{~cm}, \quad \mathrm{w}=10.3 \mathrm{~cm}, \quad \mathrm{~L}_{\mathrm{ux}}=20 \mathrm{~cm}, \quad \mathrm{H}_{\text {sup }}=25 \mathrm{~cm}
$$

Boundary conditions:

$$
M=11.35 \mathrm{Kg}, \quad \tau_{\mathrm{p}}=5.4 \mathrm{~min}, \quad Q_{\mathrm{p}}=3.33 \times 10^{4} \mathrm{~m}^{3} / \mathrm{s}, \quad \dot{m}_{\mathrm{p}}=3.5 \mathrm{Kg} / \mathrm{s}
$$

Initial superheat : $65.7 \mathrm{~K}$

Water depth : $16.2 \mathrm{~cm}$

Thermal boundary condition $: q_{c}^{\circ}=10^{6} \mathrm{w} / \mathrm{m}^{2}$ 


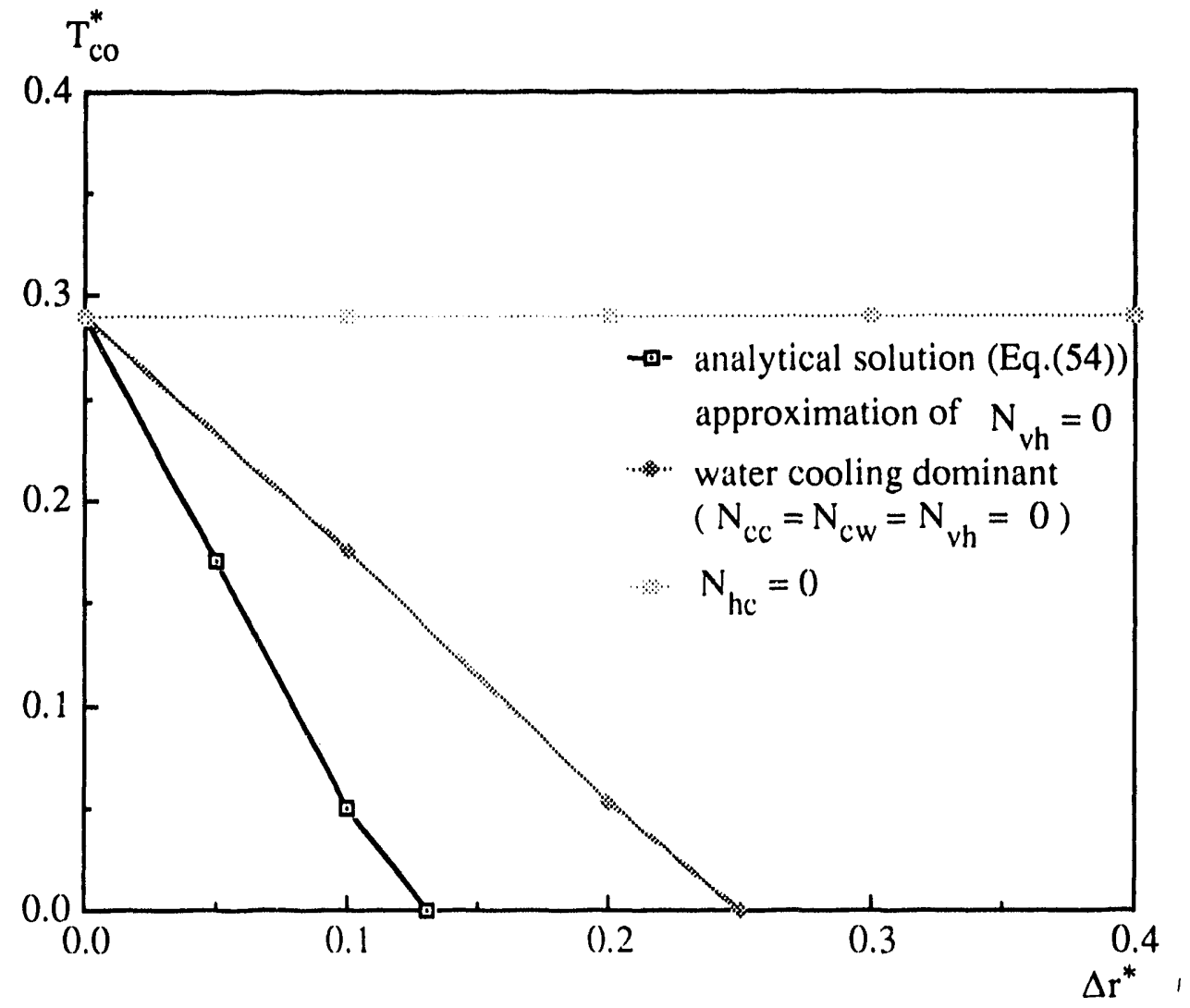

Fig. 1 Variations of corium temperature 


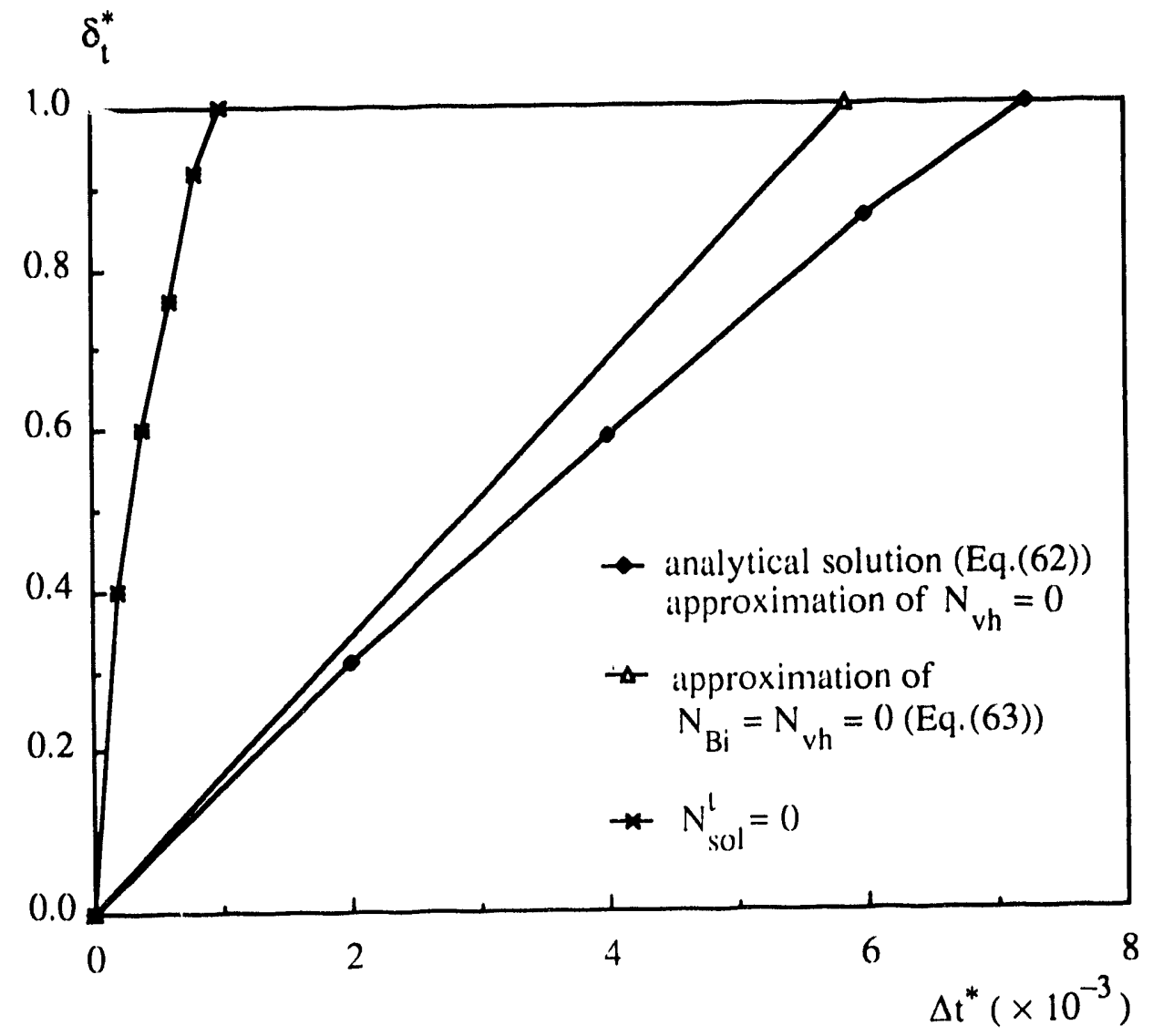

Fig. 2 Variations of top corium thickness 


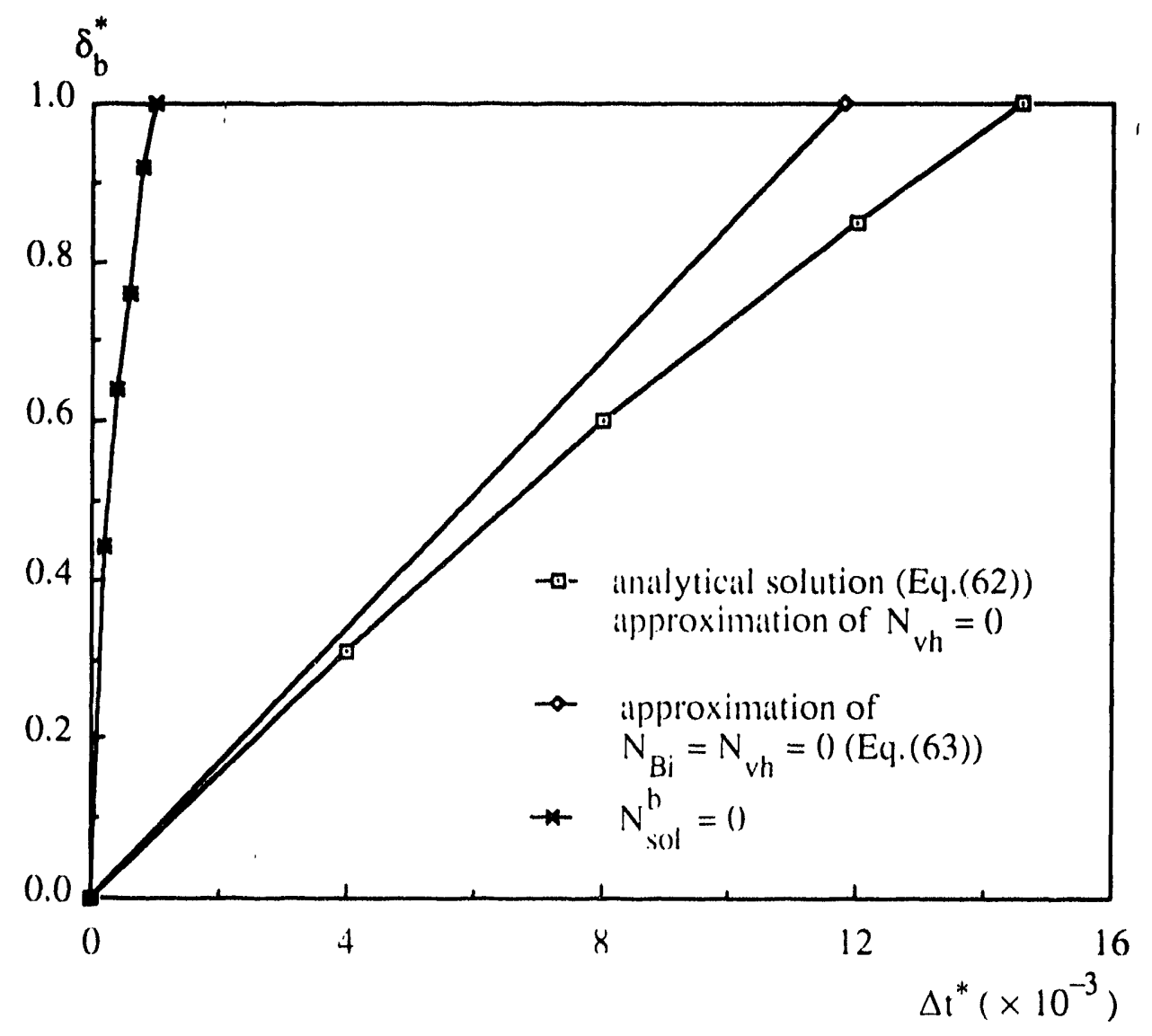

Fig.3 Variations of bottom corium thickness 


\section{SCALING STUDY OF INCORE BOIL-OFF AND HEATING PROCESS}

\subsection{Introduction}

After the TMI-2 accident, it has been realized to be essential to understand and predict phenomena governing core damage progression and termination for the proper assessment and mitigation of accidents in nuclear power plants. Several analytical efforts have been directed towards the development of models representing the phenomena involving in the accidents for the prediction of core damage progression; MARCH [5.1], SCDAP [5.2], MIMAS [5.3], and APRIL [5.4].

Since the modeling of core damage progression requires a knowledge of many complex and interrelated physical and chemical processes, these codes have been built up on the basis of a lot of assumptions for the simplification of the complex processes. In order to create a level of confidence in the codes, they should be verified through data generated from the experimental facilities which well represent the behavior of the accident responses of the nuclear power plants. In view of the difficulties coming from building up the full-scaled facility, the scaled models of prototype systems are needed, which require scaling criteria.

In order to generate the scaling criteria in two-phase flow, several studies have been performed on the base of dimensional analysis [5.5-7], differential equations [5.8], and the analytical method $[5.9,10]$.

Dimensional analysis, which generates the large number of parameters, can give misleading results if important parameters are dropped in the course of the reduction of parameters. Therefore, its application should be limited to a well-known process for easy reduction of parameters.

In order to overcome the difficulties of dimensional analysis and to ensure the neglecting of no significant variables, the method of differential equations has been studied. The information obtained by this method totally depends on the completeness of 
the differential equations. If there should be any variables neglected in the differential equations but very influential to the process, dimensional analysis can supplement the information from the differential equations. As the boundary and initial conditions should be applied to the differential equations for the closure form of solutions, the complete scaling criteria from the differential equations can be obtained considering the boundary and initial conditions. The wall-to-fluid and fluid-to-fluid boundary conditions are implemented through use of constitutive relationships in a local sense. The method of differential equations is based on a local-oriented concept in the analogous way to the local stability analysis in numerics performed through the use of the difference equations only.

In order to complete the scaling criteria, we need to propagate the information of the boundary and initial conditions through time and space domains by integrating the differential equations over their domains. As a result, the integral response functions or analytical solutions can be obtained. They keep all the parameters which are contained in the differential equations used for their analytic integration. The advantages of the integral scaling method are its production of the integral scaling criteria by implementing the boundary and initial conditions, and its facilitation to identify the level of importance of each scaling criterion. The identification of the level of importance of each scaling criterion is very important hecause it is usually impossible to design the model which satisfies all the scaling criteria and, as a result, necessary to determine which parameters should be kept or distorted. Since a certain level of confidence in the integral response scaling method is essential, the method needs to be tested against experimental data or mechanistic numerical codes.

Here, a stepwise integral scaling method described in Chapter II is applied to the boil-off and heating process in the core under accident conditions.

\subsection{Core Uncovery Process}

The core uncovery process will continue until the turnaround of the core level occurs through the operation of safety injection system. In this process it is very 
important to predict correctly the core uncovery level called the mixture level or the froth level, which is defined as the boundary between the region of continuous gas phase and of continuous liquid phase, because it controls the dryout limits in the low bundle power. In the low bundle power the dryout positions of the rods are almost the same because the mixture level is flattened by the gravitational force [5.14]. In the high bundle power the clear mixture level can not be observed because of the vertical scatter of the dryout points which is considered to be due to the break of the thin water film on the heater rods under the annular flow pattern. Since most of accident conditions occurred in nuclear power plants fall into the category of the low bundle power according to the annular transition map in Ref. [5.14], the somewhat clear mixture level is expected.

The assumptions involved in the model for predicting the mixture level in the core are as follows:

1. quasi-steady state,

2. negligible contribution of liquid droplets to the mixture level,

3. slow variations of system pressure, decay heat, and inlet velocity and enthalpy with time,

4. constant drift-flux parameters, $C_{o}$ and $u_{g j}$, for given pressure,

5. negligible contribution of subcooled nucleate boiling to the mixture level.

The differential equations governing the process are as follows:

$$
\begin{aligned}
& \text { Vapor mass : } \frac{\partial \mathrm{j}_{\mathrm{g}}}{\partial \mathrm{z}}=\frac{\Gamma}{\rho_{\mathrm{g}}}, \\
& \text { Liquid mass : } \frac{\partial \mathrm{j}_{\mathrm{f}}}{\partial \mathrm{z}}=-\frac{\Gamma}{\rho_{\mathrm{f}}}, \\
& \text { Mixture mass : } \frac{\partial \mathrm{j}}{\partial \mathrm{z}}=\frac{\rho_{\mathrm{fg}}}{\rho_{\mathrm{f}} \rho_{\mathrm{g}}} \Gamma,
\end{aligned}
$$

Energy in the subcooled region : $w \frac{\partial h}{\partial z}=\bar{q}^{\prime}$, 
where $\overline{\mathrm{q}}^{\prime}$ : radial-averaged linear heat generation rate.

Integrating Eq. (5.4) over the subcooled region from the bottom of the fuel to the subcooled length, $z_{\mathbf{b}}$, yields

$$
\mathrm{z}_{\mathrm{s}}=\frac{A_{f} \rho_{\mathrm{f}} \mathrm{u}_{\mathrm{o}} \Delta \mathrm{h}_{\mathrm{sub}}}{\overline{\mathrm{q}}^{\prime}},
$$

$$
-
$$

where $\overline{\mathrm{q}}^{\prime}$ : radial- and axial-averaged linear heat generation rate over the subcooled region of the core,

$\Delta \mathrm{h}_{\text {sub }}$ : amount of subcooled enthalpy of the inlet flow.

The local void fraction is provided using the definition of the drift velocity as follows :

$$
\alpha=\frac{j_{g}}{C_{0} j+u_{g j}}
$$

Integrating Eqs. (5.1) and (5.2) over the region from $z_{\mathrm{g}}$ to $z$ produces the following local superficial velocities :

$$
\begin{aligned}
& j_{g}=\frac{\bar{\Gamma}}{\rho_{g}}\left(z-z_{s}\right), \\
& j=j_{0}+\frac{\rho_{f B}}{\rho_{f} \rho_{g}} \bar{\Gamma}\left(z-z_{g}\right),
\end{aligned}
$$

where $\bar{\Gamma}$ : radial- and axial averaged volumetric vapor generation rate over the region from $z_{s}$ to $z$.

By inserting Eqs. (5.7) and (5.8) into Eq. (5.6), the following relationship for void fraction is obtained :

$$
\alpha=\frac{b z+d}{a z+c},
$$

where

$$
\begin{gathered}
\mathrm{a}=\mathrm{C}_{\mathrm{o}} \frac{\rho_{\mathrm{fg}}}{\rho_{\mathrm{g}} \rho_{\mathrm{g}}} \overline{\bar{\Gamma}}, \\
\mathrm{b}=\frac{\bar{\Gamma}}{\rho_{\mathrm{g}}},
\end{gathered}
$$




$$
\begin{gathered}
c=C_{0} j_{0}+u_{g j}-C_{0} \frac{\rho_{f g}}{\rho_{f} \rho_{g}} \overline{\bar{\Gamma}} z_{g}, \\
d=-\frac{\bar{\Gamma}}{\rho_{g}} z_{g} .
\end{gathered}
$$

The integration of Eq. (5.2) over the region from $z_{\mathrm{g}}$ to $\mathrm{z}_{\mathrm{q}}$ generates

$$
\mathrm{j}_{\mathrm{fq}}=\mathrm{j}_{\mathrm{o}}-\frac{\overline{\bar{\Gamma}}}{\rho_{\mathrm{f}}}\left(\mathrm{z}_{\mathrm{q}}-\mathrm{z}_{\mathrm{s}}\right) \text {. }
$$

The following equation can be obtained by the application of the Leibnitz rule to the rate of change of the liquid material just below the mixture level :

$$
\frac{d}{d t} \int_{V_{m}} \rho_{f} d V=\int_{V_{m}} \frac{\partial \rho_{f}}{\partial t} d V+\int_{A} \rho_{f} \vec{u}_{f} \cdot \vec{n} d A+\int_{\Lambda} \rho_{f} \frac{d z_{q}}{d t} d \Lambda .
$$

As the volume of the liquid material, $V_{m}$, becomes infinitesimally small, the following simple relationship is obtained :

$$
\int_{\Lambda} \rho_{f}\left(u_{f}-\frac{d z_{q}}{d t}\right) d \Lambda=0
$$

In order to satisfy the relationship of Eq. (5.12) over the region of continuous liquid phase, the liquid velocity at the interface, $z_{q}$, should be equal to the rate of change of the mixture level, $\frac{\mathrm{dz}}{\mathrm{dt}}$.

$$
u_{f q}=\frac{d z_{q}}{d t} \text {. }
$$

Intuitionally, Eq. (5.13) can be obtained considering that the liquid in the mixture is a continuous phase of which the upper surface represents the mixture level. Now Eq. (5.10) becomes

$$
\alpha_{f q} \frac{d z_{q}}{d t}=e\left(f-z_{q}\right),
$$

where

$$
\mathrm{e}=\frac{\overline{\bar{\Gamma}}}{\rho_{\mathrm{f}}},
$$




$$
f=z_{a}+j_{0} \frac{p_{f}}{\bar{\Gamma}} .
$$

By inserting Eq. (5.9) into Eq. (5.14) and integrating the resulting over the time interval from $t_{0}$ to $t$, the following mixture level, $z_{q}$, can be obtained:

$$
z_{q}=\left(f+\frac{c}{a} X\right) /(1-X)
$$

where

$$
\begin{aligned}
& X=\frac{z_{q_{0}}-f}{z_{q_{0}}+\frac{c}{a}} \exp \left(-\frac{\Delta t}{\tau_{1}}\right), \\
& \tau_{1}=\frac{c / a-d / b}{e(f+c / a)}, \\
& \Delta t=t-t_{0} .
\end{aligned}
$$

If $t$ is much greater than the time constant of level, $\tau_{1}, X$ becomes extremely large and, in turn, $z_{q}$ approaches the value of $f$. The same result can be obtained by Eq. (5.14) for a slow process.

$$
\begin{aligned}
z_{q e} & =f \\
& =z_{s}+j_{0} \frac{p_{f}}{\bar{\Gamma}},
\end{aligned}
$$

where $\mathrm{z}_{\mathrm{qe}}$ represents the equilibrium level which can he reached at last after a perturbation.

In view of $\mathrm{Eq}$. (5.16), it can be noticed that the equilibrium mixture level will increase as the subcooled length and the inlet velocity increase or the heat generation rate in the mixture level decreases. The relationship between $\bar{\Gamma}$ and $q^{\prime}$ can be oblained using the following equation :

$$
\overline{\bar{\Gamma}}=\frac{\mathrm{q}_{\mathrm{b}}^{\prime}}{\mathrm{A}_{\mathrm{fT}} \mathrm{h}_{\mathrm{fg}}},
$$

where $\mathrm{q}{ }^{\prime}$ : bundle-linear heat generation rate, 
Afr : total flow area of the bundle.

The nondimensional forms of Egs. (5.5) and (5.15) can be obtained using the following nondimensional variables and parameters:

nondimensional variables:

$$
\text { time } \begin{aligned}
-t^{*} & =V / \tau=V\left(z_{f} / u_{g j}\right), \\
-z^{*} & =z / z_{f},
\end{aligned}
$$

nondimensional paraıneters:

$$
\begin{array}{ll}
\text { phase change number } & -\mathrm{N}_{\mathrm{pch}}=\frac{\bar{\Gamma}}{\rho_{\mathrm{g}}} \tau, \\
\text { density number } & -\mathrm{N}_{\mathrm{p}}=\frac{\rho_{\mathrm{g}}}{\rho_{\mathrm{f}}}, \\
\text { subcooled number } & -\mathrm{N}_{\mathrm{sub}}=\frac{\Delta \mathrm{h}_{\mathrm{sub}}}{\mathrm{h}_{\mathrm{fg}}}, \\
\text { inlet velocity number } & -\mathrm{N}_{\mathrm{ui}}=\mathrm{j}_{\mathrm{o}} / \mathrm{u}_{\mathrm{gj}},
\end{array}
$$

nondimensional forms:

$$
\begin{aligned}
& z_{s}^{*}=\frac{N_{u i} N_{s u b}}{N_{p c h} N_{p}}, \\
& z_{q}^{*}=\left(\frac{f}{z_{f}}+\frac{c}{a z_{f}} X\right) /(1-X)
\end{aligned}
$$

where

$$
\begin{aligned}
& \frac{c}{a z_{f}}=\frac{C_{0} N_{o}-1-C_{o}\left(1-N_{\rho}\right) N_{u i} N_{s u b} / N_{\rho}}{C_{o}\left(1-N_{\rho}\right) N_{p c h}}, \\
& \frac{d}{b z_{f}}=-\frac{N_{u i} N_{s u b}}{N_{p c h} N_{\rho}},
\end{aligned}
$$




$$
\begin{aligned}
& \frac{f}{z_{f}}=N_{u i}\left(N_{s u b}+1\right) /\left(N_{p} N_{p c h}\right) \\
& X=\left[\frac{z_{q o}^{*}-f / z_{f}}{z_{q o}^{*}+\frac{c}{d z_{f}}}\right] \exp \left[-N_{p} N_{p c h}\left\{\frac{\frac{f}{z_{f}}+\frac{c}{a z_{f}}}{\frac{c}{a z_{f}}-\frac{d}{b z_{f}}}\right\} t^{*}\right]
\end{aligned}
$$

\subsection{Core Heatup Process}

Here, the core heatup process is defined as the process of heatup of the fuels in the uncovered region of the core until the cladding starts melting. The assumptions involved in the model for predicting the fuel and coolant temperatures in the uncovered region of the core are as follows:

1. quasi-steady state in the coolant due to the small heat capacity of steam,

2. generation of sufficient steam for cladding oxidation throughout the process,

3. small effects of hydrogen generated by oxidation on convection and radiation,

4. small temperature difference between cladding and fuel,

5. small effects of droplets except for the near-surface region, where a number of small droplets generated by bubble bursting, foaming, and splashing exist, and the vapor is assumed to be saturated and the heat transfer coefficients are rapidly reduced from those of nucleate boiling to those of film boiling.

Based on the above assumptions, the energy equations of fuel and coolant in each region of high power and low power are written as

Fuel: $\quad n_{\mathfrak{f}}\left[\pi R_{f}^{2}\left(\rho C_{p}\right)_{f}+\pi\left(R_{c l o}^{2}-R_{c l i}^{2}\right)\left(\rho C_{p}\right)_{c l}\right] \frac{\partial T_{f l}}{\partial t}$ 


$$
=n_{f} q_{d i}^{\prime}+n_{f i} 2 \pi R_{c l} \rho_{c l} \gamma_{c l}^{0 x} \frac{\partial X_{c l i}}{\partial t}-n_{f i} 2 \pi R_{c l} h_{i}\left(T_{f i}-T_{c i}\right)-\sum_{j} \sigma A_{i} F_{i j}\left(T_{f i}^{4}-T_{j}^{4}\right),
$$

where $\sum_{j}$ represents fuels in the neighbor region, the structure, and coolant.

$$
\text { Coolant: } \quad A_{6} G_{i} \frac{\partial h_{c i}}{\partial z}=n_{6} 2 \pi R_{c l} h_{i}\left(T_{6}-T_{c i}\right)+\sigma A_{i} F_{i c i}\left(T_{f i}^{4}-T_{c i}^{4}\right) \text {. }
$$

Integrating Eq. (5.24) over the i region from $\mathrm{z}_{\mathrm{qn}}$ to $\mathrm{z}$ yields

$$
\begin{aligned}
& A_{f i} G_{i}\left(h_{c i}-h_{g}\right)=\int_{z_{q n}}^{z} n_{f i}\left[2 \pi R_{c l} h_{i}+\sigma \frac{A_{i}}{n_{f i}} F_{i c i}\left(T_{f i}^{3}+T_{f i}^{2} T_{c i}+T_{f i} T_{c i}^{2}+T_{c i}^{3}\right)\right] \\
& \times\left(T_{f i}-T_{c i}\right) d z,
\end{aligned}
$$

where $\mathrm{z}_{\mathrm{qn}}$ indicates the position of the upper end of the near-surface region from the bottom of the fuel.

In Eq. (5.25) the amount of superheating enthalpy can be expressed as follows :

$$
h_{c i}-h_{g}=C_{p v i}\left(T_{c i}-T_{s}^{\prime}\right) \text {. }
$$

In order to get an analytical solution of Eq. (5.25), it is assumed that the amount of energy added to the coolant through convection and radiation has the same axial distribution as that of the decay heat. For example, if the decay heat has the cosine axial distribution, $\mathrm{q}^{\prime}=\mathrm{q}^{\prime}{ }_{0} \cos \mathrm{g}\left(\mathrm{z}-\mathrm{z}_{\mathrm{o}}\right)$, then

$$
n_{6} 2 \pi R_{c l} h_{i}\left(T_{6 i}-T_{c i}\right)+\sigma A_{i} F_{i c i}\left(T_{f i}^{4}-T_{c i}^{4}\right)=f_{0} \cos g\left(z-z_{0}\right) .
$$

The unknown constant $f_{o}$ in Eq. (5.27) is determined at the position of $\mathrm{z}$ as follows:

$$
f_{0}=\frac{n_{6} 2 \pi R_{c l} h_{i}\left(T_{6}-T_{c i}\right)+\sigma A_{i} F_{i c i}\left(T_{f i}^{4}-T_{c i}^{4}\right)}{\cos g\left(z-z_{0}\right)}
$$

Putting Eqs. (5.26) and (5.28) into Eq.(5.25) produces

$$
A_{6} G_{i} C_{p v i}\left(T_{c i}-T_{s}\right)=f_{o} \int_{z_{q p}}^{Z} \cos g\left(z-z_{o}\right) d z
$$




$$
=\frac{f_{0}}{g}\left[\sin g\left(z-z_{0}\right)-\sin g\left(z_{q n}-z_{0}\right)\right] .
$$

From Eq. (5.29) the following simple relationship is obtained :

$$
T_{c i}-T_{s}=P_{i}\left(T_{f i}-T_{c i}\right)
$$

where

$$
P_{i}=\frac{\sin \left[g\left(z-z_{o}\right)\right]-\sin \left[g\left(z_{q n}-z_{o}\right)\right]}{A_{6} G_{i} C_{p v i} g \cos \left[g\left(z-z_{o}\right)\right]} n_{f i}\left[2 \pi R_{c l} h_{i}+\sigma \frac{A_{i}}{n_{f i}} F_{i c i}\left(T_{6}^{3}+T_{f i}^{2} T_{c i}+T_{6} T_{c i}^{2}+T_{c i}^{3}\right)\right]
$$

The coolant temperature and the temperature difference between the fuel and the coolant are obtained from Eq. (5.30) as

$$
\begin{aligned}
& T_{c i}=\frac{1}{1+P_{i}}\left(P_{i} T_{f}+T_{s}\right), \\
& T_{6}-T_{c i}=\frac{1}{1+P_{i}}\left(T_{f i}-T_{s}\right) .
\end{aligned}
$$

For a uniform axial distribution of the decay power, $\mathrm{P}_{\mathrm{i}}$ in Eq. (5.30) becomes

$$
P_{i}=\frac{1}{A_{6 i} G_{i} C_{p v i}} n_{f i}\left[2 \pi R_{c l} h_{i}+\sigma \frac{A_{i}}{n_{f i}} F_{i c i}\left(T_{f}^{3}+T_{f i}^{2} T_{c i}+T_{6} T_{c i}^{2}+T_{c i}^{3}\right)\right]
$$

The position of the upper end of the near-surface region, $\mathrm{z}_{\mathrm{qn}}$, is determined by the following correlation [5.15]:

$$
\mathrm{z}_{\mathrm{qn}}=\mathrm{z}_{\mathrm{q}}+595.0 \mathrm{D}_{\mathrm{e}} \sqrt{\frac{\mu_{\mathrm{f}} \mathrm{j}_{\mathrm{q}}}{\sigma}}\left[1-\frac{\alpha_{\mathrm{q}}}{0.854}\right]^{1.22}
$$

This region is equivalent to the near-surface region defined by Kataoka and Ishii [5.16] where the entrainment is considerably high, usually greater than 1 in the data of Rozen et. al. [5.17] and of Cheng and Teller [5.18]. The heat transfer coefficient in the nearsurface region is obtained on the basis of Assumption 5 in Section 5.3:

$$
h=h_{s}+h_{N B} \exp \left[-\left(z-z_{q}\right) / a\right]
$$


The constant $\mathrm{a}$ is determined considering that heat transfer by droplets at $\mathrm{z}_{\mathrm{qn}}$ is equally competent with that by steam:

$$
\mathrm{a}=\left(\mathrm{z}_{\mathrm{qn}}-\mathrm{z}_{\mathrm{q}}\right) / \ln \left(\mathrm{h}_{\mathrm{NB}} / \mathrm{h}_{\mathrm{s}}\right) .
$$

In the region above the near-surface region which is equivalent to the momentumcontrolled region in Ref. [5.16], the correlation suggested by Kumamaru et. al. [5.19] is used:

$$
h=h_{s}\left\{1.0+\exp \left[-0.082\left(z-z_{q n}\right) / D_{h}\right]\right\} .
$$

The heat transfer coefficient of vapor, $h_{s}$, in Eqs. (5.35) and (5.37) is determined by the McEligot correlation [5.20] which takes account of the property variations across the boundary layer:

$$
\left[\frac{h_{s} D_{h}}{k_{v}}\right]_{b}=0.021\left(\frac{D_{h} G}{\mu_{v}}\right]_{b}^{0.8}\left[\frac{C_{p v} \mu_{v}}{k_{v}}\right]_{b}^{0.4}\left[\frac{T_{b}}{T_{w}}\right]^{0.5}
$$

Borishanski's correlation [5.21] for nucleate boiling is used :

$$
\mathrm{h}_{\mathrm{NB}}=A q^{\prime 0.7} \mathrm{~F}(\mathrm{P}) \text {, }
$$

where $\mathrm{A}=0.1011 \mathrm{P}_{\mathrm{cr}}^{0.69}$ (bar),

$$
\mathrm{F}(\mathrm{P})=1.8 \mathrm{P}_{\mathrm{r}}^{0.17}+4 \mathrm{P}_{\mathrm{r}}^{1.2}+10 \mathrm{P}_{\mathrm{r}}^{10} \text {. }
$$

The effective view factor, $F_{i j}$, is given by

$$
F_{i j}=\left[\frac{1}{\varepsilon_{j}}+\frac{A_{j}}{A_{i}}\left(\frac{1}{\varepsilon_{i}}-1\right)\right]^{-1} \text {. }
$$

The emissivity of steam, $\varepsilon_{v}$, is strongly dependent on not only its temperature but also the optical path $(\mathrm{p} \cdot \mathrm{l})$. For a given optical path $\varepsilon_{\mathrm{v}}$ is modelled using the graph produced in Ref. [5.22]:

$$
\varepsilon_{\mathrm{v}}=\mathrm{C}_{\varepsilon} / \mathrm{T}_{\mathrm{b}}
$$


With the omission of the subscript $i$ the insertion of Eq. (5.32) into Eq. (5.23) converts the partial differential equation of Eq. (5.23) into the following ordinary differential equation :

$$
a \frac{d T_{f}}{d t}=b-c T_{f}-d T_{f}^{4}+e \frac{d X_{c l}}{d t},
$$

where

$$
\begin{aligned}
& a=\pi R_{f}^{2}\left(\rho C_{p}\right)_{f}+\pi\left(R_{c l o}^{2}-R_{c l i}^{2}\left(\rho C_{p}\right)_{c l},\right. \\
& b=q_{d}{ }^{\prime}+2 \pi R_{c l} h \frac{1}{1+P} T_{s c}+\sum_{j} d_{j} T_{j}^{4}, \\
& c=2 \pi R_{c l} h \frac{1}{1+P}, \\
& d=\sum_{j} d_{j}, \\
& d_{j}=\sigma \frac{A}{n_{f}} F_{j}, \\
& e=2 \pi R_{c l} \rho_{c l} \gamma_{c l}^{0 x} .
\end{aligned}
$$

Through the assumption of a linear variation of the fuel temperature with time over a time interval, Eq. (5.40) becomes

$$
a \frac{d T_{f}}{d t}=b-c^{\prime} T_{f}+e \frac{d X_{c l}}{d t},
$$

where

$$
c^{\prime}=c+d \bar{T}_{f}^{3},
$$




$$
\begin{aligned}
\bar{T}_{f}^{3} & =\int_{t_{0}}^{t} T_{f}^{4} d t / \int_{t_{0}}^{t} T_{f} d t \\
& =\frac{2}{5}\left(T_{f}^{5}-T_{f o}^{5}\right) /\left(T_{f}^{2}-T_{f o}^{2}\right) .
\end{aligned}
$$

Integrating Eq. (5.41) over a time interval from $t_{o}$ to $t$ yields

$$
T_{f}=T_{f o}+\frac{1}{a} \int_{b_{0}}^{t} b d t-\frac{c^{\prime}}{a} \int_{t_{0}}^{t} T_{f} d t+\frac{e}{a}\left(x_{c l}-x_{c l o}\right)
$$

Equation (5.42) is also approximated as

$$
T_{f}=\left\{T_{f o}+\left(\frac{\bar{b}}{a}-\frac{T_{f_{0} c^{\prime}}}{2 a}\right)\left(t-t_{o}\right)+\frac{e}{a}\left(x_{c l}-x_{c l o}\right)\right\} /\left\{1+\frac{c^{\prime}}{2 a}\left(t-t_{0}\right)\right\},
$$

where $\bar{b}=\int_{t_{0}}^{t} b d t / \int_{t_{0}}^{t} d t$.

In order to get the thickness of the oxidation layer of the cladding, the following chemical equation is used :

$$
\frac{d x}{d t}=\frac{a}{x} \exp \left(-\frac{b}{T_{f}}\right) .
$$

For an analytical solution of Eq. (5.44) Eqs. (5.43) and (5.44) are simplified as follows :

$$
\begin{aligned}
& \dot{T}_{f}=T_{f o}+\frac{b}{a}\left(t-t_{o}\right)-\frac{c^{\prime}}{a} T_{f o}\left(t-t_{0}\right)+\frac{e}{a}\left(x_{c l}-x_{c l o}\right), \\
& \frac{d x_{c l}}{d t}=\frac{1}{x_{c l}}\left(\alpha T_{f}+\beta\right),
\end{aligned}
$$

where

$$
\begin{array}{llll}
\alpha=0.986 \times 10^{-14} & \text { and } & \beta=-1163.4 \times 10^{-14} & \text { for } 1200^{\circ} \mathrm{K} \leq \mathrm{T}<14000^{\circ} \mathrm{K}, \\
\alpha=0.547 \times 10^{-13} & \text { and } & \beta=-743.4 \times 10^{-13} & \text { for } 1400^{\circ} \mathrm{K} \leq \mathrm{T}<1600^{\circ} \mathrm{K}, \\
\alpha=0.2191 \times 10^{-12} & \text { and } \quad \beta=-467 \times 10^{-12} & \text { for } 1600^{\circ} \mathrm{K} \leq \mathrm{T}<1850^{\circ} \mathrm{K},
\end{array}
$$




$$
\alpha=0.223 \times 10^{-11} \text { and } \beta=-396 \times 10^{-11} \text { for } \mathrm{T} \geq 1850^{\circ} \mathrm{K} .
$$

Note that constants, $\alpha$ and $\beta$, are determined on the basis of the Cathcard model and the Baker-Just model for $\mathrm{T}<1850^{\circ} \mathrm{K}$ and $\mathrm{T} \geq 1850^{\circ} \mathrm{K}$, respectively, as recommended in Ref. [5.4] and that it is assumed that there is negligible oxidation before the fuel temperature reaches $1200^{\circ} \mathrm{K}$.

Inserting Eq. (5.45) into Eq. (5.46) produces the following non-linear equation :

$$
\left[\frac{x_{c l}-q(t-k)}{x_{c l o}-q\left(t_{o}-k\right)}\right]=\left[\frac{x_{c l}-p(t-k)}{x_{c l o}-p\left(t_{o}-k\right)}\right)^{\frac{p}{q}}
$$

where

$$
\begin{aligned}
& q, p=\frac{1}{2}\left[\frac{\alpha e}{a} \pm \sqrt{\left(\frac{\alpha e}{a}\right)^{2}+4\left(\frac{\alpha}{a} b^{\prime}\right)}\right] \\
& k=-\frac{a}{\alpha b^{\prime}}\left(\beta+\alpha C_{0}\right) \text {, } \\
& b^{\prime}=b-c^{\prime} T_{0} \text {, } \\
& C_{0}=T_{0}-\frac{T_{0}}{a} b^{\prime}-\frac{e}{a} x_{c l o} \$ . L P A l s o, \text { thefollowinglinearequationfor } \$ x_{c l \$} \text { canbeobtainedbytheassumptionofthı } \\
& \text { where } k=x_{\text {clo }}^{2}+\alpha \frac{b^{\prime}}{a}\left(t^{2}-t_{0}^{2}\right)+2\left(\alpha C_{0}+\beta\right)\left(t-t_{0}\right)+\alpha \frac{e}{a} x_{c l o}\left(t-t_{0}\right) \text {. } \\
& \text { The nondimensional form of Eq. }(5.43) \text { can be obtained using the following nondimen- } \\
& \text { sional variables and parameters: }
\end{aligned}
$$

nondimensional variables: 


$$
t^{*}, z^{*}, T_{f}^{*}=\frac{T_{f}}{T_{s}}, x_{c l}^{*}=\frac{x_{c l}}{\delta_{c l}}
$$

nondimensional parameters:

$$
\begin{array}{ll}
\text { decay heating number } & -\mathrm{N}_{\mathrm{dh}}=\frac{\tau \mathrm{q}_{\mathrm{d}}^{\prime}}{\mathrm{aT} \mathrm{T}_{\mathrm{s}}} \\
\text { oxidation heating number } & -\mathrm{N}_{\mathrm{ox}}=\frac{e \delta_{\mathrm{cl}}}{\mathrm{a} \mathrm{T}_{\mathrm{s}}} \\
\text { convective cooling number } & -\mathrm{N}_{\mathrm{c}}=\frac{\tau}{\mathrm{a}} 2 \pi \mathrm{R}_{\mathrm{cl}} \mathrm{h} \\
\text { radiation cooling number } & -\mathrm{N}_{\mathrm{rj}}=\frac{\tau}{\mathrm{a}} \mathrm{T}_{\mathrm{s}}^{3} \sigma \frac{\mathrm{A}}{\mathrm{n}_{\mathrm{f}}} \mathrm{F}_{\mathrm{j}} \\
\text { coolant heating number } & -\mathrm{N}_{\mathrm{p}}=\frac{\tau}{\mathrm{a}} \frac{\mathrm{A}_{\mathrm{f}}}{\mathrm{n}_{\mathrm{f}}} \mathrm{GC} C_{\mathrm{pv}}
\end{array}
$$

nondimensional form:

$$
\begin{aligned}
& \mathrm{T}_{\mathrm{f}}^{*}=\left\{\mathrm{T}_{\mathrm{fo}}^{*}+\frac{1}{\mathrm{a} \mathrm{T}_{\mathrm{s}}}\left[\left(\mathrm{b}-\frac{\mathrm{T}_{\mathrm{o}} \mathrm{C}^{\prime}}{2}\right) \tau\left(\mathrm{t}^{*}-\mathrm{t}_{\mathrm{o}}^{*}\right)+\mathrm{e} \delta_{\mathrm{cl}}\left(\mathrm{x}_{\mathrm{cl}}^{*}-\mathrm{x}_{\mathrm{clo}}^{*}\right)\right]\right\} \\
& /\left[1+\frac{\mathrm{c}^{\prime} \tau}{2 \mathrm{a}}\left(\mathrm{t}^{*}-\mathrm{t}_{\mathrm{o}}^{*}\right)\right.
\end{aligned}
$$

where

$$
\begin{aligned}
& \frac{b \tau}{a T_{s}}=N_{d b}+N_{c} \frac{1}{1+P}+\sum_{j} N_{r j} T_{j}^{* 4}, \\
& \frac{\tau}{a} c^{\prime}=N_{c}+\sum_{j} N_{r j} \bar{T}_{f}^{* 3},
\end{aligned}
$$




$$
\begin{aligned}
& \frac{e \delta_{c l}}{a T_{s}}=N_{o x}, \\
& P=N_{p}\left[N_{c}+N_{r c}\left(T_{f}^{* 3}+T_{f}^{* 2} T_{c}^{*}+T_{f}^{*} T_{c}^{* 2}+T_{c}^{* 3}\right)\right]
\end{aligned}
$$

\subsection{Assessment}

Because of the requirement of a reasonable level of confidence in the present method, it is assessed by comparing its predictions with data from the Power Bursting Facility Scoping Test (PBF-ST) [5.23] and predictions by SCDAP [5.23]. The PBF contains a 32-rod bundle of pressurized-water-reactor-type fuel rods, a $0.91-\mathrm{m}$ long enclosed in an insulated shroud. The bundle was subjected to a heatup transient initiated by coolant boil-off at a pressure of about $6.8 \mathrm{MPa}$. The bundle power of $39 \mathrm{KW}$ and the inlet flow rate of $16 \mathrm{~g} / \mathrm{sec}$ were provided to set the uncovery level in the bundle to 0.42 m. After reaching a steady state, power ramping started at $55 \mathrm{~min}$. and continued up to about $200 \mathrm{~min}$. After then, a cooldown procedure was taken.

A steady-state uncovery level at $55 \mathrm{~min}$. can be calculated using Eq. (5.16). However, since there is a suspicion on the leakage of the inlet of the shroud, the inlet flow rate is estimated for given mixture level and power level. It turns out to be $11.23 \mathrm{~g} / \mathrm{sec}$, which is within the error bound estimated by the other method [5.23]. Figure 4 shows the comparison between the measured mixture levels and predictions by the present analytical method and by SCDAP. The results predicted by the present method are in excellent agreement with data. Note that the rapid drop of the measured data at around $190 \mathrm{~min}$. was caused by the failure of the shroud. The underprediction of the method is presumed to be caused by the accumulation of the fallback of droplets in the mixture of the bundle due to reflux condensation in the upper region of the bundle [5.24].

As the method does not have the model for heat loss from the shroud to the hypass coolant, the temperature of the shroud is assumed to have the same as the coolant temperature in the bundle throughout the calculation of the present model. Figures 5 through 
7 show the variations of the fuel temperature with time at the positions of $0.35,0.5$ and $0.7 \mathrm{~m}$ from the bottom of the fuel. As shown in Fig. 5, the fuel temperature at $0.35 \mathrm{~m}$ predicted by the method without the near-surface heat transfer model jumps suddenly when the uncovery level is predicted to drop just below $0.35 \mathrm{~m}$. As time goes by, the fuel temperatures predicted with and without the model of heat transfer by droplets come close to each other because the position of $0.35 \mathrm{~m}$ escapes from the droplet-dominant heat transfer region. In a scaled bundle like the PBF bundle with the considerably shorter length of the fuel than that in a real core, the effect of the model of heat transfer by droplets is much more important in the scaled system. For example, experiments in Refs. [5.19] and [5.25] show the transition region considerably affected by droplets extending to $20 \mathrm{~cm}$ through $50 \mathrm{~cm}$. Note that this region can not be scaled properly if the same length scale between the prototype and the model is not used. There are the overpredictions by the present model during the initial transient at $0.5 \mathrm{~m}$ and $0.7 \mathrm{~m}$ where vapor convection is a dominant heat transfer mechanism. These overpredictions are presumed to result from the fallback of droplets generated hy reflux condensation in the upper region of the bundle.

The fuel heatup rate is underpredicted by the present model. As noticed in Fig. 8, energy loss by radiation to the shroud predicted by the model is larger than the estimation in Ref. [5.23]. It is presumed to be caused by the treatment of the one-radial region of the fuel bundle in the present assessment. Since the outermost fuels closest to the shroud are largely cooldowned by the energy loss by radiation to the shroud, their fuel temperatures are lower than the inner fuel temperatures and, in turn, the actual energy loss is smaller than the prediction.

In a nuclear plant the fraction of energy loss by radiation to the shroud is considerably smaller than that of other cooldown mechanisms. At a rough guess the ratio of the energy loss by radiation to the shroud in the nuclear power plant to that in the PBF is less than $4 \%$. Figure 6 shows the responses of the fuel temperatures predicted by the present model with and without the radiation model of energy loss hy radiation to the shroud. As expected, the fuel heatup rate without the model is much larger than that with the model. This demonstrates the heavy dependence of the heatup rate on the shroud model in the 
scaled system.

Figure 8 shows the variation of the fraction of each cooldown and heatup mechanism with time predicted by the analytical method. In the cooldown mechanisms the convection is dominant over the radiation before the fuel temperature reaches around $1200^{\circ} \mathrm{K}$. After then, the radiation becomes more and more dominant over the convection.

The effect of the chemical oxidation heating on the heatup process is small compared to the decay heat in the transient due to the slow heatup rate. However, its effect rapidly increases after the fuel temperature reaches $1850 \mathrm{~K}$ at which there is the sudden jump of the oxidation rate.

\subsection{Application}

The scaled system of the PBF is now examined, which is a special case with the same fluid, materials, channel and fuel geometry, and power distribution as the prototype. In the following analysis the subscript $\mathrm{R}$ is defined as the ratio between the model and the prototype in the following generalized form:

$$
\Psi_{\mathrm{R}}=\frac{\Psi_{\mathrm{m}}}{\Psi_{\mathrm{p}}}=\frac{\Psi \text { for model }}{\Psi \text { for prototype }}
$$

Three scaling criteria among four in the core uncovery process should be satisfied as follows:

$$
\begin{aligned}
& \mathrm{N}_{\text {pch R }}:\left(\overline{\mathrm{I}} \mathrm{z}_{\mathrm{f}}\right)_{\mathrm{R}}=1, \\
& \mathrm{~N}_{\text {sub R }}: \Delta \mathrm{h}_{\text {sub R }}=1, \\
& \mathrm{~N}_{\text {ui R }}: \mathrm{j}_{\mathrm{O} R}=1 .
\end{aligned}
$$

Equations (5.52) and (5.53) require the same inlet conditions:

$$
\Delta \mathrm{h}_{\text {sub } \mathrm{R}}=1 \text { and } \mathrm{j}_{\mathrm{o}}=1 \text {. }
$$


In view of Eq.(5.17) and the same power distribution, Eq.(5.51) becomes

$$
\left(q^{\prime} z_{f}\right)_{R}=1 \text {. }
$$

Since the ratio of the fuel length of the PBF to that of the core is $0.25, q^{\prime}$ in the PBF should be by four times larger than that under the accident conditions in nuclear power plants. In the PBF power was increased up to 2.4 time of the initial steady-state power in order to make up for the energy loss by radiation to the shroud. Even in the case in which the distortion of the phase change number is essential, it is possible to maintain the similarity of the mixture level by carefully distorting the inlet velocity number and/or the subcooling number with time, using Eq.(5.19) so that the same $z_{q}^{*}$ hetween the prototype and the model may be produced. The ability to make up for the effect of a distorted parameter in a global sense is one of the main advantages of the analytical method.

In the heatup process the following four scaling criteria should be considered:

$$
\begin{aligned}
& N_{d h_{R}}:\left(q^{\prime}{ }_{d} z_{f}\right)_{R}=1, \\
& N_{c_{R}}:\left(h z_{f}\right)_{R}=1, \\
& N_{r j R}:\left(\frac{n_{f o} z_{f}}{2 n_{f}}\right]_{R}=1, \\
& N_{p_{R}}:\left(G z_{f}\right)_{R}=1,
\end{aligned}
$$

where $\mathrm{n}_{\mathrm{fo}}$ : total number of the outmost fuel closest to the shroud.

Equations (5.55) 'and (5.58) are equivalent to the requirement of Eq.(5.54) if the mixture level maintains the similarity.

From Eq.(5.34)

$$
z_{q n}^{*}=z_{q}^{*}+\frac{1}{z_{f}}\left\{595 D_{e} \sqrt{\frac{\mu_{f} j_{q}}{\sigma}}\left(-\frac{\alpha_{q}}{0.854}\right)^{1.22}\right\} .
$$


In an approximate sense, $z_{\text {qn }}^{*}$ has the similarity if the axial scaling is not distorted as described in Section 5.3. If the mixture level maintains the similarity,

$$
h_{S R}=G_{R}^{0.8}=q_{R}^{0.8} \text {. }
$$

With Eq.(5.60) Eq.(5.56) becomes

$$
\left(\mathrm{z}_{\mathrm{f}} \mathrm{q}^{0.8}\right)_{\mathrm{R}}=1
$$

Since Eqs.(5.55) and (5.61) can not be satisfied at the same time, it should be determined which requirement is more important for the similarity of the fuel temperature.

The requirement of the radiation number, Eq.(5.57), is a scaling criterion which is satisfied in no way in a scaled model. For example, the ratios of $n_{f o}$ to $n_{f}$ in the PBF and a $1000 \mathrm{Mwe}$ nuclear power plant are 0.5 and 0.017 , respectively. As a result, it is recommended to used the shroud coated with the material with low emissivity.

Nomenclature

$\begin{array}{llll}\text { A } & \text { area } & \text { Subscripts } \\ \mathrm{C}_{\mathrm{o}} & \text { flow distribution parameter } & & \\ \mathrm{C}_{\mathrm{p}} & \text { specific heat } & \text { b } & \text { bundle, bulk } \\ \text { D } & \text { diameter } & \text { c } & \text { coolant } \\ \text { F } & \text { effective view factor } & \text { cl } & \text { cladding } \\ \text { G } & \text { mass flux } & \text { cr } & \text { critical } \\ \text { h } & \text { enthalpy, heat transfer coefficient } & \text { d } & \text { decay } \\ \text { j } & \text { superficial flux } & \text { e } & \text { equivalent } \\ \text { n } & \text { number of fuel } & \text { f } & \text { liquid, fuel } \\ \text { N } & \text { dimensionless number } & \text { g } & \text { vapor } \\ \text { p } & \text { pressure } & \text { i } & \text { each power region } \\ \text { pr } & \text { reduced pressure } & \text { j } & \text { neighbor region }\end{array}$




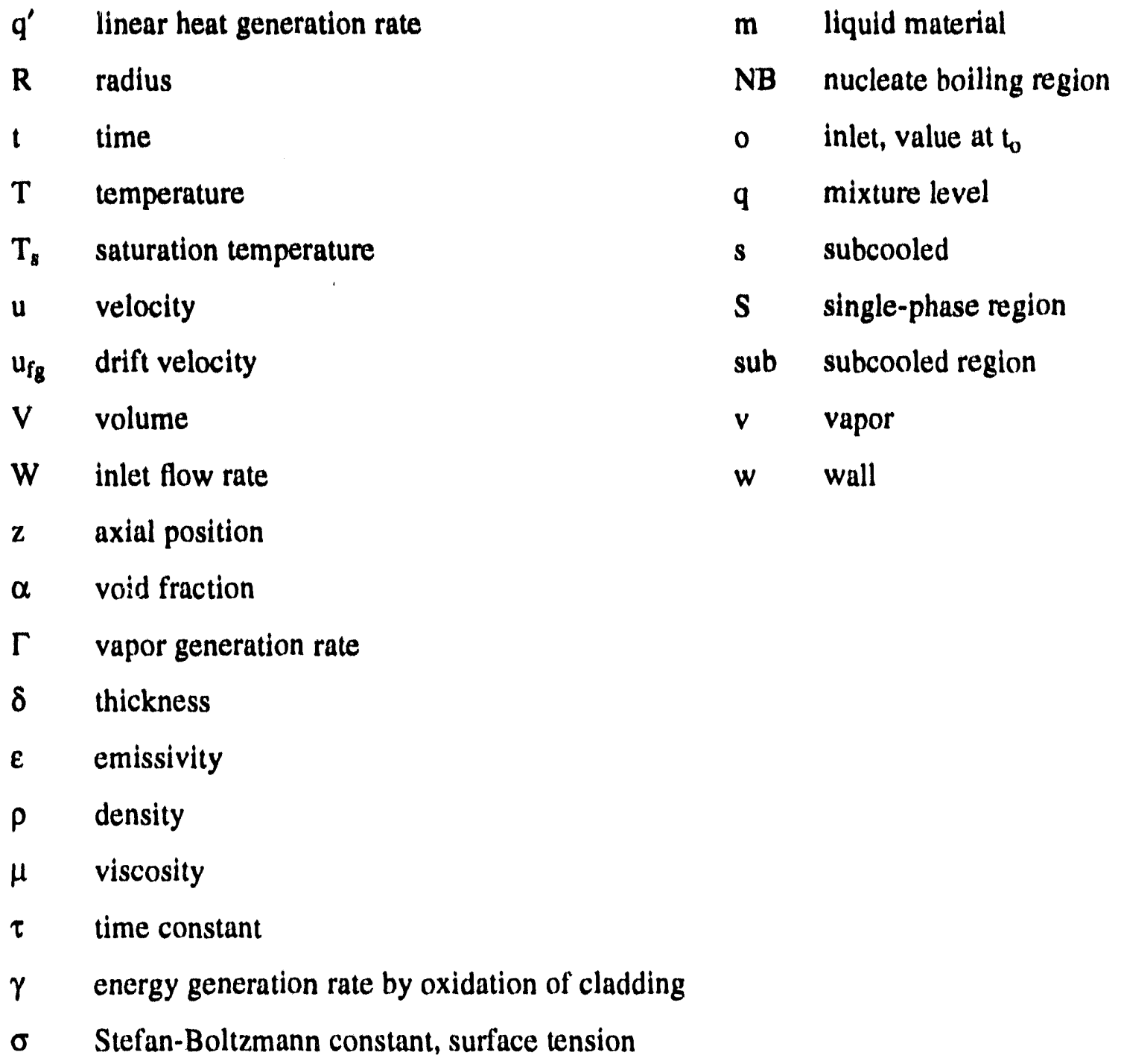

\section{References}

5.1 R. O. Wooton and H. I. Avci, "MARCH (Meltdown Accident Response Characteristics) Code Description and User's Manual", NUREG / CR-1711, 1980.

5.2 C. M. Allison, et.al., "Severe Core Damage Analysis Package (SCDAP) Code Conceptual Design Report", EGG-CDAP-5397, 1981.

5.3 T. J. Maudlin, et.al., "A Damage Assessment of TMI-2", LA-UR-83-737, 1983.

5.4 S. H. Kim, et.al., "The Development of APRIL.MOD 2 - A Computer Code for Core Meltdown Accident Analysis of Boiling Water Reactors", NUREG / CR-5157, 
1988.

5.5 J. A. Boure, "A Method to Develop Similarity Laws for Two Phase Flow"; ASME paper No. 70-HT-25, 1970.

5.6 R. W. Lockhart and R. C. Martinelli, "Proposed Correlation of Data for Isothermal Two-Phase, Two-Component Flow in Pipes," Chem. Eng. Progress, 45, 1949.

5.7 S. Y. Ahmad, "Fluid to Fluid Modeling of Critical Heat Flux: A Compensated Distortion Model," Int. J. Heat Mass Transfer, 16, 1973.

5.8 B. Spindler, "Rational Simplification of the Equations Governing the Liquid Film Flow over a Plane with Heat Flux at the Wall and Interfacial Phase Change," in Scaling in Two-Phase Flows presented at the Winter Annual Mecting of ASME, Chicago, 1980.

5.9 M. Ishii and N. Zuber, "Thermally Induced Flow Instabilities in Two-Phase Mixtures," Proc. 4th Int. Heat Transfer Conf., Paris, Paper B 5.11, 1970.

5.10 M. Ishii and O. C. Jones, "Derivation and Application of Scaling Criteria for TwoPhase Flows," Proc. NATO Advanced Study Institute, Istanbul, Turkey, 1, 1976.

5.11 M. Ishii and I. Kataoka, "Scaling Laws for Thermal-Hydraulic System under Single Phase and Two-Phase Natural Circulation," Nuclear Eng. and Des., 811984.

5.12 G. Kocamustafangullai and M. Ishii, "Scaling Criteria for Two-Phase Flow Loops and Their Application to Conceptual 2 x 4 Simulation Loop Design," Nuclear Tech., 65, 1984.

5.13 K. G. Condie, T. K. Larson,C. B. Davis, and G. E. McCreery, Evaluation of Integral Continuing Experimental Capability (CEC) Concepts for Light Water Reactor Research-PWR Scaling Concepts, NUREG / CR-4824, 1987.

5.14 M. Osakabe, et.al., "Slug to Annular Flow Transition during Boiloff in a Rod Bundle under High-Pressure Conditions," Nuclear Eng. and Des., 98, 1986.

5.15 J. G. Denton and M. Ishii, Flow Visualization Study of Post Critical Heat Flux Region for Inverted Bubbly, Slug, and Annular Flow Regimes, NUREG/CR-5171, 1988. 


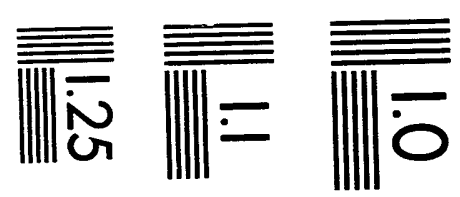

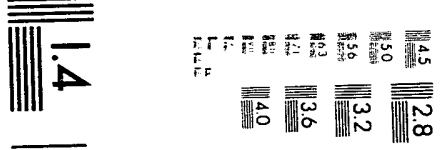

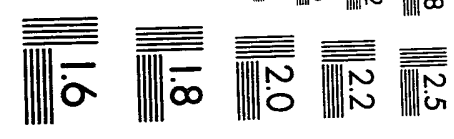



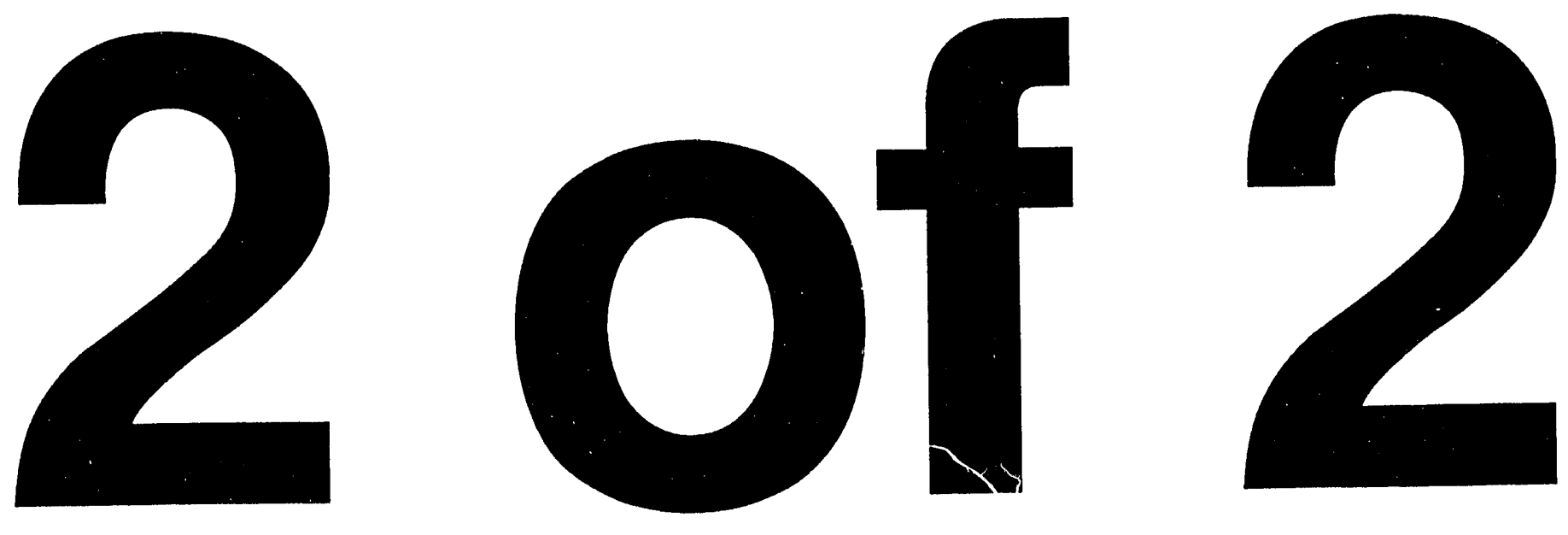
5.16 I. Kataoka and M. Ishii, "Mechanistic Modeling of Pool Entrainment Phenomenon," Int. J. Heat Mass Transfer, 27, 1984.

5.17 A. M. Rozen, S.I. Golub, and T. I. Votintseva, "Calculating Droplet Carryover with Bubbling," Teploenergetika, 23, 1976.

5.18 S. I. Cheng and A. J. Teller, "Free Entrainment Behavior in Sieve Tray," A.I.Ch.E. J. , 7, 1961.

$5.19 \mathrm{H}$. Kumamaru, et.al.,"Investigation of Uncovered-Bundle Heat Transfer under High-Pressure Boil-Off Conditions," Nuclear Eng. and Des., 96, 1986.

5.20 D. M. McEligot, L. W. Ormond, and H. C. Perkins, "Internal Low Reynolds Number Turbulent and Transitional Gas Flow with Heat Transfer," J. Heat Transfer, 88, 1966.

5.21 V. M. Borishanski, Correlation of the Effect of Pressure on the Critical Heat Flux and Heat Transfer Rates Using the Theory of Thermodynamics Similarity, Problems of Heat Transfer and Hydraulics of Two-Phase Media, Pergamon Press, 1969.

5.22 C. C. Ferriso, C. B. Ludwig, and F. P. Boynton, "Total Emissivity of Hot Water Vapor - I. High Pressure Limit," Int. J. Heat Mass Transfer, 9, 1966.

5.23 A. D. Knipe, S. A. Ploger, and D. J. Osetek, "PBF Severe Fuel Damage Scoping Test - Test Results Report", NUREG/CR-4683, 1986.

5.24 Z. Martinson, et.al., "Volume 1: PBF Severe Fuel Damage Test 1-1 - Test Results" Report, NUREG/CR-4684, 1986.

5.25 G. L. Yoder, T. M. Anklam, D.G. Morris, and C.B. Mullins, "High Dryout Quality Film Boiling and Steam Cooling Heat Transfer Data from a Rod Bundle", NUREG/CR-3502, 1983. 


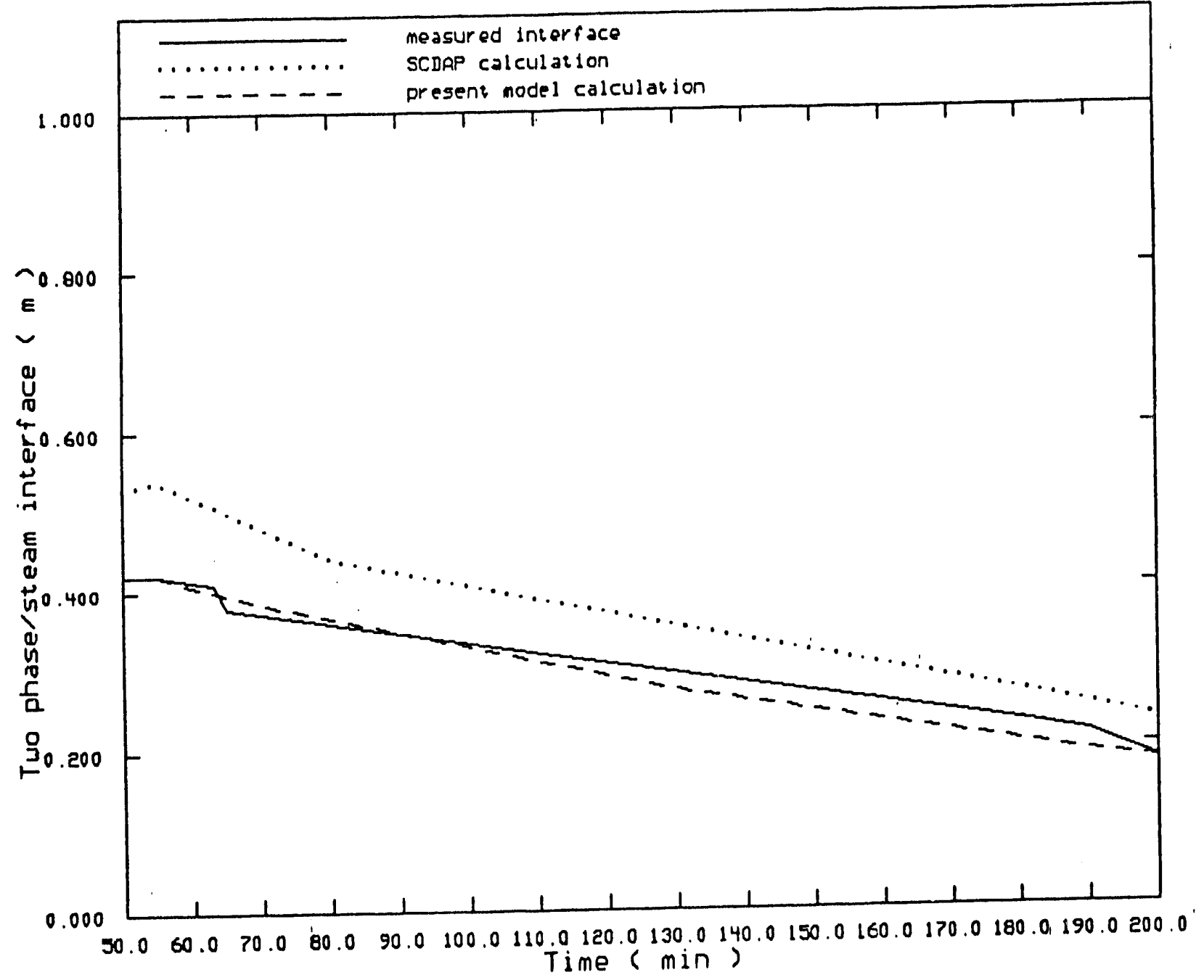

Fig. 4 Comparison ol the meitsured mixture level with the predictions by SCDAP and the present method 


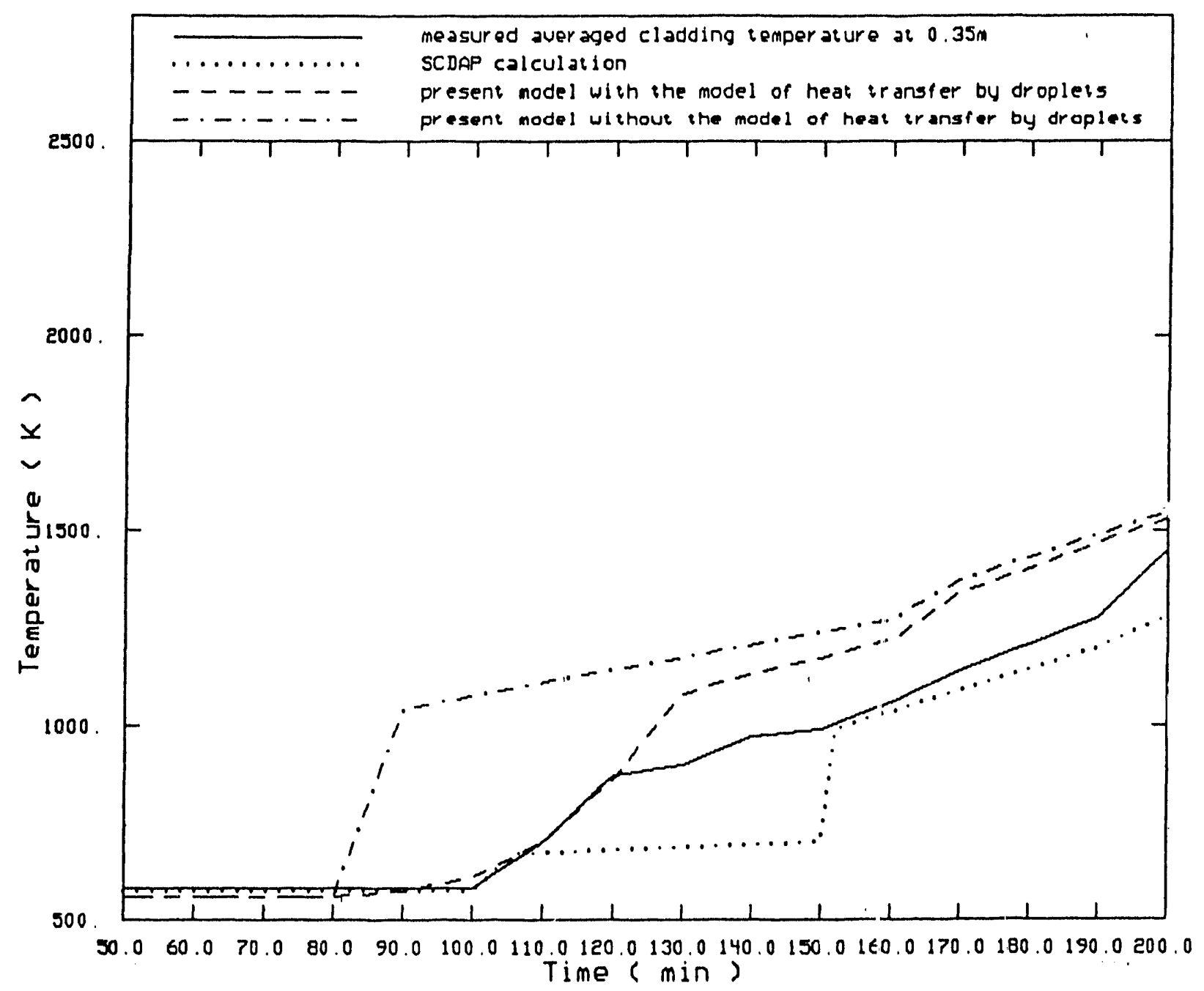

Fig. 5 Comparison of the meast.red fivel temperature at $0.35 \mathrm{~m}$ with the predictions by SCDAP and the present method 


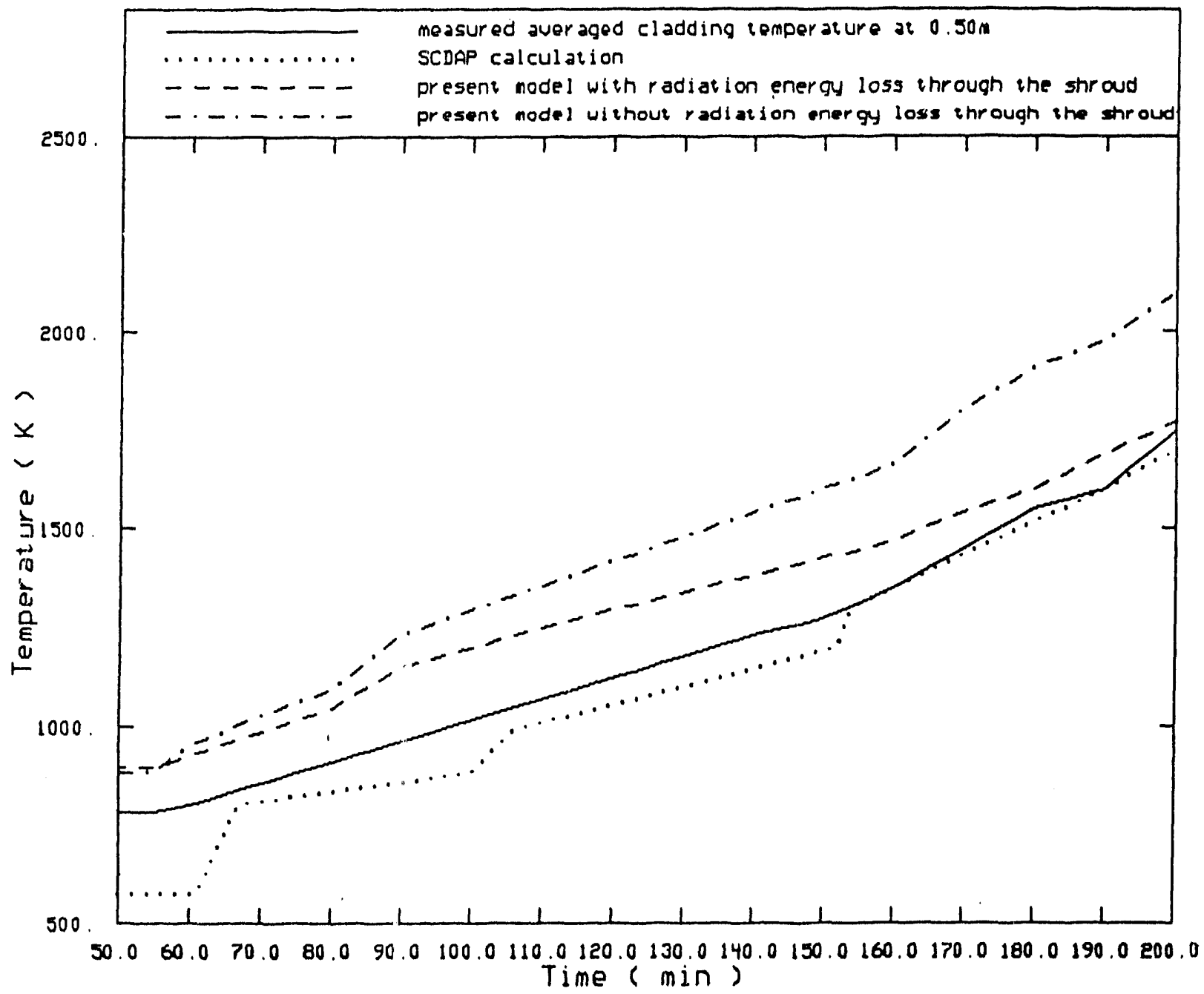

Fig. 6 Comparison of the measured fuel temperature at $0.5 \mathrm{~m}$ with the predictions by SCDAP and the present method

93 


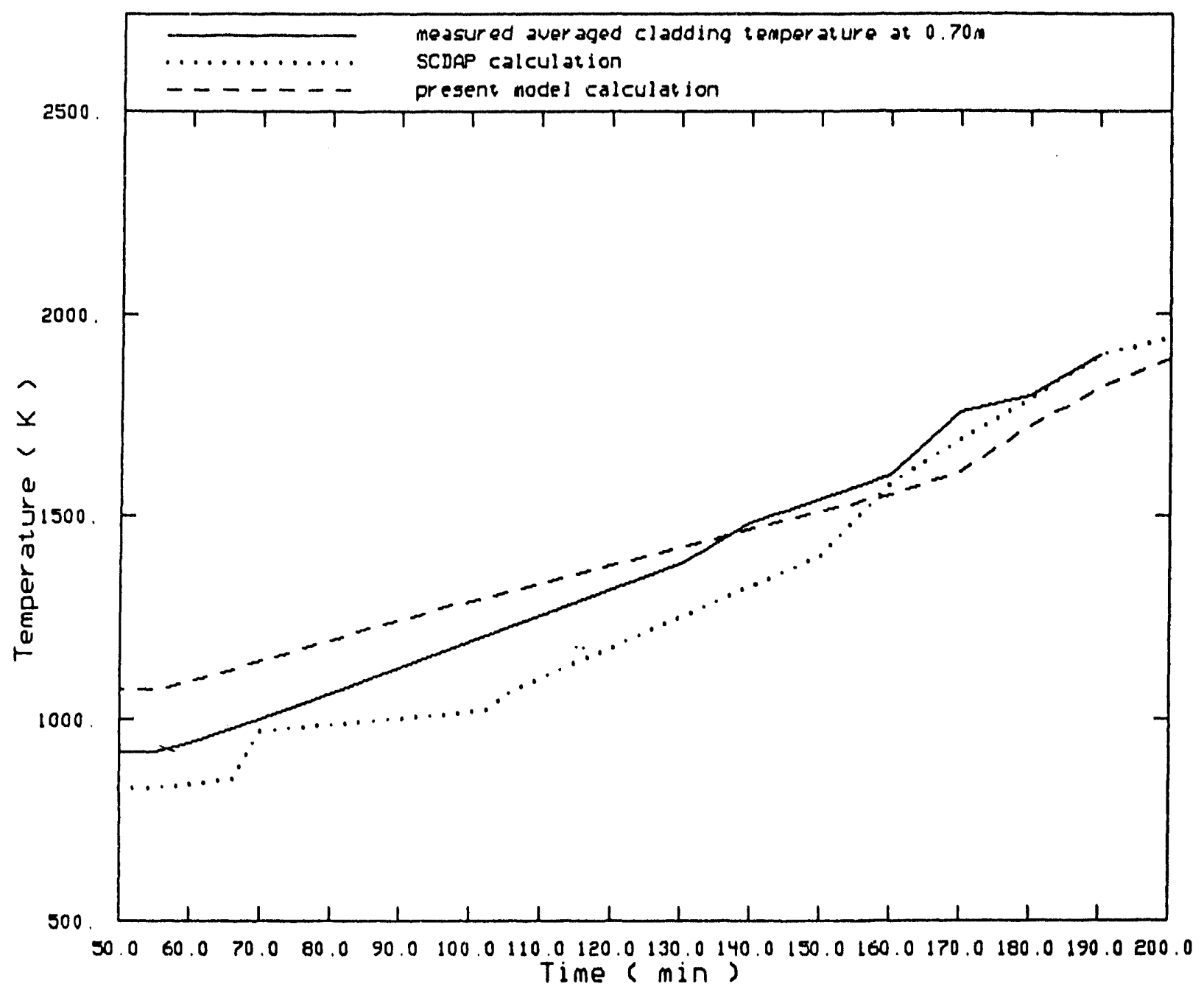

Fig. 7 Comparison of the meisured fiel temperature fuel at $0.7 \mathrm{~m}$ with the predictions by SCDAP and the present method 


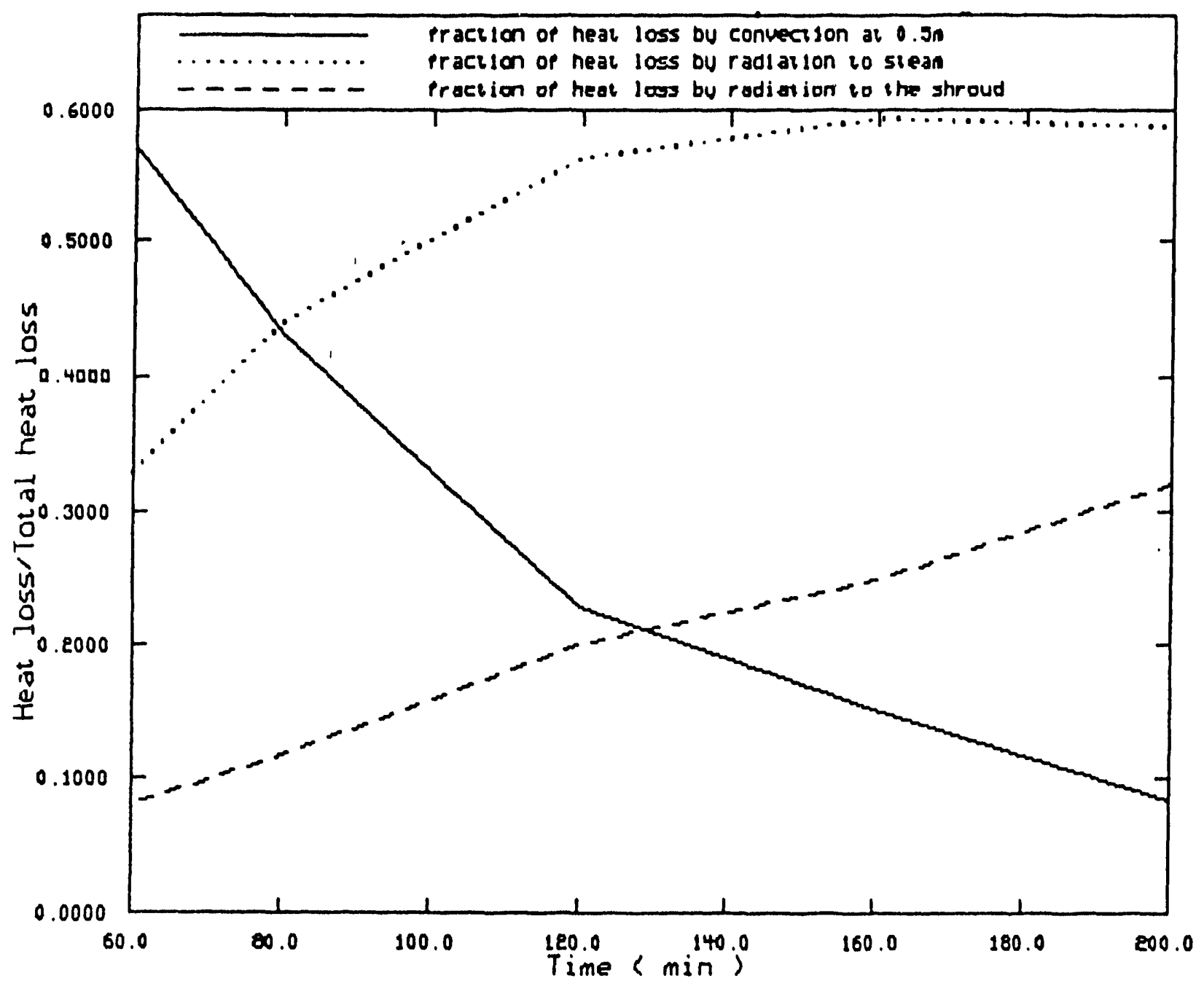

Fig. 8 Comparison of fraction of healt loss by several heat transfer mechanism at $0.5 \mathrm{~m}$ predicted by the present method 


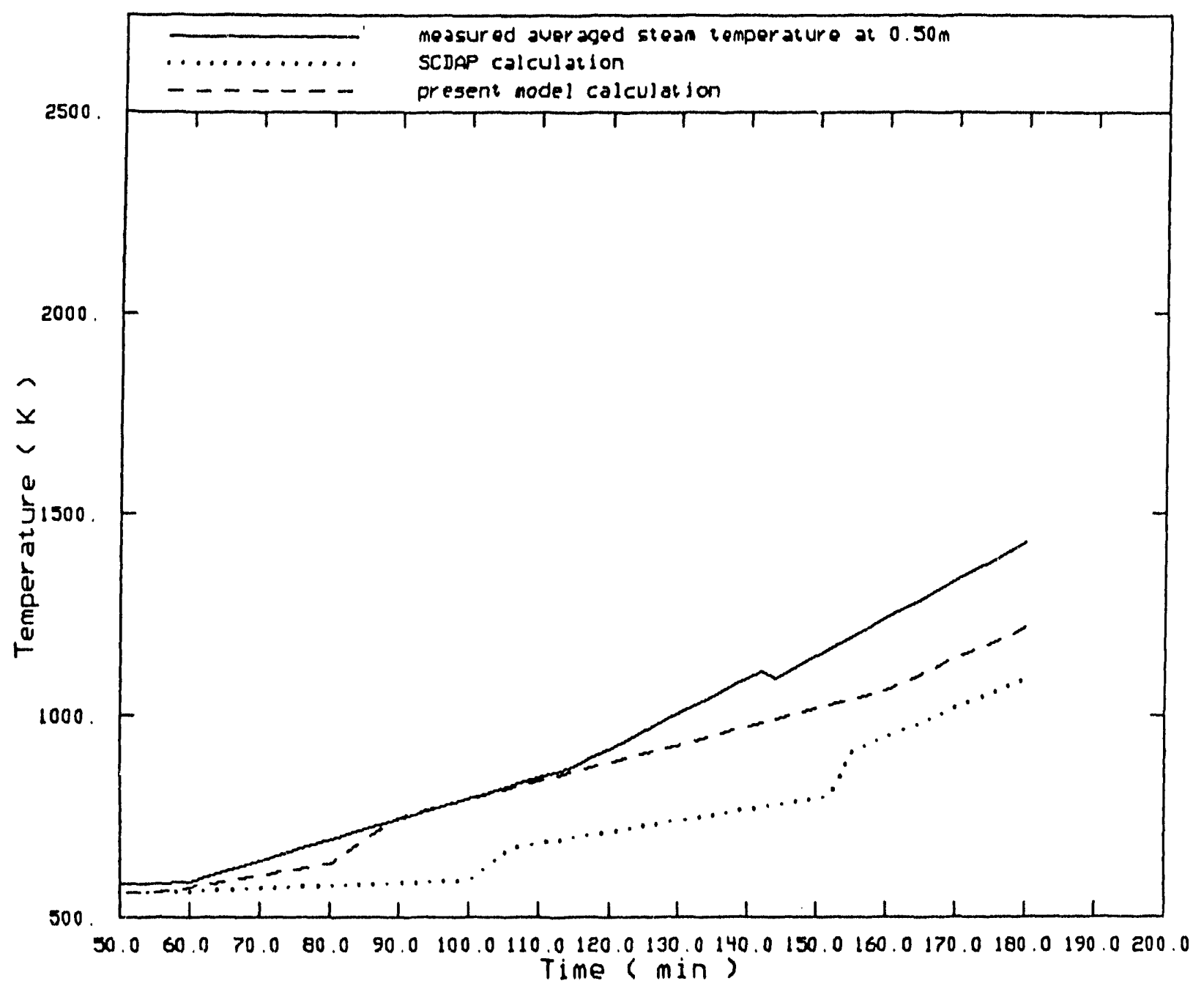

Fig.9 Comparison of the measured steam temperature at $0.5 \mathrm{~m}$ with the predictions by SCDAP and the present method 


\section{SUMMARY AND CONCLUSIONS}

A new scaling method is proposed and successfully applied to three scaling studies : corium dispersion in DCH, corium spreading in MARK-1 BWR, and boil-off process in the core.

The application to the corium dispersion in DCH demonstrate the usefulness of the proposed scaling method in evaluating various possible experimental conditions. The followings are its summary and conclusions :

1. In the case of corium-steam with $1 / 10$ scale, full $7 \mathrm{MPa}$ pressure, the relative significance of the entrainment is reduced by a factor of 7 in the scaled-down system.

2. In the case of water-air with the reduced pressure, $1.4 \mathrm{MPa}$, and 5 times break area for gas, the scaling ratio of the entrainment time to the transport time is slightly distorted by a factor of 1.2 and the geometrical scales can be well matched between the system scales and the droplet size.

3. In the case of wood metal-air with $1 / 10$ scale and reduced pressure, $1.4 \mathrm{MPa}$, and 5 times break area for gas, the relative importance of the entrainment is significantly reduced and the system behavior is similar to the $1 / 10$ scale corium-steam system.

4. As the above conclusions are based on the best available phenomenological models and correlations, the verification of both the phenomena and correlations at condition similar to the reactor conditions is necessary.

5. As the effects of water in the cavity or the solid materials in the molten corium have not been addressed here, these should also be evaluated by further researches.

The followings are the summary and conclusions derived from the scaling study of corium spreading in MARK-1 BWR :

1. Two group mechanisms are identified and considered in the first and second steps : the spreading group mechanism and water-corium-concrete interactions. 
2. Two spreading mechanisms are identified and analyzed : gravitational forcedominant spreading and surface tension-dominant spreading.

3. The second step for scaling analysis of water-corium-concrete interactions is divided into two substeps : interactions before and after solidification starts.

4. Time constants related to water-corium-concrete interactions are much shorter than those related to spreading.

5. Initial superheat, thermal convection rates, concrete cooling, and latent heat of corium solidification have high relative importance.

6. Thermal scaling is much more difficult than spreading scaling because of the relatively high scaling ratio of the corium thickness.

7. Much more cooling in the model is required because of the relatively high scaling ratio of the thickness.

8. The proposed method is a useful tool for scaling analysis of a not well-understood and complex problem.

For the scaling study of the boil-off process in the core, the analytical solutions representing uncovery and heatup in the core are derived, tested against the data of the PBF-ST, and used for generating the scaling criteria. The prediction by the analytical solutions is in excellent agreement with the measured mixture level in the PBF-ST. Also, they uderpredict both the contribution of convection to the initial fuel temperature and the heatup rate of the fuel due to the cooling effect by refluxing condensation and large energy loss by radiation to the shroud. With the scaling laws derived, the scaled system of the PBF is examined. It is found out that $q^{\prime}$ in the PBF should be by four times larger than that in the prototype system and the radiation number is highly distorted in the PBF. It is recommanded to use the shroud coated with the material with low emissivity. 





I 